ANALYSIS OF BISTABLE

MULTIVIBRATOR OPERATION 


\section{ANALYSIS OF BISTABLE MULTIVIBRATOR OPERATION}

PROEFSCHRIFT TER VERKRIJGING VAN DE GRAAD VAN DOCTOR IN DE TECHNISCHE WETENSCHAP AAN DE TECHNISCHE HOGESCHOOL TE DELFT, OP GEZAG VAN DE RECTOR MAGNIFICUS DR. O. BOTTEMA, HOOGLERAAR IN DE AFDELING DER ALGEMENE WETENSCHAPPEN, VOOR EEN COMMISSIE UIT DE SENAAT TE VERDEDIGEN OP DONDERDAG 5 JULI I956 DES NAMIDDAGS TE 2 UUR

DOOR

\section{PIETER ADRIANUS NEETESON NATUURKUNDIG INGENIEUR \\ GEBOREN TE CADZAND}

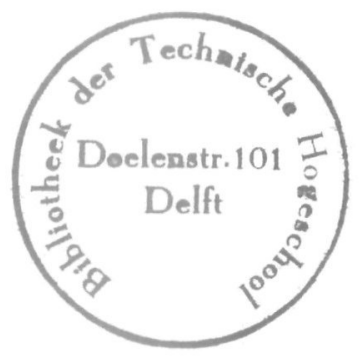


DIT PROEFSCHRIFT IS GOEDGEKEURD DOOR DE PROMOTOR prof. ir. B. D. H. TELLEGEN 
A an mijn Ouders

Aan mijn Vroww 
Op deze plaats wil ik gaarne mijn dank betuigen aan de Directie van de Hoofd Industrie Groep Electronenbuizen der N.V. Philips' Gloeilampenfabrieken te Eindhoven in het bijzonder van het Applicatie Laboratorium Professionele Buizen voor het feit dat mij toestemming verleend is een aantal resultaten van mijn werk in de vorm van een proefschrift te publiceren. 


\section{CONTENTS}

Chapter 1. General introduction

Chapter 2. Survey of literature

Chapter 3. Introduction to the problem . . . . . . . . 11

Chapter 4. Opening or closing of switches in a network . . . . 14

Chapter 5. The static condition of the bistable multivibrator . . 18

Chapter 6. The dynamic condition . . . . . . . . . 22

6.1. Introduction . . . . . . . . . . . . . 22

6.2. First phase . . . . . . . . . . . . . 22

6.3. Second phase . . . . . . . . . . . . . . . . . $\quad .25$

6.4. Third phase . . . . . . . . . . . . . . 27

Chapter 7. The complete trigger cycle . . . . . . . . 30

7.1. Discussion of the waveforms . . . . . . . . . 30

Chapter 8. The trigger sensitivity . . . . . . . . . . 41

8.1. Influence of tube characteristics and capacitive anode load . . . . . . . . . . . . . . . 44

Chapter 9. The triggering speed . . . . . . . . . . . 49

Chapter 10. Design considerations . . . . . . . . . . 54

Chapter 11. Variations of the fundamental circuit and way of triggering . . . . . . . . . . . . . . 60

11.1. Automatic grid bias . . . . . . . . . . . . 60

11.2. Trigger pulses applied to one grid only . . . . . 60

Chapter 12. Conclusion . . . . . . . . . . . . . . 62

Appendix I. Calculation of the anode- and grid voltages in the first phase . . . . . . . . . . . . 64

Appendix II. Calculation of $V_{a I I}$ in the second phase . . . . 69

Appendix III. Calculation of $V_{g I}$ in the second phase . . . 73

Appendix IV. Calculation of the transients at $A_{I I}, G_{I}$ and $A_{I}$ in the third phase . . . . . . . . . . 75

Appendix V. Discussion of the method of calculating the influence of $C_{a g}$ on the trigger sensitivity . . . . . . $\quad$. 77

Summary . . . . . . . . . . . . . . . . . 78

List of symbols . . . . . . . . . . . . . . . . . . . . . . 81 


\section{GENERAL INTRODUCTION}

In modern pulse technique a certain electronic switching circuit, known as the bistable multivibrator or Eccles-Jordan flip-flop circuit, has found widespread application. The field of pulse technique covers a great variety of apparatus, which generate a certain pulse pattern, often called the "logic", or which are caused, by the input of a given pulse pattern, to perform a certain logical operation. With this kind of electronic apparatus may be classed electronic counting and computing devices, time-measuring apparatus, pulse-modulation systems, radar, television, telemetering and automatic-telephony circuits.

The basic circuit and operation principle of a bistable electronic trigger device was first indicated by Eccles and Jordan and described in the Radio Review of December 1919, pp. 143-146, under the title: "A Trigger Relay Utilising Three-Electrode Thermionic Vacuum Tubes”.

It is worth while to cite the argumentation that led to their invention: "In a well-known method of using a triode for the amplification of wireless signals an inductive coil is placed in the filament-to-anode circuit, and another coil magnetically coupled with this is introduced into the filament-to-grid circuit. This 'back-coupling', as it is sometimes conveniently called, if it is arranged in the right sense, greatly exalts the magnification produced by the tube in any alternating E.M.F. applied to the grid; for the induced E.M.F. passed back to the grid is in correct phase relation to add directly to the original alternating E.M.F. applied there. If, instead of using inductive retroaction of this kind, weattempt to use resistance backcoupling, then the retroactive E.M.F. applied to the grid is exactly opposite in phase to the original alternating E.M.F., and the amplifying action of the triode is reduced. Since, however, one triode can produce opposition in phase in the manner indicated, it is clear that two or any even number of similar triode-circuits arranged in cascade can produce agreement in phase. Hence we conclude that retroactive amplification can be obtained by effecting a back-coupling to the first grid from the second, fourth, and so on, anode circuit of a set of triodes arranged in an ohmically-coupled cascade. It is possible to take advantage of the fact above stated for obtaining various types of continuously-acting relay, but the purpose of the present communication is to describe what may be called a one-stroke relay which, when operated by a small triggering electrical impulse, undergoes great changes in regard to its electrical equilibrium, and then remains in the new condition until re-set".

The authors then describe two possible circuits, in which the principle 
mentioned is incorporated. These circuits are represented in figs. 1-1 and 1-2, where $E_{1}$ and $E_{2}$ represent anode-voltage batteries, $e_{1}$ and $e_{2}$ gridvoltage batteries, no polarity being indicated in the latter. An external

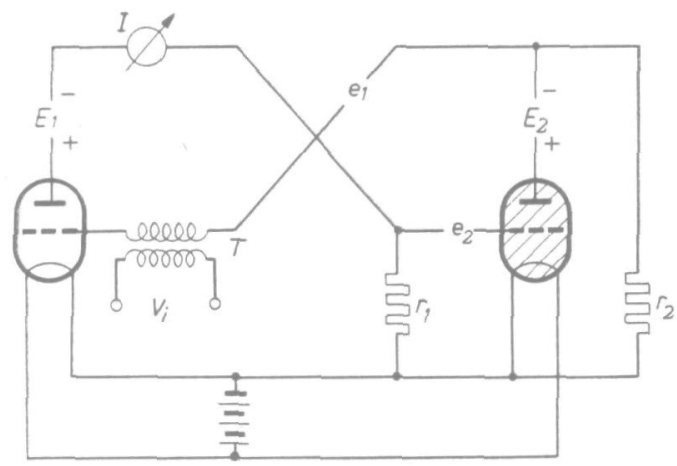

Fig. 1-1 voltage pulse $V_{i}$ is applied to the transformer $T$. No tube types are given. In the initial condition the hatched triode draws a large current, the other one a very small current. A positive voltage pulse on the grid of the lefthand triode starts a chain of events in the circuit which results finally in the lefthand tube drawing a large, and the right-hand tube a

small current. This change is indicated by an "ammeter or a moving tongue relay", $I$ in figs. $1-1$ and $1-2$.

Further, it is mentioned that "in order to restore the initial conditions it is easy to interrupt for an instant the linkage between the tubes, or to stop the operation of one or both of the tubes, as, for instance, by dimming its filament".

The change in current through the ammeter is from 0-2.5 micro-amperes, using the following values in the circuit of fig. 1-1:

$E_{1}=78 \mathrm{~V}, \quad E_{2}=74 \mathrm{~V}$, $r_{1}=22000 \mathrm{ohms}, r_{2}=12000$ ohms, $e_{1}=31 \mathrm{~V}, e_{2}=17.5 \mathrm{~V}$.

The sensitivity using a given telephonic transformer, with a telephone connected to the primary, is such that "the relay is operated with cer-

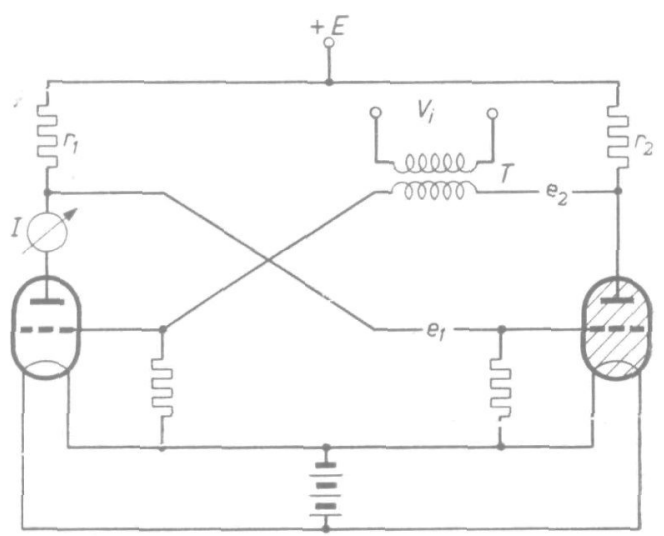

Fig. 1-2 tainty by snapping the thumb and the finger at a distance of five feet from the telephone".

The sensitivity of the circuit of fig. 1-2 could be made even greater when using the following values: 


$$
E=80 \mathrm{~V}, r_{1}=r_{2}=100000 \mathrm{ohms}, e_{1}=e_{2}=40 \mathrm{~V}
$$

No grid leak values are given.

It is clear that the main purpose of these circuits must have been to realize a very sensitive trigger relay and that the speed of operation, more precisely the repetition frequency of the trigger action, cannot have been high if the relay circuit was brought back to its initial condition by "interrupting the linkage between the tubes or dimming their filaments". It must be admitted that the authors explicitly mention the circuits as examples of a "one-stroke relay". Now, it is the possibility of successive trigger action that renders the Eccles-Jordan circuit specially suited for application in modern high-speed electronic switching devices.

In the same way as a positive voltage pulse, applied to the grid of the non-conducting tube, switches the trigger circuit into its reverse state, a subsequent negative pulse at the same grid will return it to its initial state. Or, alternatively, a second positive pulse at the grid of the other tube will again restore the initial condition. The accompanying voltage changes at the anodes of the tubes can be used advantageously for opening or closing electronic gate-circuits. This mode of operation, characterized by the application of trigger pulses to only one grid at a time, has found wide use in a variety of pulse "logic" apparatus. A second possible way of trigger operation, however, has also found important application. In this case, pulses of the same polarity are applied to both grids simultaneously. If these trigger pulses are negative, the conducting tube will always be cut off, the other tube will become conducting. At the application of every pulse the circuit will reverse its state. After two pulses the initial condition will be restored, in other words the flip-flop changes its state with a frequency that is the half frequency of the applied trigger pulses and the circuit acts as a frequency divider. Using the anode-voltage changes of one of the tubes as trigger pulses for a next flip-flop circuit results again in a frequency reduction by a factor two. Thus, the frequency of the voltage changes in the second trigger circuit is one quarter of the frequency of the input trigger pulses. This frequency division in a binary scale is one of the basic elements that has enabled the development of modern electronic computers and counting apparatus. Counting speeds up to a pulse repetition frequency of $7 \mathrm{Mc} / \mathrm{s}$ have been obtained in four cascaded flip-flop circuits with modern double-triode tubes, especially developed for computing and counting purposes. By application of suitable feedback in a four-cascade arrangement, the division by 16 may be reduced to a division by 10 . This is commonly accomplished by applying the output pulses of one or 
more stages of the cascade of four bistable multivibrators to the grids of one or more other stages in such a way that in total six of the sixteen possible positions of the counter array are skipped ${ }^{1}$ ). The same may be accomplished by the application of a gate circuit ${ }^{2}$ ). Another possibility of arranging a decimal counter with the aid of bistable multivibrators is to combine a ring-counter of five multivibrators with a single multivibrator in cascade. In this way a division by five and a division by two result in a decimal system ${ }^{3}$ ) (bi-quinary system).

These methods offer the possibility of making decimal system counters and computers. Trigger pulses ("clock-pulses") having repetition frequencies up to a few megacycles per second are used in electronic computers. The fundamental trigger circuit most generally used nowadays is represented in fig. 1-3. With a proper choice of the supply voltages $+V^{\prime}$ and $-V^{\prime \prime}$ and of the resistance values, it is possible to attain such grid-

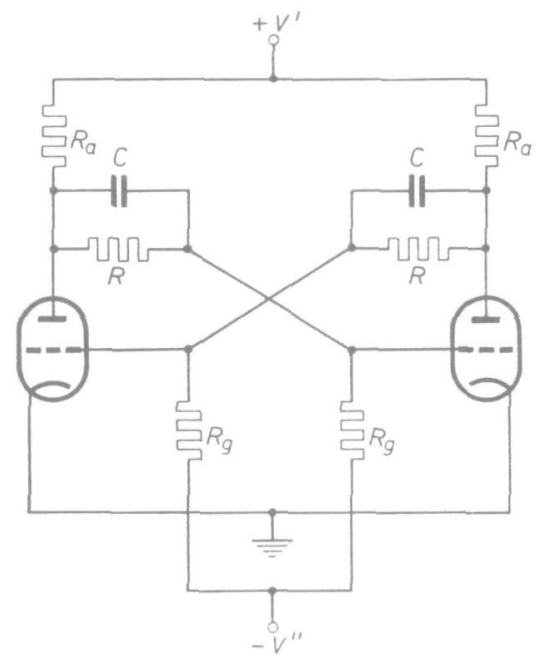

Fig. 1-3 voltage values that one of the tubes is cut off and the other conducting. Recent publications, showing the increasing interest in this trigger circuit, amply deal with this static condition and its stability. Analysis of the transient state or dynamic condition during switching of the circuit from one static condition into the other is much more complicated; nevertheless, it becomes more and more important, especially as the need to increase the repetition frequency of the trigger pulses becomes evident. Moreover, it is important to know something about the trigger sensitivity, by which is meant the minimum trigger-pulse amplitude that is necessary to obtain "complete switching from one stable state into

$\left.{ }^{1}\right)$ J. T. Potter, “A Four-Tube Counter Stage”, Electronics 17, June 1944, p. 110. J. E. Grosdorf, "Electronic Counters", R.C.A. Review, Sept. 1946, p. 438.

R. J. Blume, "Predetermined Counter", Electronics 21, Feb. 1948, p. 88.

G. J. Fergusson, G. H. Fraser, "The Design of Four-Tube Decade-Scalers", Review of Scientific Instruments 22, Dec. 1951, p. 937.

R. B. Mobsby, "A Decade Frequency Divider", Electronic Engineering 27, July 1955, p. 295.

2) E. L. Kemp, "Gated Decade Counter requires no feedback", Electronics 26, Feb. 1953, p. 145.

3) R. Weissmann, “Stable Ten-Light Decade Scaler”, Electronics 22, May 1949, p. 84. 
the other. Using, with a certain safety margin, the smallest possible trigger pulse amplitude may result in less exacting demands on the pulse-generating device. Knowledge of the mechanism of the dynamic operation of the trigger circuit offers the possibility to investigate the influence of tube characteristics on the switching speed and trigger sensitivity. In general, high repetition frequencies will be advantageous for several reasons: in counting apparatus the resolution time will be small and consequently the efficiency of counting random pulses will be high; in electronic computers very complicated computing operations can be executed in a short time. Time measurements can be done more accurately the higher the clock pulse repetition frequency, as the accuracy depends chiefly on the counting or just missing of one pulse at the close of a time measurement operation.

Different names are used to designate the special circuit under consideration. We propose to adhere to the name bistable multivibrator, as it indicates the relation with two other circuits, viz. the monostable and the astable multivibrator. The latter is also called a free-running multivibrator, and is the only one that really is a "vibrator" or oscillator, as it spontaneously generates relaxation signals. It was first described by Abraham and Bloch (Comptes Rendus, Vol. 168, p. 1105, June 1919). The essential feature of the circuit is a strong capacitive feedback from the anode of the second tube of a two-tube amplifier to the grid of the first tube.

If the feedback capacitor is shunted by a suitable resistor, the astable multivibrator is changed into a monostable multivibrator, having one stable position from which it can temporarily be brought into another position by means of a trigger pulse. However, it will always return to its stable position within a time dependent on its inherent time constants. If, moreover, the coupling capacitor between the anode of the first tube and the grid of the second tube is also shunted by a resistor of suitable value, and suitable grid bias voltages are applied, the monostable multivibrator is converted into a bistable multivibrator.

It will be clear that the main factors limiting the switching speed are to be found in the inherent time constants of the circuit, which are determined by coupling capacitances, tube capacitances, wiring and other stray capacitances and resistive components. As there is a practical limit to reducing the capacitances, the decrease in time constants will mainly have to be achieved by diminishing the resistances of the circuit. This implies an increase in power to be supplied by the D.C. voltage sources. The voltage drop across a small anode resistance, when a tube is switched 
from cut-off to full conduction or vice versa, may become too small to be of any use for further application in a logic system. This could, of course, be prevented by using more powerful tubes that could supply high anode currents, but the expense and the inevitably higher inter-electrode capacitances of these tubes limit their application.

Apart from the above-mentioned limits to the switching speed, which originate from considerations of economy or construction, there is in some applications no sense in further efforts to increase the speed. If in a radiation counter, a resolution time is attained that gives an efficiency of counting random pulses of, say, $99 \%$, then in most practical cases it will not be worth the trouble to increase the counting speed to $99.9 \%$ efficiency. In high-frequency measuring apparatus it may be more economical to bring down the frequency by superheterodyne methods - until it falls within the measuring range of the counter - than to try to extend the maximum frequency range that can be measured directly by the counter. It will also be clear that there is no use in increasing the speed of an electronic computing device if these computations take only a fraction of the time required for programming.

A high trigger sensitivity (small trigger voltage) will often be desirable, but a limit will be imposed by stability demands and possible influence of interfering signals.

Before proceeding to an exhaustive analysis of the operation of the bistable multivibrator, a survey will be given of the efforts made by others in this field for so far as they have been published in recent literature. Though most publications, as already mentioned, deal with the static condition, a few attempts have been made to get an insight into the dynamic operation of the bistable multivibrator. 


\section{SURVEY OF LITERATURE}

A summary of the contents of articles dealing with the analysis of the bistable multivibrator is presented in chronological order.

\section{B. E. Phelps: "Dual-Triode Trigger Circuits",}

Electronics, July 1945, p. 110

In this paper an approximate explanation is given of the important and necessary function of the coupling capacitors between the anodes and grids of the tubes.

If these capacitors were not present, the grid voltages of both tubes, immediately the trigger pulse had cut off the conducting tube, would tend to the same final value, determined by the static condition of the circuit with both tubes cut off. Since the time constants in the two grid circuits are the same for a symmetrical multivibrator and the change in grid voltage of the originally non-conducting tube starts at a lower value than that of the other tube, the latter tube reaches its cut-off point sooner than the former and no triggering will occur. If, however, coupling capacitors are present between anode and grid of different tubes and the time constants of these coupling networks are much larger than those of the grid circuits, then it can be assumed that the voltages across the coupling capacitors are practically constant during the setting of the grid voltages to their final states (assuming both tubes to be kept non-conducting in some way). The voltage across the capacitor coupling the anode of the originally non-conducting tube to the grid of the other tube is much greater than the voltage across the other coupling capacitor. This causes the grid voltage of the originally non-conducting tube to tend to a much higher final value than that of the other tube and consequently it is able to reach its cut-off point sooner than the other grid voltage.

Moreover, the advantage of triggering with negative pulses at the anodes or grids as compared with positive pulses is pointed out. Positive trigger pulses at the grid of the tube which is cut off must make this tube conducting, but they are counteracted by negative pulses appearing at the anode of the conducting tube. This phenomenon is dealt with in section 7.1 of this book and illustrated by a practical case.

No explicit mathematical formulae for voltage changes at the anodes and grids are derived. 
W. L. Buys: "Analysis of Scale Units",

Nucleonics, Vol. 3, November 1948, p. 49

Besides the static condition, the dynamic condition is discussed. The switching is assumed to be instantaneous, by way of sudden suppression and commencement of the anode current in the tubes. The sudden cessation of grid current flow in one tube is not taken into account in the calculation of the transient response of the circuit. In considering the positive-going grid voltage of the non-conducting tube, on the other hand, the influence of grid current is taken into account by assuming an internal grid resistance to be present between grid and cathode, as soon as the grid voltage reaches a value at which grid current starts to flow. This is assumed to coincide with the start of anode current flow, so no subdivision in three phases is made (see chapter 6 of this book). Only symmetrical circuits are considered.

M. Rubinoff: "Notes on the Design of Eccles-Jordan Flip-Flops", Communication and Electronics, Nr. 1, July 1952, p. 215

This paper is mainly devoted to stability considerations in the static condition; in particular the influence of tolerances in circuit components, tube characteristics and supply voltages is considered. A minor part of the paper is concerned with the dynamic condition of the circuit. The way of triggering is supposed to be such that the conducting tube is instantaneously cut off, giving rise to a sudden current step in the anode circuit. No grid current is taken into account. Only the grid-voltage change of the originally non-conducting tube is derived.

R. F. Johnston and A. G. Ratz: "A Graphical Method for Flip-Flop DESIGN"

Communication and Electronics, Nr. 5, March 1953, p. 52

This paper only considers the stability in the static condition, more particularly the influence of tolerances in components, tube characteristics and supply voltages. Nothing is said about the dynamic condition.

\section{R. Pressmann: "How to Design Bistable Multivibrators" \\ Electronics, Vol. 26, April 1953, p. 164}

Treats mainly D.C. stability, viz. the influence of component, supply -voltage and tube tolerances. The influence of the coupling capacitor on switching is considered in general. 
D. K. Ritchie: "The Optimum D.C. Design of Flip-Flops"

Proc. I.R.E., Vol. 41, November 1953, p. 1614

Only D.C. design considerations are given, taking into account tolerances of components, supply voltages and tube characteristics. No treatment of the dynamic condition.

R. Piloty: "Die Dimensionierung Der Eccles-Jordan-Schaltung" Archiv der Elektrischen Übertragung, Bd. 7, November 1953, p. 537

This is the most extensive analysis of the dynamic behaviour we have been able to find in the literature. Still, there are some assumptions that limit the general scope of this analysis. They are the following. Only symmetrical circuits are considered. The triggering is assumed to be initiated by a negative voltage step function at the grid of the conducting tube. This grid is assumed to be at zero potential with respect to the cathode in the static condition, no grid current being present. There is thus no automatic grid-current biasing, which implies that the voltage divider between the positive and negative HT supply sources has to contain such resistance values as to deliver exactly this zero potential at the grid mentioned. This is one of the most critical situations with respect to the sensitivity of the circuit to tolerances in components, tube characteristics and voltage supplies. In practice this kind of operation will generally be avoided. In this way, omitting grid current and neglecting finite rise time of the trigger pulse front, the only transient to be considered is the response of the circuit to the sudden ceasing of the anode-current flow in the conducting tube, when suddenly cut off. The influence of the commencement of anodecurrent flow in the initially non-conducting tube is not considered.

S. Higashi, I. Higashino, S. Kaneko and T. Oshio: "Flip-Flop Circuits",

\author{
Part I. Analysis. \\ Journal of the Institute of Polytechnics, Osaka \\ City University, Vol. 4, series B, 1953, p. 7 \\ Part II. Methods of Design. \\ Id. Vol. 5, series B, 1954, p. 37
}

The larger part of these articles is devoted to the monostable and the astable multivibrator.

The analysis of the bistable multivibrator is based on the assumption of a linear anode current/grid voltage characteristic of the tubes and a 
graphical representation of the dependence of the grid voltages on one another, giving an insight into the possible stable and unstable conditions of the circuit. The differences between the grid voltages and the anode voltages of the conducting and the non-conducting tube are defined and illustrated graphically. In the same way the upper and lower limits of the trigger-pulse amplitude are determined. The influence of the coupling capacitances is not included.

W. Renwick and M. Phister: "A Design Method for Direct-Coupled FLIP-FLOPS"

Electronic Engineering, Vol. 27, June 1955, p. 246

If, as limits of the grid voltages in the static condition, we take the values zero and cut-off voltage, it is possible to derive nominal values for the resistances of the circuit for which those limits will never be exceeded; for this we assume certain tolerances in resistances, voltage supplies and valve characteristics, and given nominal values of the supply voltages. Furthermore, on the assumption that the coupling network timeconstant $R C$ is equal to the grid-circuit time-constant $R_{r} C_{i}$ (see fig $6-1$ ), an expression can be derived for the time-constant of the most important transient, which occurs during switching as Rubinoff showed (loc. cit.). By combining this expression with those derived for the resistances, it is possible to find a minimum value of this time-constant when varying the supply-voltages. No explicit analysis of the transients in general is given.

In conclusion, it can be stated that only a few accounts of the triggering mechanism of the bistable multivibrator have been published, and these have been based on rough approximations. In the following Chapters it will be pointed out how it is possible to analyse the complete trigger cycle with fairly close approximation to practice, making use of two fundamental tools, viz. the operational calculus and a few theorems about sudden closing or opening of switches in networks. 


\section{INTRODUCTION TO THE PROBLEM}

Before proceeding to a detailed analysis of the bistable multivibrator circuit it is necessary to define the starting conditions, the assumptions and the limitations which form the basis on which the analysis rests. The circuit to be analyzed will be that represented in fig. 1-3. The triggering is assumed to be performed by applying a negative-going voltage change via coupling capacitors $C_{c}$ to both grids at the same time (see also fig. $3-1$ ).

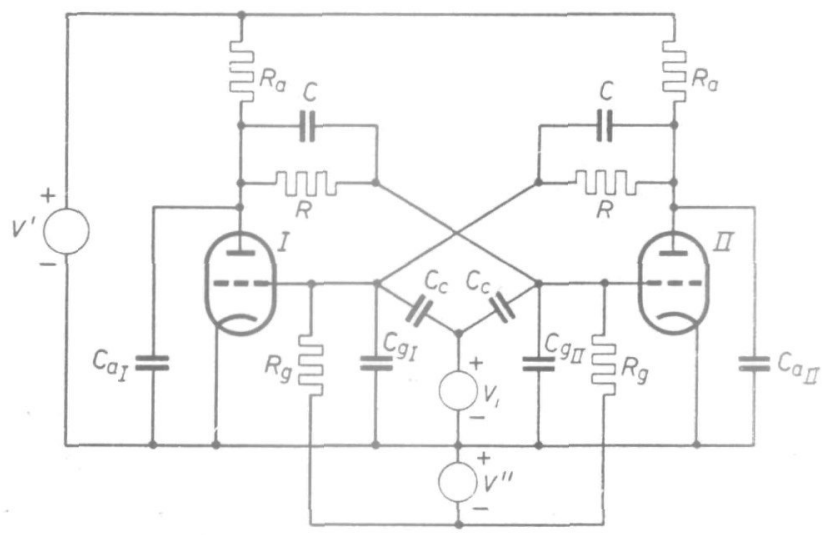

Fig. 3-1

The internal resistances of the trigger voltage supply as well as of the DC-supplies $V^{\prime}$ and $V^{\prime \prime}$ are assumed to be negligibly small. Inter-electrode and stray capacitances are taken into consideration as far as concerns parallel capacitances between the anodes and cathodes $C_{a}$ and between the grids and cathodes $C_{g}$ of the tubes. The influence of the anode-to-grid capacitance of each tube is difficult to determine exactly and will only be calculated approximatively. When an asymmetrical circuit is considered, the asymmetry will only consist of a

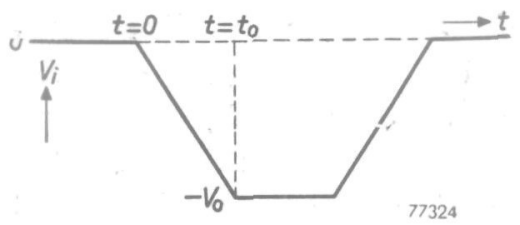

Fig. 3-2 different capacitive loading of the anodes, which is often met in practice, as the voltage changes in one of the anode circuits are generally used to operate further circuitry of which the multivibrator forms a part.

The form of the trigger voltage $V_{i}$ is represented in fig. 3-2. For $t \leq o, V_{i}=o$. For $o \leq t \leq t_{o}, V_{i}=-\alpha t$, where $\alpha$ is a positive constant. For $t \geq t_{o}, V_{i}$ is supposed to be constant, at 
a value $V_{i}=-V_{0}$. Thus the rise time is $t_{0}$ and the slope of the trigger voltage

$$
\alpha=\frac{V_{o}}{t_{o}} \text {. }
$$

In practice the trigger voltage will, after a certain time, fall back to zero. If the rear flank of this pulse-shaped trigger voltage is linear as well, the pulse will be trapezium shaped, which is a good approximation to many pulse forms in practice. The negative going front flank causes the multivibrator to trigger, which phenomenon will be analysed, whereas the positive-going rear flank has only a minor effect, mostly not able to disturb the triggering as will be pointed out later. This effect can also be calculated but this will not be done here.

At the instant $t=0$, when the trigger pulse starts, the circuit is assumed to be quiescent, all preceding transients having died out. In cther words, for times $t<0$ the multivibrator is in a state that we referred to before as the static condition. At the instant $t=0$ a chain of transients starts and for $t>o$ the multivibrator is in a state which will be called the dynamic condition. This condition is to be regarded as consisting of three phases. The first phase starts at the instant $t=0$ when the trigger signal is applied, the amplitude and slope of which are supposed to be so high that within a time small with respect to the time $t_{o}$ the conducting tube is cut off and the other tube is not yet conducting, which will generally be the case in practice. Both tubes are non-conducting and the circuit may thus be considered as a passive network during the first phase, which ends as soon as one of the tubes starts conducting again. For the multivibrator to operate in the desired way the originally non-conducting tube must reach its cut-off point first. The instant this occurs will be denoted $t=t_{I I}$. Care must be taken that the resistance values of the voltage divider $R_{\alpha}$ $R, R_{g}$ are such that the final value to which the grid-to-cathode voltage of the tubes tends will be above the cut-off value.

At the instant $t=t_{I}$ the second phase of the dynamic condition starts, during which one of the tubes is drawing more and more anode current, its anode voltage consequently decreasing and, because of the coupling network $R$ and $C$ in parallel (see fig. $3-1$ ), keeping the grid voltage of the other tube below the cut-off value. Should the final value of the grid voltage of the conducting tube, determined by the choice of the values of $R_{a}, R$ and $R_{g}$, be below the voltage at which grid current starts to flow, then no other transients would occur and there would be no third phase of the dynamic condition, assuming as well that the final value of the grid 
voltage of the other tube is below the cut-off point. However, the first mentioned condition is seldom chosen in practice as in that case the stabilizing influence of grid current is absent and tolerances in circuit components and supply voltages greatly influence the operation point of the conducting tube. This will be explained later, when dealing with the static condition.

Supposing that the final value of the grid voltage of the conducting tube is above the value at which grid current starts to flow, then at the instant the grid voltage reaches this special value new transients appear because of the commencement of grid current. At this instant $t=t_{s}$ the third phase of the dynamic condition starts and lasts until all transients have died out.

Recapitulating, tube I of fig. $3-1$ is assumed to be conducting at $t<0$ and drawing grid current; it is then supposed that both the anode current and the grid current fall to zero in such a short time that it may be regarded as instantaneous. Both tubes are then non-conducting and the voltage changes at the anodes and the grids of the tubes can be calculated as the response of the as yet passive network to the trigger voltage, and to the suddenly disappearing anode and grid currents of tube I. The first phase ends at the instant $t=t_{I I}$ when tube II becomes conductive. Then the response of the network to the increasing anode current of tube II must be calculated and superimposed on the transients resulting from the first phase. The second phase ends and the third commences at the instant $t=t_{s}$ when grid current starts to flow in tube II. This causes new transients to be superimposed on those resulting from preceding phases.

Before proceeding to the calculation of all the transients mentioned, it will be necessary to consider more closely the effect of the sudden opening or closing of switches in a network, as the transition of a tube from the conducting to the non-conducting state or vice versa can be reduced to an analogy with such switching phenomena. 


\section{OPENING OR CLOSING OF SWITCHES}

\section{IN A NETWORK}

In fig. $4-1$ the block $N$ represents a linear, passive network, which may contain one or more voltage or current sources. Because of these sources a voltage $V(t)$ is present between points $A$ and $B$. The effect of closing the switch at the instant $t=o$ can be derived in

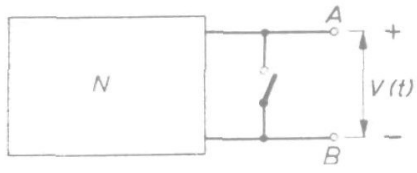

Fig. 4-1 the following way. $V(t)$ is the voltage between points $A$ and $B$ if the switch remains open. If $V_{1}(t)$ represents the voltage between $A$ and $B$ when the switch is closed at the instant $t=0$, then $V_{1}(t)=V(t)$ for $t<0$ and $V_{1}(t)=0$ for $t>0$. This can be written $V_{1}(t)=\{1-U(t)\} V(t)$, where $U(t)$ represents a unit step function. The application of a voltage source $V_{\mathbf{1}}(t)$ thus has the same effect as the closing of the switch. This voltage source can be considered as the sum of two voltage sources $V(t)$ and $V_{c}(t)$, where $V_{c}(t)=-V(t) U(t)$. The currents and voltages in the network, therefore, are determined by the voltage or current sources contained in $\mathrm{N}$, the voltage source $V(t)$ and the voltage source $V_{c}(t)$. The effect of the sources in $N$ together with $V(t)$ is the same as that of the $N$-sources alone if the switch remains open. If this has been calculated, the effect of closing the switch can be found by calculating the effect of the voltage source $V_{c}(t)=-V(t) U(t)$ and superimposing it on the results calculated before. If, on the other hand, the switch is originally not open but closed, and it is opened at the instant $t=0$, the foregoing

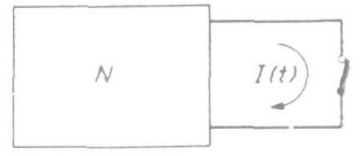

Fig. 4-2 considerations remain valid, if the output voltage between points $A$ and $B$ is replaced by the output current flowing through the switch and in general voltages are replaced by currents, open-circuit by short-circuit, etc. This will be analysed with the aid of fig. 4-2.

If the switch is not opened at all, a current $I(t)$ is supposed to flow at the output of the network $N$ because of the voltage or current sources contained in $N$. In the case of opening the switch at the instant $t=0$, the current flowing through it will be called $I_{1}(t)$ and can be represented by $I_{1}(t)=\{1-U(t)\} I(t)$. Thus, the application of a current source $I_{1}(t)$ has the same effect as the opening of the switch. This current source can be considered as the sum of two current sources $I(t)$ and $I_{o}(t)$, where $I_{o}(t)=-I(t) U(t)$. The currents and voltages in the network are now determined by the voltage or current sources contained in $N$, the current 
source $I(t)$ and the current source $I_{o}(t)$. The effect of the sources in $N$ together with $I(t)$ is the same as that of the internal $N$-sources only, if the switch remains closed.

The effect of opening the switch at $t=o$ then can be calculated by superimposing on the former result the response of the network to the current source $I_{o}(t)=-I(t) U(t)$.

The foregoing procedure results in the replacement of switches by current or voltage sources containing discontinuities. Their effect on the network can be determined by application of the operational calculus. It can also be said that a variable network is transformed into a constant, linear network, containing discontinuous voltage or current sources. To a linear network the superposition theorem is applicable.

In the following analysis of the operation of the multivibrator, the first switching action, initiated by the trigger pulse, is assumed to be instantaneous for the sake of simplicity and this will mostly be a good approximation to practice, as care will be taken to make the slope of the trigger pulse as steep as possible. In that case the effect of suddenly cutting off the conducting tube can be taken into account by introducing between the anode and the cathode of this tube a current source of a strength $I_{o}(t)=-I_{a}(t) U(t)$, where $I_{a}(t)$ is the anode current flowing if no trigger pulse were applied. The response of the network to this current source must be superimposed on the undisturbed state of the multivibrator. If the tube is drawing grid current $I_{g}(t)$, a current source $-I_{g}(t) U(t)$ between the grid and the cathode must be applied as well.

At the end of the first phase the originally non-conducting tube starts conducting, because its grid-to-cathode voltage rises above the cut-off point. This tube now acts as a switch that is being closed. The time it takes the grid voltage to rise from the cut-off value to a value near zero is determined by the inherent time constants of the circuit and will usually not be negligibly small compared with the complete trigger cycle. Therefore, it will be necessary to consider in more detail the switching of a tube from cut-off to full conduction in a finite

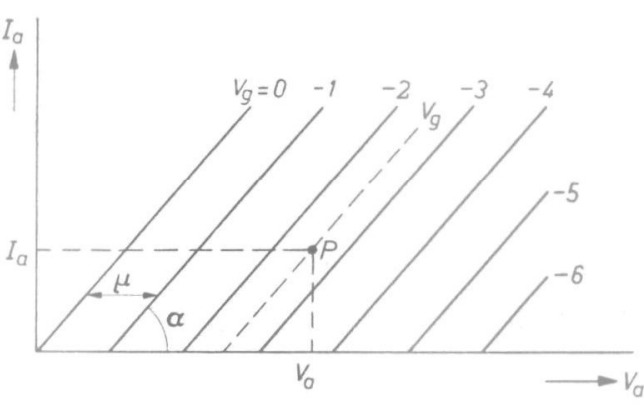

Fig. 4-3 time. To this purpose the anode-current against anode-voltage characteristics of a triode will be approximated by straight lines as represented 
in fig. 4-3. The reciprocal slope of these lines is a measure for the internal resistance $r_{a}$ of the tube $\left(r_{a}=\cot \alpha\right)$. The amplification factor $\mu$ is equal to the horizontal distance between the lines. The transconductance is given by the vertical distance between the lines. An arbitrary operating point $P$ of the tube is defined by the anode voltage $V_{a}$ and the grid voltage $V_{g}$ in such a way that

$$
I_{a}=\left(V_{a}-V_{a_{1}}\right) \tan \alpha \quad \text { or } \quad I_{a}=\frac{V_{a}-V_{a_{1}}}{r_{a}} .
$$

Where, $V_{a_{1}}=-\mu V_{g}$, thus

$$
I_{a}=\frac{V_{a}+\mu V_{g}}{r_{a}} .
$$

Generally, the anode of a tube is fed from a voltage source $V(t)$ via an

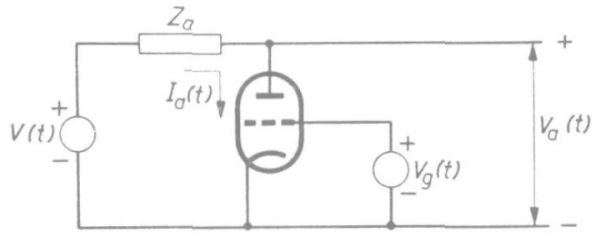

Fig. 4-4 impedance $Z_{a}$ (see fig. 4-4). $V(t)$ will mostly be a constant voltage, but need not be so.

A second relation between $I_{a}$ and $V_{a}$ can then be derived:

$V(t)-V_{a}(t)=Z_{a} I_{a}(t)$

From equations (4-1) and (4-2) it

follows that:

$$
V_{a}(t=) \frac{r_{a}}{r_{a}+Z_{a}} V(t)-\frac{Z_{a}}{r_{a}+Z_{a}} \mu V_{g}(t)
$$

This expression is valid only as long as $V_{a}(t)+\mu V_{g}(t) \geq 0$, as eq. (4-1) shows that $I_{a}=o$ for $V_{a}(t)+\mu V_{g}(t)=o$ or

$$
V_{g}(t)=-\frac{V_{a}(t)}{\mu}
$$

This value of $V_{g}$ is the cut-off grid voltage corresponding to the particular value of the anode voltage.

If $V_{g}(t)<-\frac{V_{a}(t)}{\mu}$ the tube draws no anode current.

It will be assumed now that at times $t<t_{a}$ the tube is cut off, or in formula $V_{g}(t)<-\frac{V(t)}{\mu}$. At the instant $t=t_{a}$, the grid voltage reaches the cut-off value, in other words eq. (4-4) is valid

$$
V_{g}\left(t_{a}\right)=-\frac{V\left(t_{a}\right)}{\mu}
$$


If the time functions $V_{g}(t)$ and $V(t)$ are known, the value of $t_{a}$ can be calculated from condition (4-5).

The effect of the tube becoming conductive at the instant $t=t_{a}$ can be interpreted with the aid of fig. 4-5.

If the voltage source $V_{1}(t)$ is given the following value: $V_{1}(t)=V(t)-$ $\left\{V(t)+\mu V_{g}(t)\right\} U\left(t-t_{a}\right)$, then for $t<t_{a}, V_{a}(t)=V(t)$ the tube is non-conducting, and for $t \geq t_{a}$

$$
V_{a}(t)=\frac{r_{a}}{r_{a}+Z_{a}} V(t)+\frac{Z_{a}}{r_{a}+Z_{a}} V_{1}(t)=\frac{r_{a}}{r_{a}+Z_{a}} V(t)-\frac{Z_{a}}{r_{a}+Z_{a}} \mu V_{g}(t)
$$

which corresponds to equation (4-3).

The expression for $V_{a}(t)$, valid in the non-conducting condition for $t<t_{a}$ as well as in the conducting condition for $t \geqq t_{a}$ is the following:

$$
V_{a}(t)=V(t)-\frac{Z_{a}}{\gamma_{a}+Z_{a}}\left[V(t)+\mu V_{g}(t)\right] U\left(t-t_{a}\right)
$$

In most bistable multivibrator circuits the grid voltage of the tube will rise beyond the point where grid current starts to flow. It will be assumed that this point is reached at a value zero of the grid voltage and that the internal grid resistance is so small that the grid and cathode can be considered to become short-circuited as soon as $V_{g}=o$. At the instant $t=t_{s}$, when $V_{g}$ becomes zero, the second phase of the dynamic condition ends and the third commences. On the voltages and currents caused by transients during the preceding phases must be super-

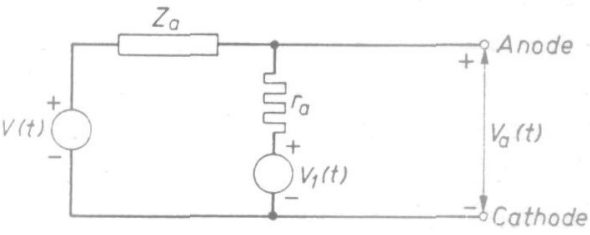

Fig. 4-5 imposed the response of the network to the sudden short-circuiting of the grid and cathode of the conducting tube. This response can be calculated by assuming a voltage source $V_{c}(t)$ to be present between grid and cathode, where $V_{c}(t)=-V_{g}(t) U\left(t-t_{s}\right)$.

After the preliminary observations made in this chapter about switching in networks, it is possible to deal with a systematical analysis of the operation of the multivibrator. First the static condition will be examined, which in the time scale used above exists during the time $t \leqq 0$. Any possible transients of preceding trigger cycles are supposed to have completely faded out. This static condition is the initial state, to which the transients have to be added when the dynamic condition starts at the instant $t=0$, with the application of the trigger pulse. 


\section{THE STATIC CONDITION OF THE BISTABLE MULTIVIBRATOR}

In the static condition only constant voltage sources are present in the circuit, hence all capacitances can be left out of consideration, and in this case the circuit of fig. $3-1$ can be simplified to that of fig. $5-1$.

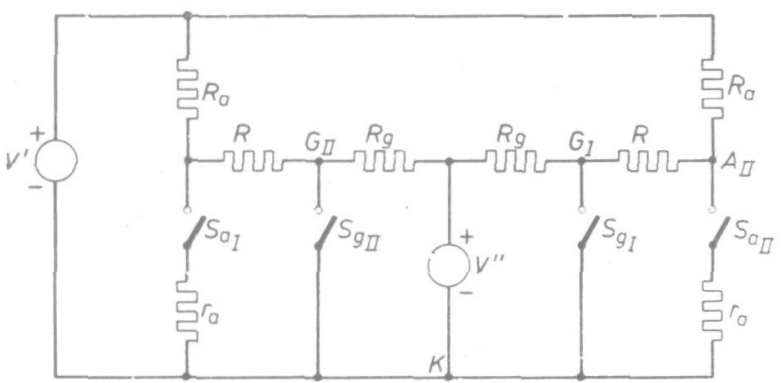

Fig. 5-1

In this figure all indices $I$ refer to tube I and all indices $I I$ to tube II. $A_{I}$ and $A_{I I}$ are the anodes of the tubes, $G_{I}$ and $G_{I I}$ the grids, $K$ is cathode. It is supposed that tube I is conducting and tube II is cut off. Thus, switches $S_{a I}$ and $S_{g I}$ are closed and $S_{a I I}$ and $S_{g I I}$ are open. The circuit can be separated into two independent parts, which are represented in figs $5-2$ and $5-3$. In fig. 5-3 the more general case of a finite internal grid resistance $r_{g}$ is represented. In the circuit of fig. 5-2 an anode current $I_{a o}$ flows through tube I and if two other currents $I_{1}$ and $I_{2}$ are introduced, the following relations exist:

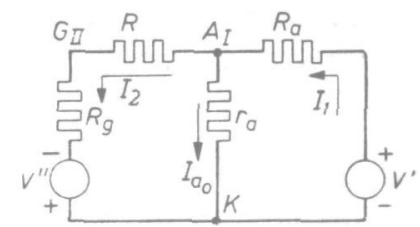

Fig. 5-2

$$
\begin{aligned}
& I_{1}=I_{a o}+I_{2} \\
& V^{\prime}+V^{\prime \prime}=I_{1} R_{a}+I_{2}\left(R+R_{g}\right)
\end{aligned}
$$

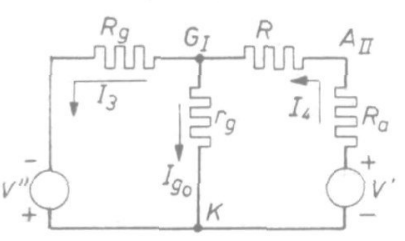

Fig. 5-3

$$
\text { Introducing } \varepsilon_{a}=\frac{R_{a}}{R_{g}+R+R_{a}}
$$

it follows from expressions (5-1) and (5-2) that

$$
I_{2}=-\varepsilon_{a} I_{a o}+\frac{V^{\prime}+V^{\prime \prime}}{R_{g}+R+R_{a}}
$$


and

$$
I_{1}=\left(1-\varepsilon_{a}\right) I_{a o}+\frac{V^{\prime}+V^{\prime \prime}}{R_{g}+R+R_{a}}
$$

From fig. 5-2 it can easily be seen that the voltage between $G_{I I}$ and cathode is

$$
V_{g I I o}=-V^{\prime \prime}+I_{2} R_{g}=-V^{\prime \prime}+\frac{R_{g}}{R_{g}+R+R_{a}}\left(V^{\prime}+V^{\prime \prime}\right)-R_{g} \varepsilon_{a} I_{a o}
$$

Introducing

$$
\varepsilon_{g}=\frac{R_{g}}{R_{g}+R+R_{a}}
$$

it can be written

$$
V_{g I I o}=\varepsilon_{g}\left(V^{\prime}-R_{a} I_{a o}\right)-\left(1-\varepsilon_{g}\right) V^{\prime \prime}
$$

since

$$
\varepsilon_{a} R_{g}=\varepsilon_{g} R_{a}
$$

This value of $V g_{I I o}$ has to be below the cut-off voltage, as tube II must be non-conducting.

The voltage between $A_{I}$ and cathode is

$$
V_{a I o}=V^{\prime}-I_{1} R_{a}=V^{\prime}-\varepsilon_{a}\left(V^{\prime}+V^{\prime \prime}\right)-\left(1-\varepsilon_{a}\right) R_{a} I_{a o}
$$

or

$$
V_{a I o}=\left(1-\varepsilon_{a}\right)\left(V^{\prime}-R_{a} I_{a o}\right)-\varepsilon_{a} V^{\prime \prime}
$$

Since $V_{a I_{o}}=r_{a} I_{a o}$ as well, a relation between $I_{a o}$ and $r_{a}$ can be derived

$$
I_{a o}=\frac{\left(1-\varepsilon_{a}\right) V^{\prime}-\varepsilon_{a} V^{\prime \prime}}{\left(1-\varepsilon_{a}\right) R_{a}+r_{a}}
$$

The internal anode resistance $r_{a}$ can be evaluated from the tube characteristics (see fig. $4-3$, where $r_{a}=\cot a$ ).

From fig. 5-3 it can be seen that

$$
\begin{gathered}
I_{3}+I_{g o}=I_{4} \\
V^{\prime}+V^{\prime \prime}=I_{3} R_{g}+I_{4}\left(R_{a}+R\right)
\end{gathered}
$$

From (5-10) and (5-11) it follows that

$$
I_{3}=\frac{V^{\prime}+V^{\prime \prime}}{R_{g}+R+R_{a}}-\left(1-\varepsilon_{g}\right) I_{g o} ; I_{4}=\frac{V^{\prime}+V^{\prime \prime}}{R_{g}+R+R_{a}}+\varepsilon_{g} I_{g o}
$$

Thus

$$
V_{g I o}=\varepsilon_{g} V^{\prime}-\left(1-\varepsilon_{g}\right)\left(V^{\prime \prime}+R_{g} I_{g o}\right)
$$

and

$$
V_{a I I o}=\left(1-\varepsilon_{a}\right) V^{\prime}-\varepsilon_{a}\left(V^{\prime \prime}+R_{g} I_{g o}\right)
$$


The grid current $I_{g o}$ can be evaluated for the case that the internal grid resistance $r_{g}$ is assumed to be zero. Then $V_{g I o}=o$ or

$$
I_{g o}=\frac{\varepsilon_{g} V^{\prime}-\left(1-\varepsilon_{g}\right) V^{\prime \prime}}{\left(1-\varepsilon_{g}\right) R_{g}}
$$

Introducing this value of $I_{g_{0}}$ into eq $(5-13)$ gives

$$
V_{a I I o}=\frac{R}{R+R_{a}} V^{\prime}
$$

This result could have been read directly from fig. 5-3 for $r_{g}=0$, as it shows that in that case the voltage at $A_{I I}$ is determined by the voltage divider $R, R_{a}$ across the supply source $V^{\prime}$. However, the expression (5-13) will be of advantage in later calculations, and has therefore been derived first.

It will now be pointed out why it is advantageous to operate the conducting tube in the grid-current region. If the internal grid resistance is not zero, but has a finite value, determined by a grid current/grid voltage characteristic as represented in fig. 5-4, then the grid voltage $V_{g I o}$ and the grid current $I_{g o}$ are defined on the one hand by this characteristic, on the other hand by the relation $(5-12)$. This relation is represented by the straight line $\mathrm{I}_{2}$ in fig. 5-4. The voltage $V_{o}=\varepsilon_{g} V^{\prime}-\left(\mathrm{I}-\varepsilon_{g}\right) V^{\prime \prime}$ and the reciprocal slope of $1_{2}$ is equal to $\left(1-\varepsilon_{g}\right) R_{g}$. The point of intersection of $1_{2}$ and the characteristic determines $I_{g_{0}}$ and $V_{g I o}\left(=V_{g 2}\right.$ in fig. 5-4). If

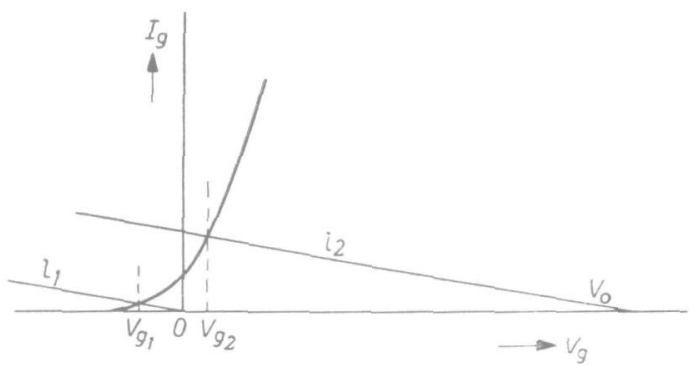

Fig. 5-4 it is assumed that the supply voltages $V^{\prime}$ and $V^{\prime \prime}$ vary to such a value that $V_{o}=0$, then the line $1_{2}$ changes to $I_{1}$ and the resulting gridvoltage change would be only from $V_{g 2}$ to $V_{g 1}$. If $V_{o}$, however, had been situated to the left of the grid-current cut-off point, then the grid voltage change would have been equal to the change of $V_{o}$. The steeper the characteristic rises, the more the grid voltage will be stabilized. In the ideal case that has been considered previously, the characteristic was assumed to coincide with the vertical axis.

The influence of tolerances in the resistances will also be minimized, though it is more difficult to calculate, as both $V_{0}$ and the slope of $1_{2}$ depend on the values of these resistances. 
Changes in $V_{g I o}$ greatly influence the value of $I_{a o}$ and therefore at the same time the total voltage change at the anodes of the tubes when the multivibrator is triggered. This voltage change $\Delta V_{a}$ is given by the difference between $V_{a I I o}$ and $V_{a I 0}$. From eqs (5-13) and (5-8) it follows

$$
\Delta V_{a}=\left(1-\varepsilon_{a}\right) R_{a} I_{a o}-\varepsilon_{a} R_{g} I_{g o}
$$

It must be noted that the presence of grid current reduces the value of this voltage change, but $I_{g o}$ is mostly so small compared with $I_{a o}$ that the second term of the right-hand part of eq. (5-16) is only a small fraction of the other term. This disadvantage is more than counterbalanced by the advantage of the stabilizing effect of the grid current.

The anode and grid voltages of both tubes in the static condition have now been derived. They are the initial conditions for the transient phenomena which occur when a trigger pulse is applied to both grids. These transients must be superimposed on the static voltages and currents. There is no need to take into account the DC-supply voltages for calculating the transients, the influence of these voltages being included in the static conditions. The voltages $\mathrm{V}^{\prime}$ and $\mathrm{V}^{\prime \prime}$ are therefore omitted in the circuits which are used for determining the dynamic condition. 


\section{THE DYNAMIC CONDITION}

\subsection{InTRODUCTION}

The dynamic condition starts at the instant $t=0$ when the input voltage $V_{i}$ remains no longer zero but falls linearly with a slope $\alpha$ to a value $-V_{o}$ (see fig. 3-2), which is reached at the instant $t=t_{0}$. From this instant onwards $V_{i}$ remains constant at the value $-V_{0}$.

For $0 \leq t \leq t_{o}$

where

$$
V_{i}=-a t,
$$

$$
\alpha=\frac{V_{o}}{t_{o}}
$$

The voltage source $V_{i}$ in series with the coupling capacitors $C_{c}$ will be replaced by a current source $I_{i}$ in parallel with $C_{c}$, where

$$
I_{i}=C_{c} \frac{d V_{i}}{d t}
$$

For

$$
\begin{aligned}
& t \leq o: I_{i}=o \\
& J \leq t \leq \mathrm{t}_{o}: I_{i}=-\alpha C_{c} \\
& t \geq t_{o}: I_{i}=0
\end{aligned}
$$

For

Thus, $I_{i}$ is a rectangular, negative-going pulse with a duration of $t_{o}$ and an amplitude $\alpha C_{c}$, or the superposition of a negative-going current step $-\alpha C_{c}$ at the instant $t=o$, and a positive-going current step $+\alpha C_{c}$ at the instant $t=t_{0^{\circ}}$. This can be denoted by

$$
I_{i}=-\alpha C_{c}\left\{U(t)-U\left(t-t_{o}\right)\right\}
$$

The coupling capacitance $C_{c}$ in parallel with the capacitance $C_{g}$ (see fig. $3-1)$ gives a total grid-to-cathode capacitance

$$
C_{i}=C_{c}+C_{g}
$$

As assumed previously the input voltage instantaneously cuts off tube I and therefore current sources $I_{a o}$ and $I_{g o}$ have to be introduced between the anode and cathode, and between the grid and cathode respectively of tube I.

\subsection{FirST PHASE}

The resulting circuits of the bistable multivibrator during the first phase of the dynamic condition can be represented by the diagram of fig. $6-1$. By neglecting the influence of the anode-to-grid capacitances $\mathrm{C}_{a g}$, the 
circuit can be considered to consist of two separate parts as represented in figs. $6-2$ and $6-3$.

The response of the network to three current sources has to be determined. All current sources are step functions:

$I_{i}$ is given by expression (6-7)

$$
\begin{aligned}
& I_{a}=I_{a o} U(t) \\
& I_{g}=I_{g o} U(t)
\end{aligned}
$$

The calculation of the voltages between the grids and earth (or cathode)

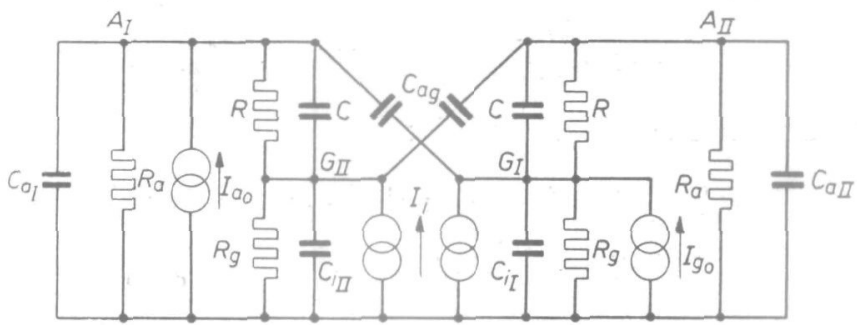

Fig. 6-1

and between the anodes and earth will be possible if the following impedances are known.

(a) The impedances between the grids and earth.

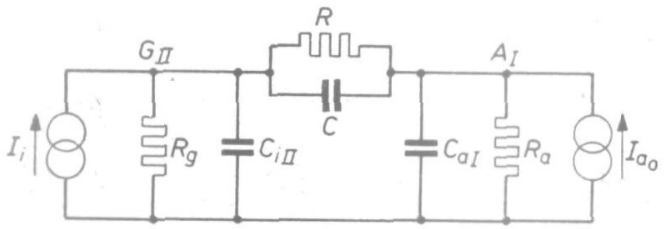

Fig. 6-2

(b) The transfer impedances giving the ratio of the voltages between the anodes and earth to the currents applied between the grids and earth.

(c) The transfer impedances giving the ratio of the voltages between the grids and earth to the currents applied between the anodes and earth.

(d) The impedances between the anodes and earth.

The derivation of these impedances and subsequent calculation of the voltages is fully given in appendix I. In order not to get lost in details, only the results will be represented

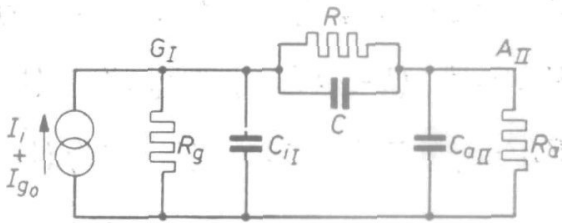

Fig. 6-3 here. The voltage between $G_{I I}$ and earth is: 


$$
V_{g I I}\left(t_{0} \leqq t \leq t_{I I}\right)=V_{1}+V_{2} e^{p_{1} t}+V_{3} e^{p_{2} t}
$$

See appendix I, expression (I-36)

The voltage between $A_{I}$ and earth is:

$$
V_{a I}\left(t_{0} \leqq t \leqq t_{I I}\right)=V_{\mathbf{7}}+V_{8} e^{p_{1} t}+V_{9} e^{p_{2} t}
$$

See appendix I, expression (1-40)

The voltage between $G_{I}$ and earth is:

$$
V_{g I}\left(t_{o} \leqq t \leqq t_{I I}\right)=V_{10}+V_{11} e^{p_{1}^{\prime} t}+V_{12} e^{p_{2}^{\prime} t}
$$

See appendix I, expression (I-42)

The voltage between $A_{I I}$ and earth is:

$$
V_{a I I}\left(t_{o} \leqq t \leqq t_{I I}\right)=V_{4}+V_{5} e^{p_{1}{ }^{\prime} t}+V_{6} e^{p_{2}{ }^{\prime} t}
$$

See appendix I, expression (1-44)

Where

$$
\begin{aligned}
& V_{1}=V_{g I I o}+I_{a o} \varepsilon_{a} R_{g}=\varepsilon_{g} V^{\prime}-\left(1-\varepsilon_{g}\right) V^{\prime \prime} \\
& V_{2}=\frac{1}{2} \alpha C_{c}\left(1-\varepsilon_{g}\right) R_{g}(1-K)\left(1-e^{-p_{1} t_{o}}\right)-\frac{1}{2} I_{a o} \varepsilon_{a} R_{g}(1-P) \\
& V_{3}=\frac{1}{2} \alpha C_{c}\left(1-\varepsilon_{g}\right) R_{g}(1+K)\left(1-e^{-p_{2} t_{o}}-\frac{1}{2} I_{a o} \varepsilon_{a} R_{g}(1+P)\right. \\
& V_{4}=V_{a I I o}+I_{g o} \varepsilon_{a} R_{g}=\left(1-\varepsilon_{a}\right) V^{\prime}-\varepsilon_{a} V^{\prime \prime}
\end{aligned}
$$$$
V_{5}=\frac{1}{2} \alpha C_{c} \varepsilon_{a} R_{g}\left(1-P^{\prime}\right)\left(1-e^{-p_{1}{ }^{\prime} t_{o}}\right)-\frac{1}{2} I_{g o} \varepsilon_{a} R_{g}\left(1-P^{\prime}\right)
$$$$
V_{6}=\frac{1}{2} \alpha C_{c} \varepsilon_{a} R_{g}\left(1+P^{\prime}\right)\left(1-e^{-p_{2}{ }^{\prime} t_{o}}\right)-\frac{1}{2} I_{g_{o}} \varepsilon_{a} R_{g}\left(1+P^{\prime}\right)
$$$$
V_{7}=V_{a I o}+I_{a o}\left(1-\varepsilon_{a}\right) R_{a}=\left(1-\varepsilon_{a}\right) V^{\prime}-\varepsilon_{a} V^{\prime \prime}
$$$$
V_{8}=\frac{1}{2} \alpha C_{c} \varepsilon_{a} R_{g}(1-P)\left(1-e^{-p_{1} t_{o}}\right)-\frac{1}{2} I_{a o}\left(1-\varepsilon_{a}\right) R_{a}(1-L)
$$$$
V_{9}=\frac{1}{2} \alpha C_{c} \varepsilon_{a} R_{g}(1+P)\left(I-e^{-p_{2} t_{o}}\right)-\frac{1}{2} I_{a o}\left(1-\varepsilon_{a}\right) R_{a}(I+L)
$$$$
V_{10}=I_{g o}\left(1-\varepsilon_{g}\right) R_{g}=\varepsilon_{g} V^{\prime}-\left(1-\varepsilon_{g}\right) V^{\prime \prime}
$$

$V_{11}=\frac{1}{2} \alpha C_{c}\left(1-\varepsilon_{g}\right) R_{g}\left(1-K^{\prime}\right)\left(1-e^{-p_{1}{ }^{\prime} t_{o}}\right)-\frac{1}{2} I_{g o}\left(1-\varepsilon_{g}\right) R_{g}\left(1-K^{\prime}\right)$

$$
V_{12}=\frac{1}{2} \alpha C_{c}\left(1-\varepsilon_{g}\right) R_{g}\left(1+K^{\prime}\right)\left(1-e^{-p_{2}{ }^{\prime} t_{0}}\right)-\frac{1}{2} I_{g \circ}\left(1-\varepsilon_{g}\right) R_{g}\left(1+K^{\prime}\right)
$$




$$
\begin{aligned}
& K=\frac{2 A-B}{B \sqrt{1-4 E / B^{2}}} \\
& P=\frac{2 T-B}{B \sqrt{1-4 E / B^{2}}} \\
& L=\frac{2 D-B}{B \sqrt{1-4 E / B^{2}}}
\end{aligned}
$$

See appendix I expr. (I-31), (I-34) and (I-39)

$K^{\prime}, P^{\prime}, L^{\prime}$ follow from $K, P, L$ respectively by interchanging the indices I and II in $A, B, E$ and $D$.

If the bistable multivibrator is symmetrical, i.e. if in fig. $6-1$

$$
C_{i I}=C_{i I I} \text { and } C_{a I}=C_{a I I} \text {, then } K=K^{\prime}, P=P^{\prime}, p_{1}=p_{1}{ }^{\prime} \text { and } p_{2}=p_{2}{ }^{\prime} \text {. }
$$

\section{3 SECOND PHASE}

During the first phase of the dynamic condition both tubes are cut off. Their grid voltages tend to the following final values (at $t=\infty)$ :

$V_{g I}(\infty)=I_{g o}\left(1-\varepsilon_{g}\right) R_{g}$, as can easily be seen from expression (6-13) and $V_{g I I}(\infty)=V_{g I I o}+I_{a o} \varepsilon_{a} R_{g}$. (see expression (6-11)). Introducing expressions (5-14) and (5-7) results in

$$
V_{g I}(\infty)=V_{g I I}(\infty)=\varepsilon_{g} V^{\prime}-\left(1-\varepsilon_{g}\right) V^{\prime \prime}
$$

This is simply the voltage at the mid-point of the voltage divider $R_{g}$, $\left(R+R_{a}\right)$ between the supply sources $-V^{\prime \prime}$ and $+V^{\prime}$. It must be assumed that this voltage is above the cut-off voltage of the tubes, otherwise the bistable multivibrator would not function at all. Furthermore it will be assumed that the originally non-conducting tube II reached its cut-off point earlier than tube $\mathrm{I}$, as this is the condition for correct functioning of the multivibrator circuit. The limit of this correct operation is reached when the tubes attain their cut-off points simultaneously. When determining the sensitivity of the multivibrator, this condition will be investigated more thoroughly.

Tube II reaches its cut-off point at the instant $t=t_{I I}$, this instant marks the end of the first phase and the start of the second phase of the dynamic condition. According to chapter 4 this instant $t_{I I}$ can be determined from the condition

$$
V_{g I I}\left(t_{I I}\right)=-\frac{V_{a I I}\left(t_{I I}\right)}{\mu}
$$


New transients occur from this instant onwards, but only in the anode voltage $V_{a I I}$ and consequently in the grid voltage $V_{g I}$ as well. The voltages $V_{a I}$ and $V_{g I I}$ are represented by the same expressions that hold for the first phase $((6-12)$ and $(6-11)$, respectively).

According to expression (4-6) the anode voltage of the second tube during the second phase is given by

$$
V_{a I I}(t)=V_{a I I}(t)_{1}-\frac{Z_{i a I I}}{Z_{i a I I}+r_{a}}\left\{V_{a I I}(t)_{1}+\mu V_{a I I}(t)\right\} U\left(t-t_{I I}\right)
$$

where $V_{a I I}(t)_{1}$ and $V_{g I I}(t)$ are given by the expressions for the first phase, (6-14) and (6-11), respectively. $Z_{\text {iaII }}$ corresponds to $Z_{a}$ of expression (4-6) and can be derived from expression (I-19) by interchanging indices I and II. As $V_{g I I}(t)$ is valid for the first as well as for the second phase, no index 1 is used here.

The evaluation of this voltage $V_{a I I}$ is presented in appendix II.

$$
\begin{gathered}
V_{a I I}(t)=V_{a I I}(t)_{1}-\frac{\left(1-\varepsilon_{a}\right) R_{a}}{\left\{\left(1-\varepsilon_{a}\right) R_{a}+r_{a}\right\} G^{\prime}}{ }^{p_{j}=p_{1}, p_{2}, p_{1}^{\prime}, p_{2}^{\prime}} \sum_{j} V_{j} p_{j} e^{p_{j} t_{I I}} \\
{\left[\frac { X _ { 1 ^ { j } } } { - p _ { 3 } } \left\{1-e^{\left.p_{3}\left(t-t_{0}\right)\right\}}+\frac{X_{2^{j}}}{-p_{4}}\left\{1-e^{\left.p_{4}\left(t-t_{I I}\right)\right\}}+\frac{X_{3^{j}}}{-p_{j}}\left\{1-e^{p_{j}\left(t-t_{I I}\right)}\right\}\right] \times\right.\right.} \\
\times U\left(t-t_{I I}\right)
\end{gathered}
$$

This is expression (II-21) of appendix II. $V a_{I I}(t)_{1}$ is given by expression (6-14), $p_{j}$ is $p_{1}, p_{2}, p_{1}{ }^{\prime}, p_{2}{ }^{\prime}$, respectively. For a symmetrical multivibrator $p_{1}=p_{1}{ }^{\prime}$ and $p_{2}=p_{2}{ }^{\prime}$. $V_{j}$ is given by expressions (II-22) to (II-25) inclusive. $p_{3}$ and $p_{4}$ are represented by expressions (II-14) and (II-15). For $G^{\prime}$ and $F^{\prime}$ see expressions (II-3) and (II-2). The $X$-quantities are given by expressions (II-16), (II-17) and (II-18).

For a symmetrical multivibrator the still rather cumbersome expression is represented in full by (II-28) of appendix II.

The voltage at the grid of tube I during the second phase is derived in appendix III. This voltage is given by expressions (III-8) and (III-12) of this appendix, viz.

$$
\begin{aligned}
& V_{g_{I}}(t)=V_{g I}(t)_{1}-\frac{R_{g}\left(1-\varepsilon_{a}\right) R_{a}}{\left(R+R_{g}\right)\left\{\left(1-\varepsilon_{a}\right) R_{a}+r_{a}\right\} G^{\prime}} \stackrel{p_{j}=\sum_{p_{1}-\cdots}^{p_{2}^{\prime}}}{\Sigma_{j}} V_{j} p_{j} e^{p_{j}} t_{I I} \\
& {\left[\frac{Y_{1^{j}}}{-p_{3}}\left\{1-e^{p_{3}\left(t-t_{I I}\right)}\right\}+\frac{Y_{2^{j}}}{-p_{4}}\left\{1-e^{p_{4}\left(t-t_{I I}\right)}\right\}+\frac{Y_{3^{j}}}{-p_{j}}\left\{1-e^{p_{j}\left(t-t_{I I}\right)}\right\}\right] \times} \\
& \times U\left(t-t_{I I}\right)
\end{aligned}
$$


Recapitulating, the grid and anode voltages of tubes I and II have been determined as functions of time during the first and second phases of the dynamic condition of the multivibrator circuit, where

$V g_{I}$ is given by expressions (6-13) and (6-31),

$V a_{I}$ by expression (6-12),

$V g_{I I}$ by expression (6-11) and

$V a_{I I}$ by expressions (6-14) and (6-30).

\subsection{THIRD PHASE}

As already assumed in chapter 4 , the grid voltage of the second tube will rise until the point where grid current starts to flow, i.e. at $V_{g_{I I}}=o$ where grid $G_{I I}$ and cathode are suddenly short-circuited. This can be taken into account by introducing between grid $G_{I L}$ and cathode a voltage source

$$
V_{c}(t)=V g_{I I}(t) U\left(t-t_{s}\right)
$$

where $V g_{I I}(t)$ is given by expression (6-11), valid during the first and second phases and $t_{s}$ is the instant at which $V g_{I I}$ becomes zero. This value $t_{s}$ is to be determined from expression (6-11) by putting $V_{g I I}\left(t_{s}\right)=0$. This new voltage source $V_{c}(t)$ causes new terms in the voltages at $A_{I I}$, at $A_{I}$ and at $G_{I}$.

The new transient at $A_{I I}$ is:

$$
V_{a I I}^{* *}(t)=\frac{Z_{i a I I}}{Z_{i a I I}+\gamma_{a}} \mu V_{g I I}(t) U\left(t-t_{s}\right)
$$

The new transient at $G_{I}$ is:

$$
\begin{gathered}
V_{g I}^{* *}(t)=\frac{Z_{g I} Z_{a I I}}{\left(Z+Z_{g I}\right) Z_{a I I}+r_{a}\left(Z+Z_{g I}+Z_{a I I}\right)} \mu V_{g I I}(t) U\left(t-t_{s}\right)(6-34) \\
{[\text { compare expression (III-5)]. }}
\end{gathered}
$$

The new transient at $A_{I}$ is:

$$
V_{a I}^{* *}(t)=-\frac{Z_{a I}}{Z+Z_{a I}} V_{g I}(t) U\left(t-t_{s}\right)
$$

These transients are evaluated in Appendix IV and are given by expressions (IV-4), (IV-5) and (IV-13).

The total voltage at $A_{I I}$ during the three phases of the dynamic condition is the sum of expressions (6-30) and (IV-4). 


$$
\begin{aligned}
& V_{a I I}(t)=V_{a I I}(t)_{1}-\frac{\left(1-\varepsilon_{a}\right) R_{a}}{\left\{\left(1-\varepsilon_{a}\right) R_{a}+r_{a}\right\} G^{\prime}}\left[\stackrel{p_{j}=p_{1}-p_{2}^{\prime}}{\Sigma} V_{j} p_{j} e^{p_{j} t_{I I}}\right. \\
& \left\{\frac{X_{1^{j}}}{-p_{3}}\left\{1-e^{p_{3}\left(t-t_{I I}\right)}\right\}+\frac{X_{2^{j}}}{-p_{4}}\left\{1-e^{p_{4}\left(t-t_{I I}\right)}\right\}+\frac{X_{3^{j}}}{-p_{j}}\left\{1-e^{p_{j}\left(t-t_{I I}\right)}\right\}\right\} \\
& U\left(t-t_{I I}\right)-\sum^{p_{j}=p_{1}, p_{a}} V_{j} p_{j} e^{p_{i} t_{s}}\left\{\frac{X_{1^{j}}}{-p_{3}}\left\{1-e^{p_{3}\left(t-t_{s}\right)}\right\}+\frac{X_{2^{j}}}{-p_{4}}\left\{1-e^{p_{4}\left(t-t_{s}\right)}\right\}+\right. \\
& \left.\left.+\frac{X_{3^{j}}}{-p_{j}}\left\{1-e^{p_{j}\left(t-t_{s}\right)}\right\}\right\} U\left(t-t_{s}\right)\right]
\end{aligned}
$$

where $V a_{I I}(t)_{1}$ is given by expression (6-14).

The total voltage at $G_{I}$ during the three phases is the sum of expressions $(6-31)$ and $(\mathrm{IV}-5)$ :

$$
\begin{aligned}
& V_{g I}(t)=V_{g I}(t)_{1}-\frac{R_{g}\left(1-\varepsilon_{a}\right) R_{a}}{\left(R+R_{g}\right)\left\{\left(1-\varepsilon_{a}\right) R_{a}+r_{a}\right\} G^{\prime}}\left[\sum^{p_{j}=p_{1}-p^{p_{2}{ }^{1}}} V_{j} p_{j} e^{p_{j} t_{I I}}\right. \\
& \left\{\frac{Y_{1^{j}}}{-p_{3}}\left\{1-e^{p_{3}\left(t-t_{I I}\right)}\right\}+\frac{Y_{2^{j}}}{-p_{4}}\left\{1-e^{p_{4}\left(t-t_{I I}\right)}\right\}+\frac{Y_{3^{j}}}{-p_{j}}\left\{1-e^{p_{j}\left(t-t_{I I}\right)}\right\}\right\} \\
& U\left(t-t_{I I}\right)-\sum_{j}^{p_{j}=p_{1}, p_{2}} V_{j} p_{j} e^{p_{j} t_{s}}\left\{\frac{Y_{1^{j}}}{p_{3}}\left\{1-e^{p_{3}\left(t-t_{s}\right)}\right\}+\right. \\
& \left.\left.+\frac{Y_{2^{j}}}{-p_{4}}\left\{1-e^{p_{4}\left(t-t_{s}\right)}\right\}+\frac{Y_{3^{j}}}{-p_{j}}\left\{1-e^{p_{j}\left(t-t_{s}\right)}\right\}\right\} U\left(t-t_{s}\right)\right]
\end{aligned}
$$

where $V_{g I}(t)_{1}$ is given by expression (6-13).

The total voltage at $A_{I}$ during the three phases is the sum of expressions (6-12) and (IV-13):

$$
\begin{gathered}
V_{a I}(t)=V_{a I}(t)_{1,2}+\frac{R_{a}}{\left(R+R_{a}\right)} p_{n}\left[p _ { 1 } V _ { 2 } e ^ { p _ { 1 } t _ { s } } \left\{\frac{1+T p_{n}}{-p_{n}\left(p_{n}-p_{1}\right)}\right.\right. \\
\left.\left\{1-e^{p_{n}\left(t-t_{s}\right)}\right\}+\frac{1+T p_{1}}{p_{1}\left(p_{n}-p_{1}\right)}\left\{1-e^{p_{1}\left(t-t_{s}\right)}\right\}\right\}+p_{2} V_{3} e^{p_{2} t_{s}}\left\{\frac{1+T p_{n}}{-p_{n}\left(p_{n}-p_{2}\right)}\right. \\
\left.\left\{1-e^{p_{n}\left(t-t_{s}\right)}\right\}+\frac{1+T p_{2}}{p_{2}\left(p_{n}-p_{2}\right)}\left\{1-e^{p_{2}\left(t-t_{s}\right)}\right\}\right\} U\left(t-t_{s}\right)
\end{gathered}
$$

where $V_{a 1}(t)_{1,2}$ is given by expression 6-12.

The anode and grid voltages of tubes I and II have now been calculated as functions of time during the whole trigger-cycle. $V_{a_{I I}}$ is represented by expression (6-36), $V_{g I}$ by expression $(6-37)$ and $V_{a I}$ by expression (6-38), whilst $V_{g I I}$ can be represented by the following expression: 


$$
V_{g I I}(t)=V_{g I I}(t)_{1,2}\left\{1-U\left(t-t_{s}\right)\right\}
$$

Where $V_{g I I}(t)_{\mathbf{1 2}}$ is given by expression (6-11), valid during the second phase as well.

Note: A check on the calculation of the expressions for the voltage changes at the anodes and grids is to compare the final values (at $t=\infty$ ) with the initial values (at $t \leq 0$ ) of the other tube. The following relations hold:

The grid voltage $V_{g I o}$ must be equal to $V_{g I I}$ at $t=\infty$, and $V_{g I I o}$ must be the same as $V_{g_{I}}$ at $t=\infty$. The same applies to the anode voltages, which also change rôles when the multivibrator is triggered. These relations have been verified and confirmed. 


\section{THE COMPLETE TRIGGER CYCLE}

The time functions for the anode and grid voltages during the complete trigger cycle have been calculated for a numerical example and are graphically represented in figs. $7-1,2,3,4$. The calculations were simplified as it turned out that the transient components of $V_{a I I}$ from the first phase have practically disappeared at the instant $t=t_{I I}$, which means that $V_{a I I}=V_{4}=$ constant (expr. (6-14)). The circuit- and other data are the following (see fig. $3-1$ and 3-2): $V^{\prime}=150 \mathrm{~V}, \mathrm{~V}^{\prime \prime}=100 \mathrm{~V}, R_{a}=20 \mathrm{k} \Omega$, $R=R_{g}=200 k \Omega, C=100 p F, C_{c}=40 p F, C_{g}=10 p F, t_{o}=0.2 \mu$ sec., $V_{o}=25 \mathrm{~V}, \mu=35, r_{a}=8 \mathrm{k} \Omega$.

The curves marked $a$ apply to a symmetrical multivibrator of which $C_{a I}=C_{a I I}=5 p F$, whilst the curves marked $b$ and $c$ apply to an asymmetrical multivibrator with $C_{a I}=110 p F$ and $C_{a I I}=5 p F$. The calculated curves are represented by the fully-drawn lines. No account has been taken of the influence of $C_{a g}$ or of the rear flank of the trigger pulse. It is possible to account for the influence of $C_{a g}$, but this involves such complicated calculations (fourth-order equations to be solved for determining the normal modes of the circuit) that they become very impracticable to handle. The influence of $C_{a g}$ on the waveforms may be considered to be such that their slopes and amplitudes are reduced to some extent, but calculations in which $C_{a g}$ is ignored will nevertheless give a good idea of the general aspect of the waveforms. Differences of a few volts in amplitude may, however, considerably influence the values of the times $t_{I}$ and $t_{I I}$ at which the tubes should reach their cut-off points. Therefore, in calculating the trigger sensitivity the influence of $C_{a g}$ has not been neglected and fortunately this did not lead to excessively complicated formulae.

For the sake of comparison with practice, the curves displayed by an oscilloscope have also been plotted in the figures (broken lines). It should be recognized that the time scale on the screen of the oscilloscope was only about one tenth of that used for the graphs, so that some inaccuracy was introduced in drawing the steep fronts.

\subsection{Discussion of the Waveforms}

From fig. 7-1, which represents the waveform of $V_{g I I}$, it can be clearly seen that $V_{g I I}$ reaches the cut-off value (approximately $-4 V$ ) in a much shorter time $\left(t=t_{I I}\right)$ in case $a\left(C_{a I}=5 p F\right)$; than in case $b$ (capacitive load, $\left.\mathrm{C}_{a I}=110 p F\right)$, in other words the capacitive load considerably increases the duration of the first phase. 

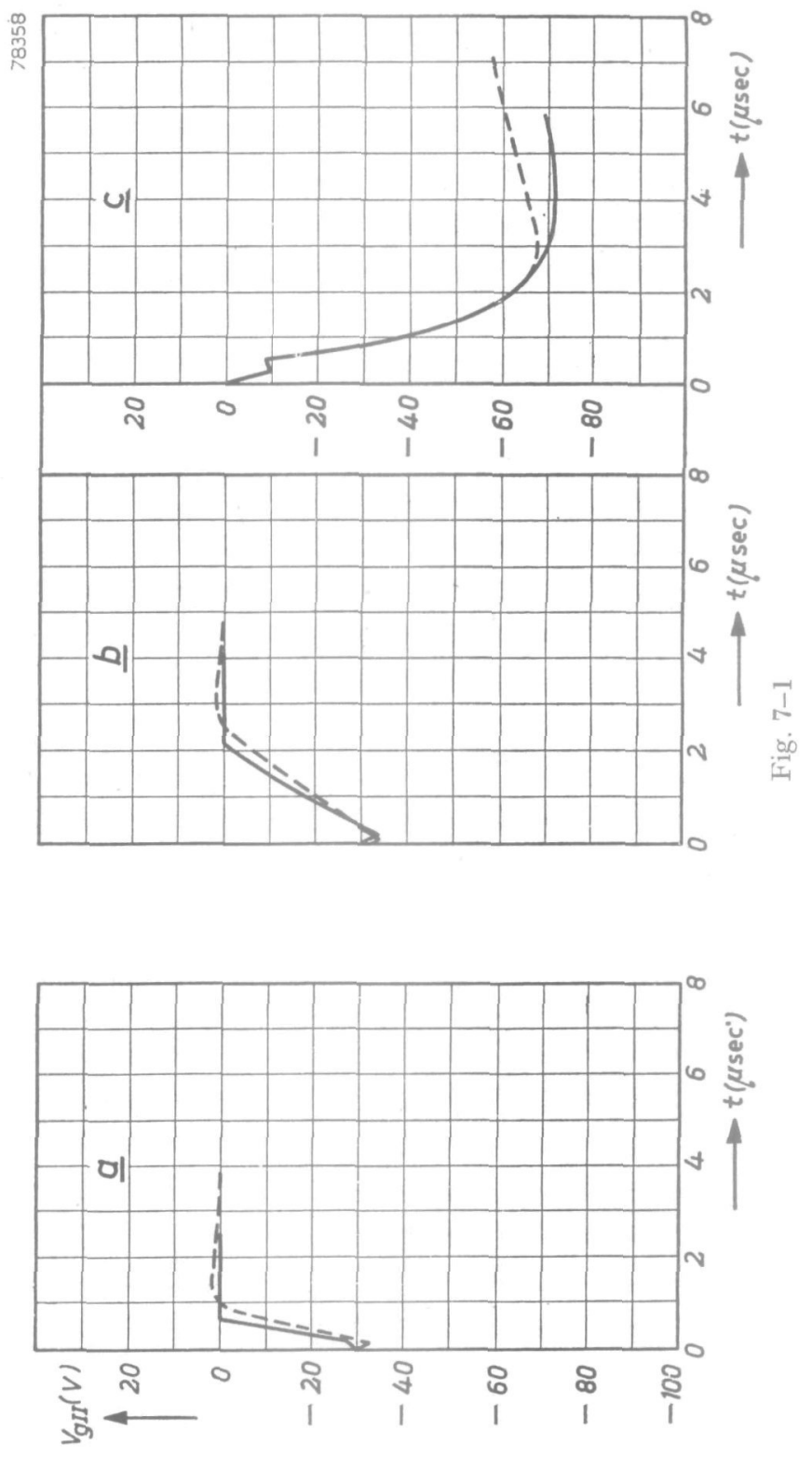
总
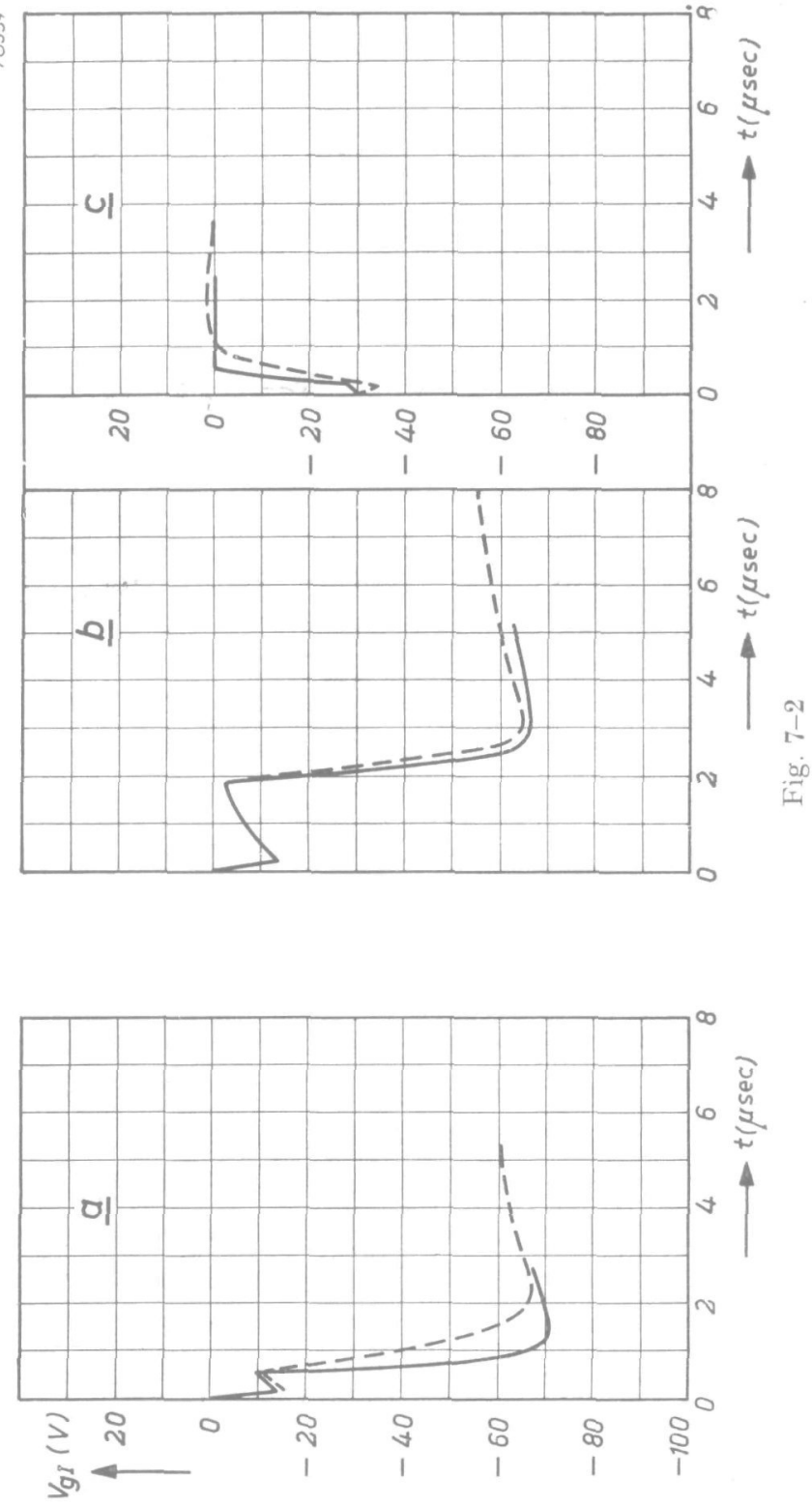

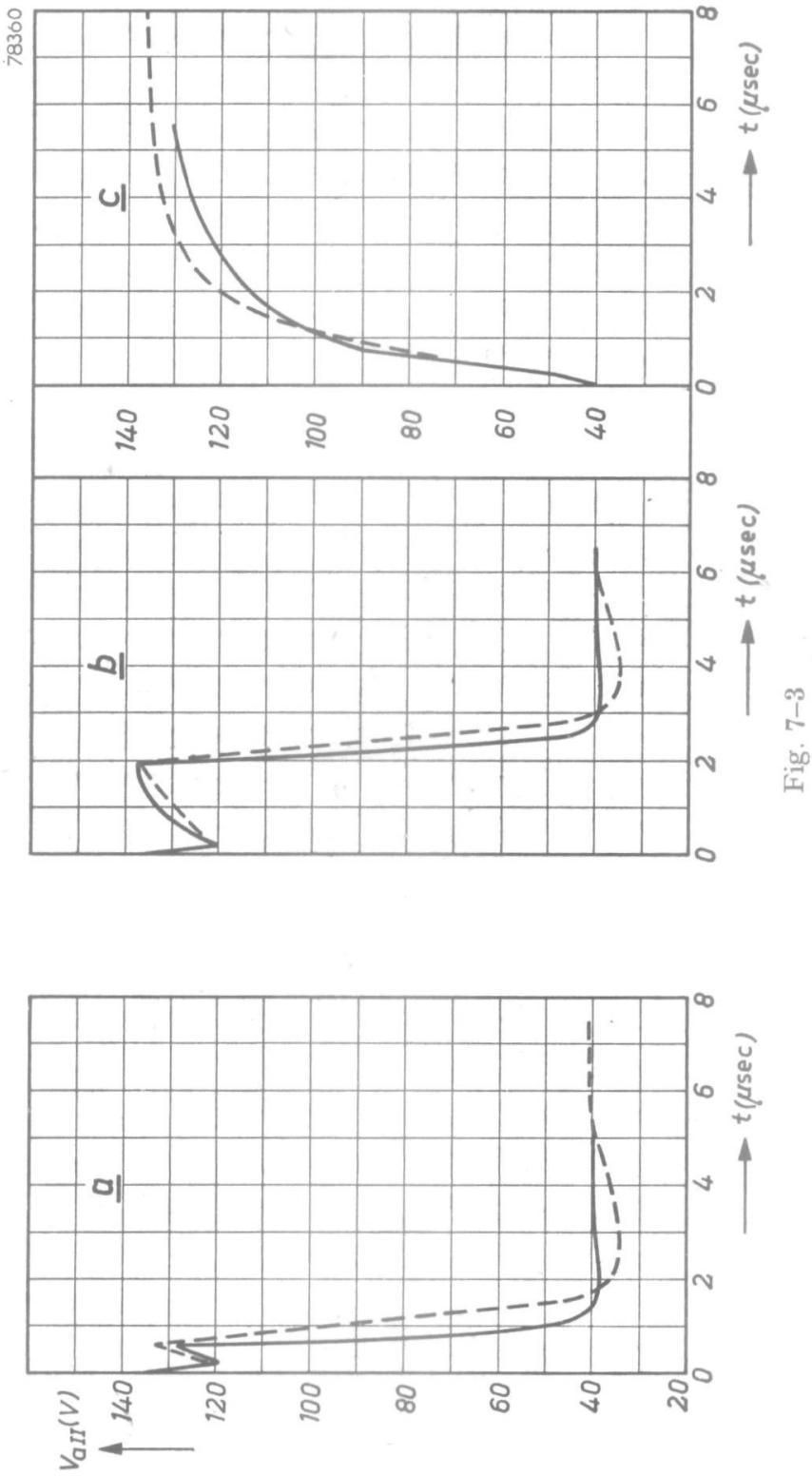

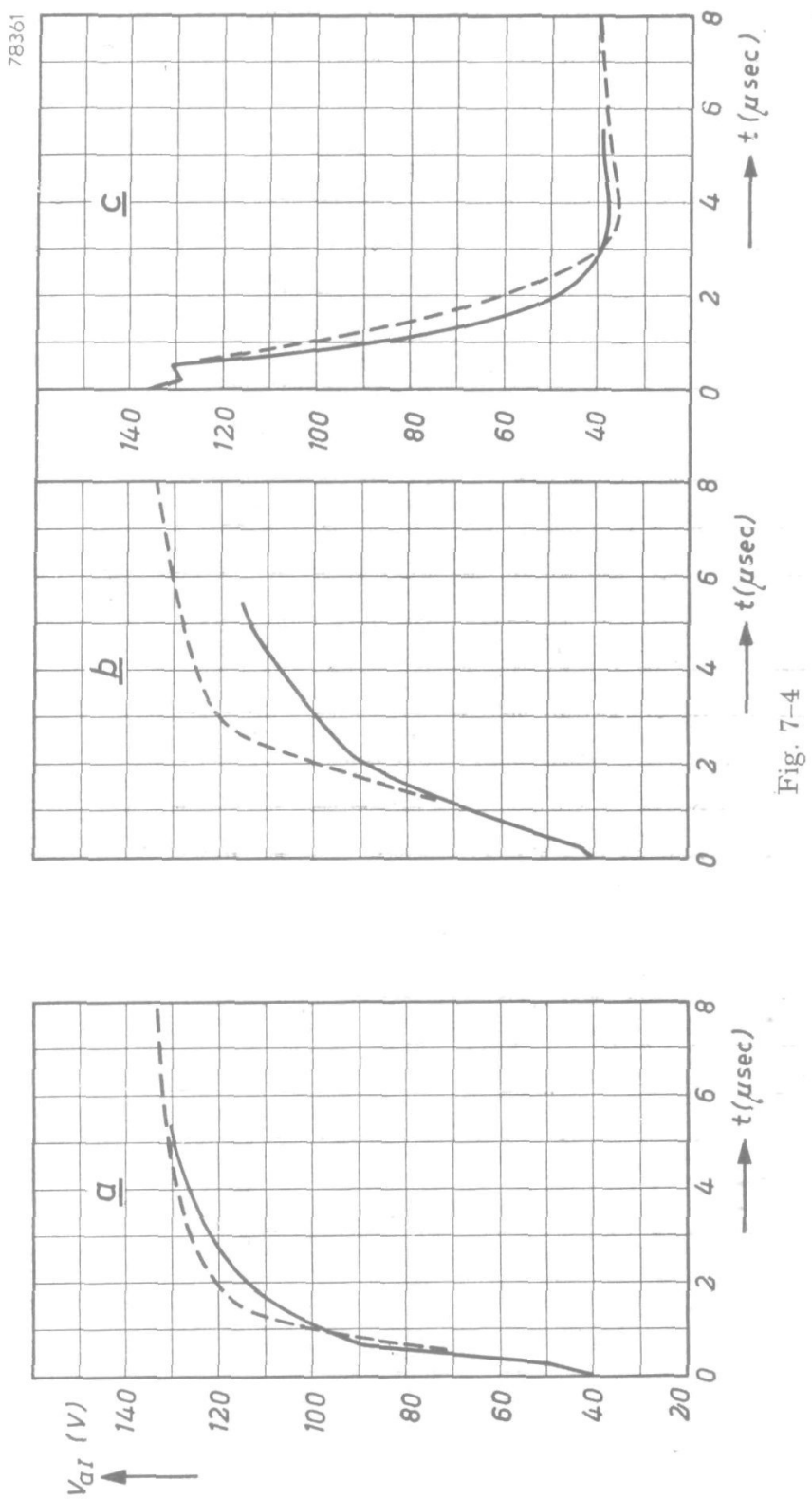
At the instant $t=t_{I I}$ the grid voltage of tube I, represented in fig. 7-2, has reached a value $-10 \mathrm{~V}$ and $-4 \mathrm{~V}$ in case $a$ and case $b$ respectively. This shows that the triggering is much more certain in the unloaded than in the loaded condition. It is only because the anode voltage of tube I (see fig. 7-4b, about $85 \mathrm{~V}$ ) is much smaller than the anode voltage of tube II (see fig. $7-3 \mathrm{~b}$, about $138 \mathrm{~V}$ ) at the instant $t_{I I}$, that the cut-off voltage of tube $\mathrm{I}$ is not yet reached at $V_{g I}=-4 \mathrm{~V}$.

At the instant $t=t_{I I}$ the second phase of the trigger cycle commences. Curves $a$ and $b$ of fig. 7-3 reveal that the anode voltage $V_{a I I}$ greatly decreases from this instant onwards, and consequently the grid voltage $V_{g I}$ (see fig. 7-2) also decreases. The multivibrator is finally triggered. Fig. 7-1 shows that $V_{g I I}$ reaches the value zero shortly after the instant $t=t_{I I}$; owing to the flow of grid current, $V_{g I I}$ is then kept constant at this value. In practice there is some overshoot, which should be attributed to the fact that the grid resistance is not zero as was assumed in the calculations. The influence of the discontinuity will therefore be smaller than calculated.

The fully-drawn curves plotted in fig. 7-4 show the calculated effects of this discontinuity (at approximately $0.7 \mu \mathrm{sec}$ for curve $a$ and at approximately $2 \mu$ sec for curve $b$ ) on the anode voltage $V_{a I}$. This effect could not be clearly discerned on the oscillograms. The oscillograms shown in figs. 7-6 and 7-9, which apply to other trigger circuits, do show these discontinuities.

The oscillograms of figs. 7-5 and 7-6 refer to a symmetrical unloaded multivibrator having the same data as the previously mentioned circuit. Triggering was, however, achieved by means of square-wave pulses with a period of $15 \mu \mathrm{sec}$. Fig. $7-5$ shows the grid voltage variation of one of the tubes; that of the other tube is obviously identical. Fig. 7-6 displays the anode-voltage variation of both tubes. The discontinuity which can be clearly seen in the ascending part of the oscillogram is due to the start of grid current flow in the other tube.

Figs. 7-7, 8, 9, 10 show the oscillograms of the grid and anode voltages of an asymmetrical multivibrator, triggered by negative-going pulses having a width of $40 \mu \mathrm{sec}$, a period of $60 \mu \mathrm{sec}$ and an amplitude of $35 \mathrm{~V}$. The circuit data are once again identical to those of the previous circuits; $C_{a I}$ and $C_{a I I}$ were $110 p F$ and $5 p F$, respectively.

The variation of $V_{g I I}$ is displayed by the oscillogram shown in fig. 7-7; the negative-going front should be compared with curve $c$ of fig. 7-1 and the positive-going front with curve $b$ of this figure.

Fig. 7-8 shows the variation of $V_{g I}$; this should be compared with curves $b$ and $c$ of fig. 7-2. 


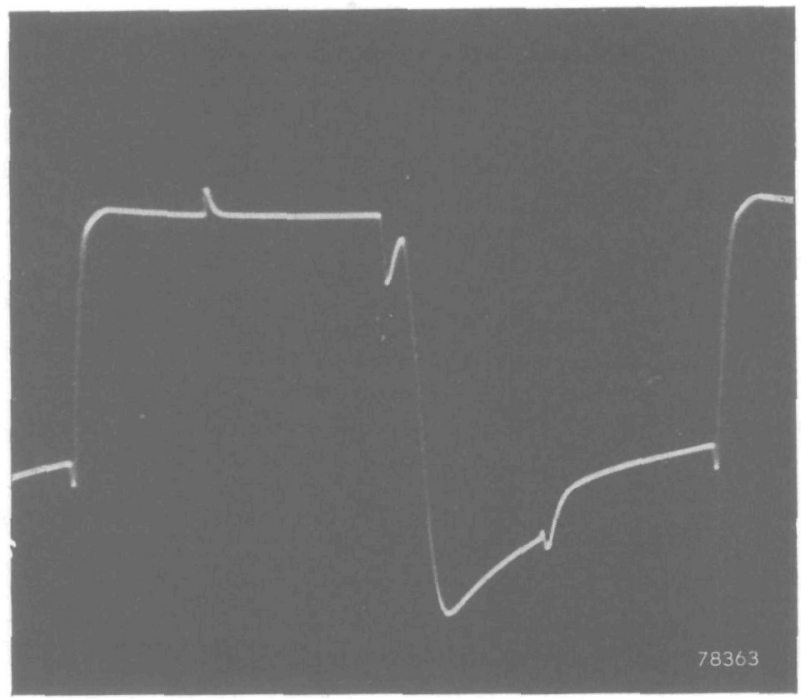

Fig. 7-5

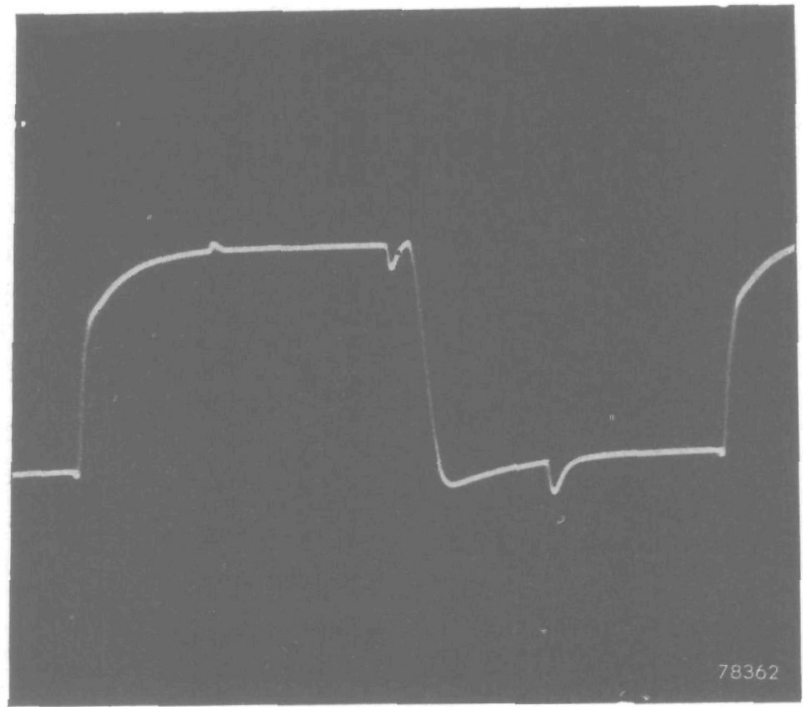

Fig. 7-6 


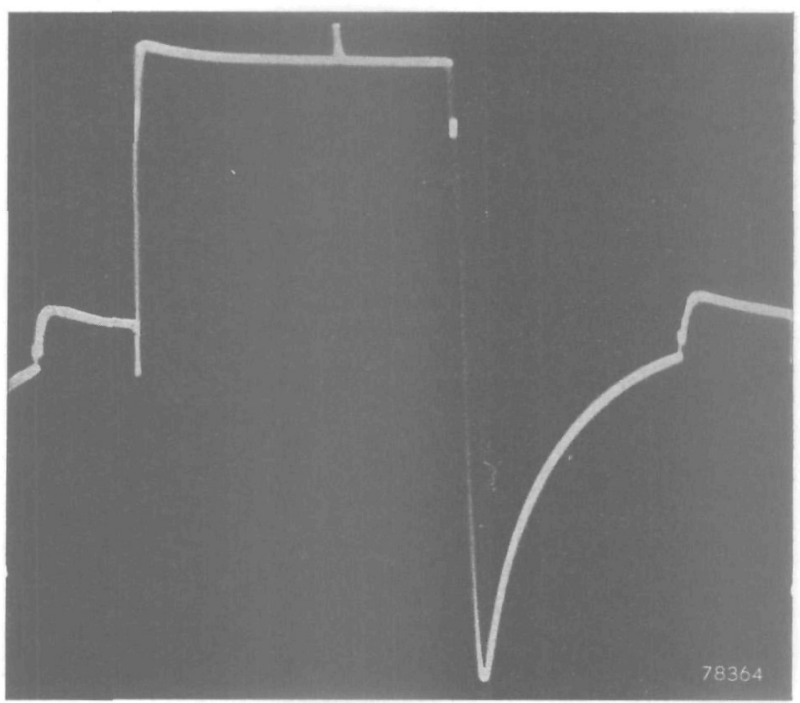

Fig. 7-7

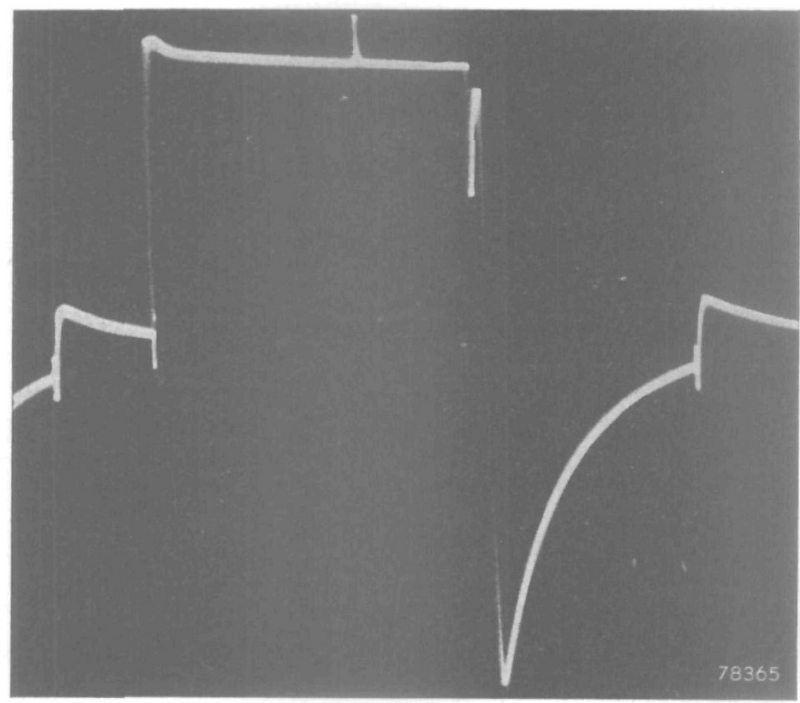

Fig. 7-8 


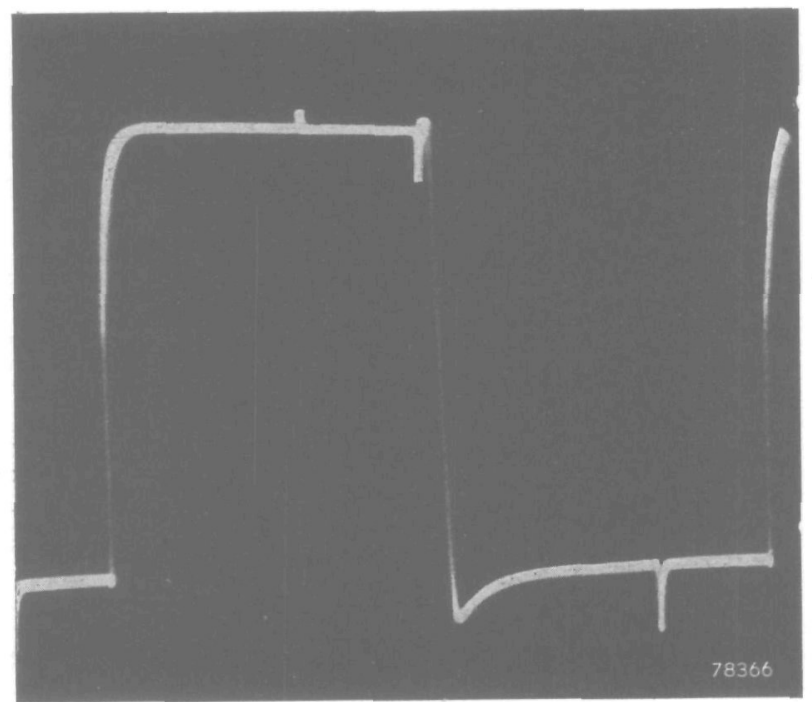

Fig. 7-9

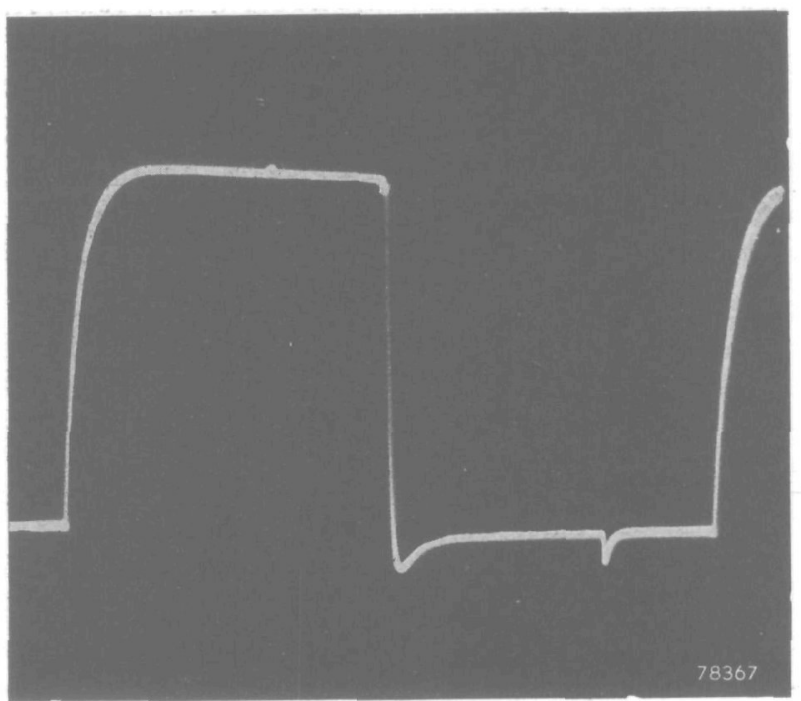

Fig. 7-10 
Fig. 7-9 gives the oscillogram of $V_{a I I}$ and should be compared with curves $b$ and $c$ of fig. 7-3.

Finally, the oscillogram of fig. $7-10$ shows the variation of $V_{a I}$ and should be compared with curves $b$ and $c$ of fig. 7-4.

In the curves representing the calculated time functions the influence of the positive-going rear flanks of the trigger pulses has been disregarded. In practice care should be taken that these positive-going flanks do not disturb the normal triggering. These pulses should not, for example, drive the grid voltage of the non-conducting tube (i.e. the initially conducting tube I) above its cut-off point. Curves $a$ and $b$ of fig. 7-2 reveal the considerable overshoot of $V_{g I}$ in the negative direction, its final value being $-30 \mathrm{~V}$. It would therefore be advantageous to choose the width of the trigger pulse in such a way that the positive-going rear flank coincides with this overshoot region. This will not be possible, however, when a multivibrator is triggered by a preceding one, because the pulses produced thereby are always roughly square-wave shaped and the positive-going flank will always occur just between two negative-going flanks. However, the negative anode-voltage pulse, caused by the positive-going flank at the grid of the conducting tube, has a compensating effect on the positive-going flank at the grid of the non-conducting tube. This effect is clearly shown by the oscillogram of fig. $7-5$ half way along the gradually increasing part of the voltage curve. Initially, the voltage tends to rise, but the slightly delayed negative pulse at the anode of the conducting tube is passed to the grid of the non-conducting tube via the coupling capacitor $\mathrm{C}$ and even overcompensates the positive-going input pulse, so that a negative pulse results.

The final static conditions for the curves $a$ and $b$ of figs. 7-1, 2, 3, 4 are: $V_{g I}=-30 \mathrm{~V}, V_{a I}=136 \mathrm{~V}, V_{g I I}=0 \mathrm{~V}$ and $V_{a I I}=40 \mathrm{~V}$. The functions are now reversed, tube I being cut off and tube II being conducting. The next negative-going flank of $V_{i}$ will trigger the multivibrator once again. In the case of a symmetrical circuit $\left(C_{a I}=C_{a I I}=5 p F\right)$ the waveforms during this new trigger action follow from the theoretical results, by changing the indices I and II in all formulae, the waveform of $V_{g I I}$ thus being indentical to that of $V_{g I}$ during the preceding trigger action. The new waveforms corresponding to figs. $7-1 \mathrm{a}, 2 \mathrm{a}, 3 \mathrm{a}, 4 \mathrm{a}$ have therefore not been given separately, as the new fig. 7-2a corresponds to 7-1a and the new fig. $7-4 \mathrm{a}$ to $7-3 \mathrm{a}$, and vice versa.

In the case of an asymmetrically loaded multivibrator the situation is less simple, but the waveforms can nevertheless also be calculated; the results are shown by curves $c$. 
Notwithstanding the presence of the load capacitance $C_{a I}=110 p F$ the switching time, or the duration of the first trigger phase, is now much shorter than in the first case $b$. This is due to the fact that the switching time is now defined by the waveform of $V_{g I}$, which is independent of $C_{a I}$. The switching time is about $0.6 \mu \mathrm{sec}$, whereas it was about $2 \mu \mathrm{sec}$. in the first case.

It can, moreover, be seen that the trigger sensitivity will be better in the second case. In the first case the grid voltage of the initially conducting tube, $V_{g I}$, has almost reached its cut-off value at the instant in which tube II starts to draw anode current (at $t \approx 2 \mu \mathrm{sec}$; see curve $b$ fig. $7-2$ ). In the second case, however, the grid voltage of the initially conducting tube, $V_{g I I}$ (curve $c$, fig. $7-1$ ), rises at a much slower rate owing to the influence of $C_{a I}=110 \mathrm{pF}$. At the instant at which tube I starts to draw current the (negative) value of $V_{g I Y}$ will still be almost three times that of $V_{g I}$ in the first case. In other words, $V_{g I}$ rises much faster than $V_{g I I}$ during the same periods of time.

The sensitivity of an asymmetrical multivibrator is thus not the same for the two stable conditions, and is smallest for the initial condition in which the capacitively loaded tube is conducting. In practice this smallest sensitivity defines the usefulness of the circuit.

It can also be seen that the sensitivity of an asymmetrically loaded multivibrator is improved by loading the multivibrator symmetrically (for example $C_{a I}=C_{a I I}=110 p F$ ). In that case the grid voltage $V_{g I}$ (curve $b$, fig. 7-2) will rise more slowly and reach the cut-off point later, so that it will be easier for the grid voltage of the other tube to reach its cut-off value first.

This fact has been confirmed experimentally. By way of example the average value of $V_{c r}$, the minimum input voltage amplitude wanted to trigger the multivibrator, measured on a series of some 40 experimental samples of double triodes, will be given. For symmetrical, unloaded multivibrator circuits the critical trigger amplitude had an average value of $17 \mathrm{~V}$. For an asymmetrical circuit ( $150 \mathrm{pF}$ load in one of the anode circuits) this average value was $38 \mathrm{~V}$. By connecting the load of $150 p F$ to both anode circuits the sensitivity of the multivibrator was increased, the average value of $V_{c r}$ then being $31.5 \mathrm{~V}$. 


\section{THE TRIGGER SENSITIVITY}

In chapter 6 explicit expressions have been derived for the anode and grid voltages as functions of time during the complete trigger cycle. With the aid of these expressions various properties of the circuit can be investigated, including in particular the trigger sensitivity; in fact, the need for knowing the influence of tube characteristics on the sensitivity was the reason for starting the investigation and analysis given here. In section 6-2 it has already been mentioned that the limit of correct triggering operation is reached if both tubes attain their cut-off grid voltages simultaneously. The $t_{I}$ and $t_{I I}$ that elapse before tube I and tube II reach their respective cut-off points after the application of the trigger voltage $V_{i}$, when the feedback was temporarily inactive, can be calculated from the relations

$$
V_{g I}\left(t_{I}\right)=\frac{-V_{a I}\left(t_{I}\right)}{\mu}
$$

and

$$
V_{g I I}\left(t_{I I}\right)=\frac{-V_{a I I}\left(t_{I I}\right)}{\mu}
$$

The time functions representing the anode and grid voltages are given by expressions $(6-11,12,13,14)$. One of the variables defining these functions is the amplitude $V_{o}$ of the trigger voltage $V_{i}$ (see fig. 3-2). Varying $V_{o}$ will result in varying the values of $t_{I}$ and $t_{I I}$. Practical experience shows that at too low a value of $V_{o}$ no switch-over of the multivibrator occurs. It is evident that in this case $t_{I}<t_{I I}$. At a certain value, $V_{o}=V_{c r}$, the values of $t_{I}$ and $t_{I I}$ will be equal and this will be a limit for correct triggering. Therefore $V_{c r}$ will be called the critical trigger voltage amplitude, and is a measure for the trigger sensitivity. The lower $V_{c r}$, the higher the sensitivity of the multivibrator circuit.

Up till now, the influence of the capacitance $C_{a g}$ between the anode and grid of each tube has not been allowed for in the calculations, as it considerably complicates the problem. However, practical experience showed evidence that the anode-to-grid capacitance of the tubes had a considerable influence on the trigger sensitivity. Therefore it is desirable to take into account this influence of $C_{a g}$.

For a non-conducting tube the effect of $C_{a g}$ will nearly be equivalent to the presence of a capacitive voltage divider between anode and grid, and will influence signals with a steep slope. A fraction of the anode voltage variation is transmitted to the grid of the same tube due to the anode-to- 
grid capacitance of the tube. For tube I this can be taken into account by the factor

$$
b_{I}=\frac{C_{a g I}}{C_{a g I}+C_{c}+C_{g I}+\frac{C C_{a I I}}{C+C_{a I I}}}
$$

and for tube II by the factor

$$
b_{I I}=\frac{C_{a g I I}}{C_{a g I I}+C_{c}+C_{g I I}+\frac{C C_{a I}}{C+C_{a I}}}
$$

For a more elaborate discussion of the influence of $C_{a g}$ see Appendix VI. The anode-voltage variation is the difference between the total anode voltage during the first phase of the dynamic condition and the staticcondition voltage. With this correction the expressions (8-1) and (8-2) become:

$$
\begin{gathered}
V_{g I}\left(t_{I}\right)+b_{I}\left\{V_{a I}\left(t_{I}\right)-V_{a I_{o}}\right\}=-\frac{1}{\mu} V_{a_{I}}\left(t_{I}\right) \\
V_{g I I}\left(t_{I I}\right)+b_{I I}\left\{V_{a I I}\left(t_{I I}\right)-V_{a I I o}\right\}=-\frac{1}{\mu} V_{a I I}\left(t_{I I}\right)
\end{gathered}
$$

Introducing expressions $(6-11,12,13,14)$ into these equations gives

$$
\begin{gathered}
\left(b_{I}+\frac{1}{\mu}\right) V_{8} e^{p_{1} t_{I}}+\left(b_{I}+\frac{1}{\mu}\right) V_{9} e^{p_{2} t_{I}}+V_{11} e^{p_{1}{ }^{\prime} t_{I}}+V_{12} e^{p_{2}{ }^{\prime} t_{I}}+V_{10}+ \\
+\left(b_{I}+\frac{1}{\mu}\right) V_{7}-b_{I} V_{a I o}=0 \\
V_{2} e^{p_{1} t_{I I}}+V_{3} e^{p_{2} t_{I I}}+\left(b_{I I}+\frac{1}{\mu}\right) V_{5} e^{p_{1}{ }^{\prime} t_{I I}}+\left(b_{I I}+\frac{1}{\mu}\right) V_{6} e^{p_{2}{ }^{\prime} t_{I I}}+V_{1}+ \\
+\left(b_{I I}+\frac{1}{\mu}\right) V_{4}-b_{I I} V_{a I I o}=0
\end{gathered}
$$

To solve these equations for $t_{I}$ and $t_{I I}$, one can only try, by substituting several values of $V_{o}$, to find a value $V_{c r}$ for which $t_{I}=t_{I I}$. For the symmetrical multivibrator, however, a more elegant method can be derived. In that case $p_{1}=p_{1}{ }^{\prime}, p_{2}=p_{2}{ }^{\prime}$ and $b_{I}=b_{I I}=b$. The equations take the following form:

$$
\begin{gathered}
\left\{\left(b+\frac{1}{\mu}\right) V_{8}+V_{11}\right\} e^{p_{1} t_{I}}+\left\{\left(b+\frac{1}{\mu}\right) V_{9}+V_{12}\right\} e^{p_{2} t_{I}}+V_{10}+ \\
+\left(b+\frac{1}{\mu}\right) V_{7}-b V_{a I o}=0
\end{gathered}
$$




$$
\begin{gathered}
\left\{\left(b+\frac{1}{\mu}\right) V_{5}+V_{2}\right\} e^{p_{1} t_{I I}}+\left\{\left(b+\frac{1}{\mu}\right) V_{6}+V_{3}\right\} e^{p_{2} t_{I I}}+V_{1}+ \\
\left(b+\frac{1}{\mu}\right) V_{4}-b V_{a I I o}=0
\end{gathered}
$$

The following notations will be used:

$$
\begin{gathered}
e^{p_{1} t_{I}}=x_{I} \\
e^{p_{1} t_{I I}}=x_{I I} \\
\frac{p_{2}}{p_{1}}=\gamma
\end{gathered}
$$

Then equations (8-9) and (8-10) become:

$$
\begin{gathered}
\left\{\left(b+\frac{1}{\mu}\right) V_{8}+V_{11}\right\} x_{I}+\left\{\left(b+\frac{1}{\mu}\right) V_{9}+V_{12}\right\} x_{I}^{\gamma}+V_{10}+ \\
+\left(b+\frac{1}{\mu}\right) V_{7}-b V_{a I o}=0 \\
\left\{\left(b+\frac{1}{\mu}\right) V_{5}+V_{2}\left\{x_{I I}+\left\{\left(b+\frac{1}{\mu}\right) V_{6}+V_{3}\right\} x_{I I}^{\gamma}+V_{1}+\right.\right. \\
+\left(b+\frac{1}{\mu}\right) V_{4}-b V_{a I I o}=0
\end{gathered}
$$

When $V_{o}=V_{c r}$ then $t_{I}=t_{I I}$, or $x_{I}=x_{I I}=x$. Substituting these values in eqs (8-14) and (8-15) and subtracting these equations gives:

Where

$$
A_{2} x^{\gamma}+A_{1} x+A_{0}=0
$$

$$
\begin{aligned}
\mathrm{A}_{2}=- & \left.\frac{1}{2}\left(b+\frac{1}{\mu}\right)\left\{I_{a o}\left(1-\varepsilon_{a}\right) R_{a}(1+L)-I_{g o} \varepsilon_{a} R_{g} \backslash 1+P\right)\right\}- \\
& -\frac{1}{2} I_{g o}\left(1-\varepsilon_{g}\right) R_{g}(1+K)+\frac{1}{2} I_{a o} \varepsilon_{a} R_{g}(1+P) \\
A_{1}= & -\frac{1}{2}\left(b+\frac{1}{\mu}\right)\left\{I_{a o}\left(1-\varepsilon_{a}\right) R_{a}(1-L)-I_{g o} \varepsilon_{a} R_{g}(1-P)\right\} \\
& -\frac{1}{2} I_{g o}\left(1-\varepsilon_{g}\right) R_{g}(1-K)+\frac{1}{2} I_{a o} \varepsilon_{a} R_{g}(1-P) \\
A_{o}= & b\left(V_{a I I_{o}}-V_{a I_{o}}\right)=b\left\{\left(1-\varepsilon_{a}\right) R_{a} I_{a o}-\varepsilon_{a} R_{g} I_{g o}\right\}
\end{aligned}
$$


Equation (8-16) is independent of $V_{c r}$ and therefcre, if $x$ is determined by solving the equation, then $V_{c r}$ can be calculated from either eq. (8-14) or $(8-15)$. However, in general, eq. (8-16) will not be easily solved by conventional methods, as $\gamma$ is normally a rather high power and not even a whole number. Therefore, a graphical method is to be applied.

If in one graph the functions $F_{1}(x)=x^{\gamma}$ and $F_{2}(x)=-\frac{A_{1}}{A_{2}} x-\frac{A_{o}}{A_{2}}$ are plotted, then the point of intersection of the graphical representations gives the value of $x$ to be determined.

\subsection{INFLUENCE OF TUBE CHARACTERISTICS AND CAPACITIVE ANODE LOAD}

An example of calculating the influence of tube characteristics and of a capacitive load in both anode circuits on the sensitivity will be given. The circuit to be investigated is assumed to have the following characteristic data (compare figs. (3-1) and (3-2)). $V^{\prime}=150 \mathrm{~V}, V^{\prime \prime}=100 \mathrm{~V}$, $R_{a}=20 \mathrm{k} \Omega, R=R_{g}=200 \mathrm{k} \Omega, C=100 p F, C_{c}=40 p F, t_{o}=0.2 \mu \mathrm{sec}$. The grid-to-cathode capacitance of each tube is assumed to be $C_{g}=10 p F$. This gives $C_{i}=C_{c}+C_{g}=50 \mathrm{pF}$ (see expr. (6-8)). The anode-to-cathode capacitance $C_{a}$ will be chosen as a parameter, taking values of $5 p F$, $50 p F$ and $150 p F$.

If the amplification factor of the tubes is $\mu=50$, and the internal anode resistance $r_{a}=7 k \Omega$, then the critical trigger-voltage amplitude $V_{c r}$ depends, according to the calculations, on the value of the anode-to-grid capacitance $C_{a g}$ in the way indicated in table I.

\section{Table I}

\begin{tabular}{|c|c|c|c|c|c|c|}
\hline $\begin{array}{c}C_{a g} \\
(p F)\end{array}$ & $A_{2}$ & $A_{1}$ & $A_{0}$ & $x$ & $\begin{array}{l}V_{c r} \\
(V)\end{array}$ & \\
\hline 2.5 & 60.63 & -34.84 & 1.92 & 0.970 & 9.2 & \multirow{3}{*}{$\begin{array}{l}C_{a}=5 p F \\
\gamma=21.2\end{array}$} \\
\hline 4.5 & 57.68 & -34.90 & 5.32 & 0.967 & 13.4 & \\
\hline 6.8 & 54.19 & -35.01 & 8.78 & 0.964 & 18.0 & \\
\hline 2.5 & 62.80 & -35.66 & 0.79 & 0.935 & 13.0 & \multirow{3}{*}{$\begin{array}{l}C_{a}=50 p F \\
\gamma=9.7\end{array}$} \\
\hline 4.5 & 60.75 & -35.70 & 2.90 & 0.931 & 17.2 & \\
\hline 6.8 & 58.36 & -35.72 & 5.31 & 0.927 & 21.6 & \\
\hline 2.5 & 62.82 & -35.23 & 0 & 0.852 & 20.8 & \multirow{3}{*}{$\begin{array}{l}C_{a}=150 p F \\
\gamma=4.75\end{array}$} \\
\hline 4.5 & 60.96 & -35.25 & 2.12 & 0.850 & 26.0 & \\
\hline 6.8 & 59.46 & -35.28 & 3.69 & 0.848 & 29.5 & \\
\hline
\end{tabular}


These results are graphically represented in figs $8-1$ and $8-2$. It can be seen from these figures that the critical trigger-voltage amplitude is an approximately linear function of the capacitive load in the anode circuits, with a mean slope $\frac{d V_{c r}}{d C_{a}}=0.082 \frac{V}{p F}$, and that it is also an approximately

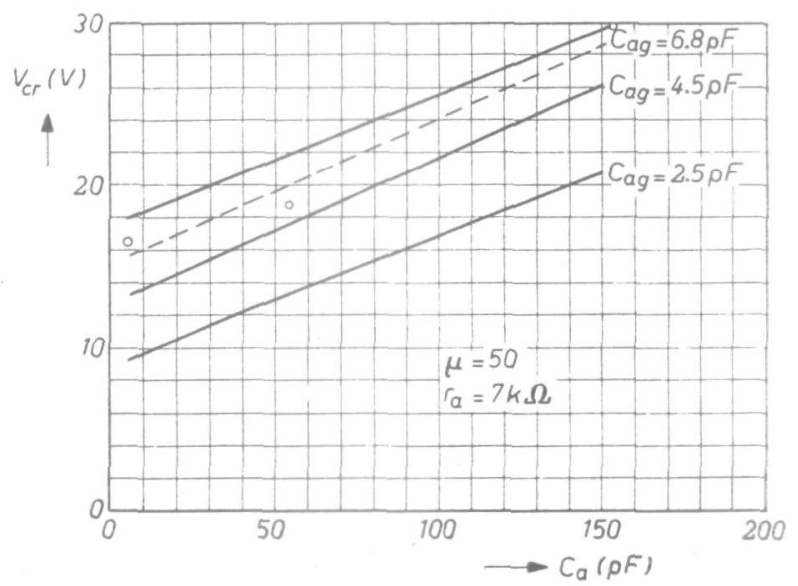

Fig. 8-1

linear function of the anode-to-grid capacitance of the tubes, having a mean slope $\frac{d V_{c r}}{d C_{a g}}=2 \frac{V}{p F}$.

The influence of the amplification factor $\mu$ is calculated, assuming that $C_{a}=50 p F, C_{a g}=4.5 p F$ and $r_{a}=7 \mathrm{k} \Omega$.

The result is presented in table II and graphically in fig. 8-3 (curve I).

\section{Table II}

\begin{tabular}{|c|c|c|c|c|c|l|}
\hline$\mu$ & $A_{2}$ & $A_{1}$ & $A_{0}$ & $x$ & $\begin{array}{c}V_{\text {cr }} \\
(V)\end{array}$ & \\
\hline 25 & 58.79 & -35.69 & 2.90 & 0.933 & 20.6 & \\
35 & 59.51 & -35.69 & 2.90 & 0.933 & 18.8 & $\gamma=9.7$ \\
50 & 60.75 & -35.70 & 2.90 & 0.931 & 17.2 & $\gamma$ \\
\hline
\end{tabular}

The influence of the internal anode resistance $r_{a}$ at values $C_{a}=50 p F$, $C_{a g}=4.5 p F, \mu=50$ is also calculated, and the result is given in table III and fig. 8-4 (curve I). 
The critical trigger-voltage amplitude decreases with increasing amplification factor and constant internal anode resistance and increases with increasing internal anode resistance and constant amplification factor.

Table III

\begin{tabular}{|c|c|c|c|c|c|c|}
\hline $\begin{array}{c}r_{a} \\
k \Omega\end{array}$ & \multicolumn{1}{|c|}{$A_{2}$} & \multicolumn{1}{|c|}{$A_{1}$} & $A_{0}$ & $x$ & $\begin{array}{c}V_{c r} \\
(V)\end{array}$ & \\
\hline 5.4 & 64.9 & -36.91 & 0 & 0.936 & 16.3 & \\
7.0 & 60.75 & -35.70 & 2.90 & 0.931 & 17.2 & $\gamma=9.7$ \\
9.0 & 56.62 & -34.22 & 6.21 & 0.923 & 18.6 & $\gamma=9.7$ \\
\hline
\end{tabular}

As the amplification factor $\mu$ and the internal anode resistance $r_{a}$ are related to the transconductance $g_{m}$ by the following expression

$$
\frac{\mu}{r_{a}}=g_{m}
$$

it must be expected that, for constant transconductance, their influence on the critical trigger-voltage amplitude will be small, at least in the cal-

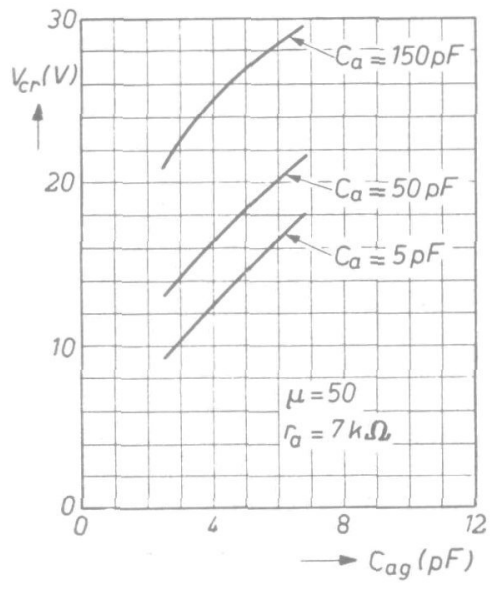

Fig. 8-2

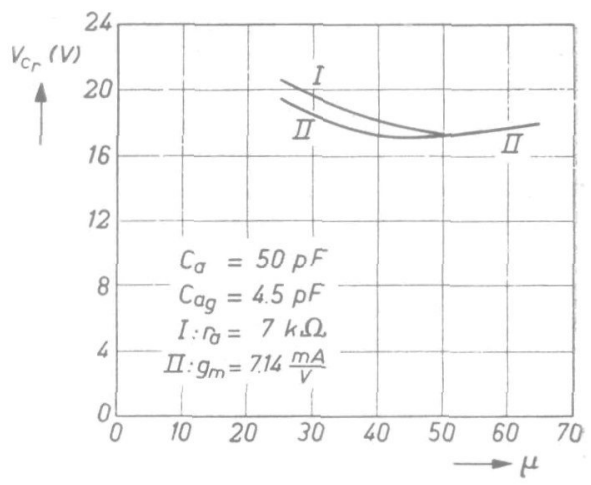

Fig. 8-3

culated region. This has been investigated by varying $\mu$ and $r_{a}$ in such a way that their ratio remains constant, starting from the values $\mu=50$ and $r_{a}=7 \mathrm{k} \Omega$, corresponding to $g_{m}=7.14 \frac{m A}{V}$. For these values the critical trigger voltage $V_{c r}$ has already been calculated and amounts to 17.2 
volts. The results of these additional calculations are represented in table IV and in the graphs of figs. 8-3 and 8-4 (curves II).

Table IV

\begin{tabular}{|l|c|c|c|c|c|c|l|}
\hline \multicolumn{1}{|c|}{$\mu$} & $\begin{array}{c}r_{a} \\
(k \Omega)\end{array}$ & $A_{2}$ & $A_{1}$ & $A_{0}$ & $x$ & $\begin{array}{c}V_{c r} \\
(V)\end{array}$ & \\
\hline 64.3 & 9.0 & 56.92 & -34.44 & 5.92 & 0.922 & 17.8 & $C_{a g}=4.5 p F$ \\
50 & 7.0 & 60.75 & -35.70 & 2.90 & 0.931 & 17.2 & $C_{a}=50 p F$ \\
40 & 5.6 & 63.64 & -37.11 & -0.504 & 0.938 & 17.1 & $\gamma=9.7$ \\
32 & 4.5 & 66.18 & -37.57 & 1.72 & 0.942 & 18.2 & $g_{m}=7.14$ \\
25 & 3.5 & 68.20 & -38.57 & 3.60 & 0.938 & 19.5 & \\
\hline
\end{tabular}

As can be seen, there is a certain minimum value of $V_{c r}$, in other words for a given value of the transconductance there are optimum values of $r_{a}$ and $\mu$.

It must be borne in mind that all conclusions drawn from the foregoing calculations are not of a general character, but apply to the specific data treated.

The results of calculations can be compared with experimental investigations.

The trigger sensitivity of a double triode type E92CC has been measured under similar conditions as were assumed to exist in the foregoing calculations. The amplification factor of this tube is $\mu=50$, its internal anode resistance being $7 \mathrm{k} \Omega$. This internal resistance is

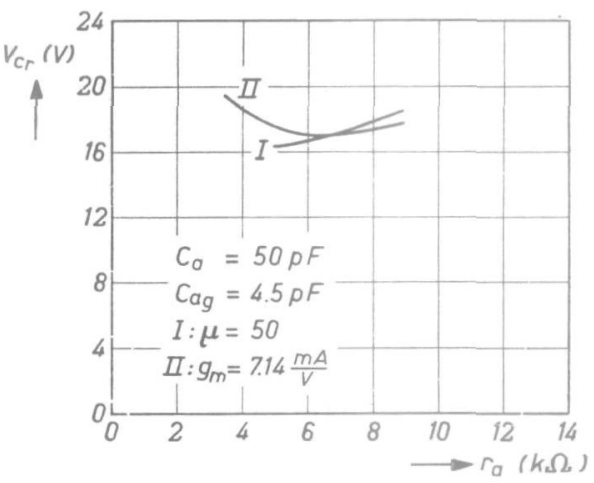

Fig. $8-4$ taken as the reciprocal value of the slope of the $I_{a}-V_{a}$ characteristic at $V_{g}=0$. The capacitances in the anode circuit have been put equal to $5 p F$, which is based on experimental experience. The trigger sensitivity is measured to be $16.5 \mathrm{~V}$, when no extra capacitive load is applied to the anodes, whereas it is $18.7 \mathrm{~V}$ with $47 \mathrm{pF}$ applied between the anode and cathode of each tube, and $29.6 \mathrm{~V}$ with $150 p F$ anode load applied. These measuring data are represented by the small circles in fig. 8-1. A mean straight line, drawn through these measuring points is represented by the 
dotted line in fig. $8-1$. The conclusion to be drawn from these measuring data is that an effective anode-to-grid capacitance of about $6 p F$ should be assumed to exist. The $C_{a g}$ of an E92CC is $2.5 p F$. The wiring capacitance of the circuit between anode and grid was measured and found to be $4.6 p F$. Thus, the total capacitance between anode and grid of the tubes was 7.1 pF. The conclusion is that these experimental data are in quite good agreement with those derived from the calculations.

One more check on the theory was carried out.

Assuming $C_{a g}$ to be $6 p F$, the trigger sensitivity with asymmetrical capacitive anode load was calculated. If one anode is loaded with $47 p F$ and the other tube has no externally applied capacitive load, then $\mathrm{C}_{a I}=52 p F$ and $\mathrm{C}_{a I I}=5 p F$. With these capacitance values the trigger sensitivity is calculated to be $23 \mathrm{~V}$, whereas it is actually measured to be $21 \mathrm{~V}$, which is also quite a good agreement.

In chapter 10 some considerations on the influence of the coupling capacitors $C$ and $C_{c}$ have been included. 


\section{THE TRIGGERING SPEED}

In the calculations of the transient behaviour of the bistable multivibrator the assumption was made that before the instant of application of an input trigger voltage the circuit was in its static condition, i.e. all the previous triggering effects had died out by this instant. Theoretically it would last an infinitely long time before all transients of the dynamic condition have completely died away. In practice, however, a subsequent triggering will occur at a definite time after the first trigger pulse has been applied. An important question is, what will be the lower limit in the time interval between two trigger pulses at which the multivibrator is still operating satisfactorily. It is difficult to define this limit explicitly, at any rate not as plainly as could be done with respect to the trigger sensitivity.

What are the operations to be performed by the multivibrator circuit? When triggering at both grids simultaneously the aim is, as has been formulated previously, to get one output pulse at every two input pulses, i.e. essentially a frequency division. As soon as this ratio $2: 1$ is lost because of too high a repetition frequency of the input pulses, one can say that the maximum triggering speed is attained. In another way of operation, negative trigger pulses are fed to the grid of the tube that is momentarily conducting or alternatively positive pulses to the grid of the non-conducting tube. In this application the aim is to change the potential of the anodes or grids as rapidly as is necessary in the given circumstances. A certain minimum change of potential level will be wanted, and as soon as the next trigger pulse occurs so rapidly after the previous pulse that this change is not obtained, the maximum trigger speed is reached. It is not possible from the foregoing analysis to derive the speed limits mentioned for the two cases, as this analysis assumes that the system is at rest before it is triggered, and this would by no means be satisfied at the speed limit. A new way of approach would have to be introduced, a quasi-stationary condition being assumed to exist. Nevertheless, the results of calculations presented in the foregoing chapters may give an idea of the triggering speed to be attained by a given circuit, and of means to improve it.

There is one absolute upper limit of triggering speed to be defined, viz. the time $t_{I I}$, during the first phase of the dynamic condition, when both tubes are cut off. Within this time no new input pulse will be able to produce further triggering. The time $t_{I I}$ depends on the time constants of the circuit, given by the negative reciprocal values of $p_{1}$ and $p_{2}$ (expressions $(\mathrm{I}-25)$ and $(\mathrm{I}-26)$. From section 8 it can be seen that $t_{I I}$ also 
depends on the amplitude of the trigger pulse. At the critical amplitude $V_{c r}$ it can be calculated from the value of $x$ as given in tables I, II, III, IV. According to expression (8-12):

$$
x=e^{p_{1} t_{I I}}
$$

or

$$
t_{I I}=\frac{\ln x}{p_{1}}
$$

To give an idea of the value of $t_{1 I}$ at the critical trigger voltage amplitude for the circuit, for which table I is calculated, expression (9-2) will be evaluated with the aid of the values of $x$ from table I and of $p_{1}$ from the following table $\mathrm{V}$

Table $V$

\begin{tabular}{|r|l|}
\hline$C a(p F)$ & $p_{1}\left(\mu \mathrm{sec}^{-1}\right)$ \\
\hline 5 & -0.0661 \\
50 & -0.0663 \\
150 & -0.0665 \\
\hline
\end{tabular}

The results are given in table VI

Table VI

\begin{tabular}{|r|c|l|}
\hline$C a(p F)$ & $t_{I I}(\mu \mathrm{sec})$ & \\
\hline 5 & 0.45 & \\
50 & 1.01 & $C_{a g}=2.5 p F$ \\
150 & 2.42 & \\
5 & 0.56 & \\
50 & 1.14 & $C_{a g}=6.8 p F$ \\
150 & 2.49 & \\
\hline
\end{tabular}

The influence of the anode-to-grid capacitance is not very great but that of the anode capacitance is.

As can be concluded from the values of $x$ in tables II, III and IV, het influence of $\mu$ and $v_{a}$ is not marked ( $p_{1}$ does not depend on $\mu$ and $r_{a}$ ).

Next it can be stated that the sooner the circuit approaches its finalstatic state, after having been triggered, the smaller the time interval between 
two subsequent trigger-pulses may be. This implies that the time constants of the circuit should be small. These time constants are:

$$
\begin{gathered}
T_{1}=-\frac{1}{p_{1}}, T_{2}=-\frac{1}{p_{2}}, T_{1}^{\prime}=-\frac{1}{p_{1}{ }^{\prime}}, T_{2}{ }^{\prime}=-\frac{1}{p_{2}{ }^{\prime}}, T_{3}=-\frac{1}{p_{3}}, \\
T_{4}=-\frac{1}{p_{4}} \text { and } T_{n}=-\frac{1}{p_{n}} .
\end{gathered}
$$

(see chapter 6).

It can be shown that a decrease in any resistance or capacitance of a circuit composed of resistances and capacitances only results in a decrease in all the time constants. This will be derived for the multivibrator circuit considering first the circuit arrangement during the first phase of the dynamic condition. It then holds that the driving-point impedances of the circuit are of the following general form, apart from a constant multiplication factor:

$$
Z(p)=\frac{p+b_{1}}{p^{2}+a_{1} p+a_{2}}
$$

as can be seen from expressions (I-7), and (I-19). The zeros and poles of this impedance function are defined by the roots of equations

$$
p+b_{1}=0
$$

and

$$
p^{2}+a_{1} p+a_{2}=0
$$

respectively.

There will be one zero, viz, at $p=-b_{1}$ and two poles, viz. at $p=p_{1}$ and $p=p_{2}$ (see expressions (I-25) and (I-26)). These values of $p$ determine the normal modes of the circuit.

From general network theory it is known that for a network, consisting of R's and C's only, the quantities $a_{1}, a_{2}$ end $b_{1}$ are positive, real; further that the normal modes are always negative, real; finally that

$$
p_{2}<-b_{1}<p_{1}<0
$$

(Reference is made to p. 211 of vol. II of ,Communication Networks”, by E. A. Guillemin, Wiley \& Sons, 1935).

With this knowledge it is possible to sketch the impedance function $Z(p)$ as it depends on $p$. In fig. $9-1$ the curves I, II and III represent the general form of $Z(p)$ as a function of $p$ given by expression (9-3).

It will now be assumed that a resistance $R$ is shunted across the impedan- 
ce $Z(p)$. In that case the normal modes are to be determined from the condition

$$
Z(p)=-R
$$

In fig. 9-1 these normal modes are determined by the intersection points of curves II, III and the dotted curve VI. It can be seen that the values of $p$ corresponding to these points of intersection will always be more negative than $p_{1}$ and $p_{2}$ respectively.

Thus, inserting a resistance across one of the resistances of the circuit, or decreasing one of the circuit resistances, which amounts to the same-

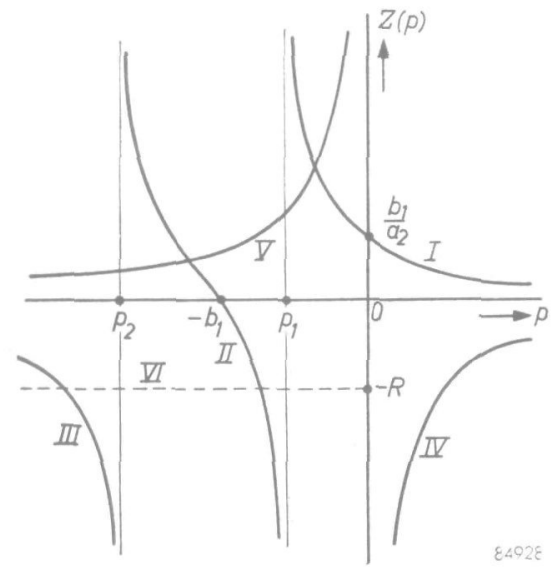

Fig. 9-1 thing, will always result in a decrease of the characteristic time constants of the circuit. From this general statement it can be concluded that the time constants during the second phase of the dynamic condition, $T_{\mathbf{3}}$ and $T_{4}$, are always smaller than the corresponding values, $T_{1}{ }^{\prime}$ and $T_{2}{ }^{\prime}$ respectively, from the first phase. For during the second phase one of the anode resistances of the multivibrator circuit is shunted by the internal anode resistance of the conducting tube. In the third phase one of the grid resistances is shunted by the internal grid resistance of the conducting tube, which will result in a still smaller time constant in this phase. The influence of a change in one of the capacitances of the circuit on the characteristic time constants can be derived in a similar way to the method used for a change in resistances. Assuming a capacitance $C$ to be shunted across $Z(p)$, the new characteristic frequencies have to be determined from the condition

$$
-\frac{1}{C p}=Z(p)
$$

The function $-\frac{1}{C p}$ is represented in fig. $9-1$ by the curves IV and V, and the roots of equation (9-8) are given by the points of intersection of curve $\mathrm{V}$ and curves I and II. To these points correspond values of $p$ that are always less negative than $p_{1}$ and $p_{2}$, respectively. In other words, 
the new time constants will be larger than $T_{1}$ and $T_{2}$ as a result of the increase of one of the capacitances of the circuit.

When aiming at a high triggering speed it is thus advantageous to reduce the value of all resistances and capacitances as much as possible. There are limits, of course, to this reduction. The resistances, for instance, greatly determine the values of the voltages and currents of the circuit in the static condition. Considerations of supply power available and tolerable, and the anode voltage change wanted when triggering the multivibrator, will fix the minimum values of resistances to be applied. Tubes with a low internal anode resistance (low $\mu$ high $g_{m}$ ) will be advantageous for obtaining small time constants during the second phase of the complete cycle. How far can the capacitances be reduced? The anode-to-cathode capacitances $C_{a}$ are determined by the tube capacitances and the wiring capacitances. Both have to be reduced to the utmost. The same holds for the input capacitances between grid and cathode of the tubes and the wiring capacitances, which together form $C_{g}$. However, the sum $C_{i}=C_{g}+C_{c}$ determines the grid circuit constant $T_{g}$, where $C_{c}$ is the coupling capacitance between the trigger-voltage source and the grids. Therefore, $C_{c}$ should be reduced as much as possible. Here of course, there is also a limit. Too small a value of $C_{c}$ reduces the current pulse $I_{i}$ $=-\alpha C_{c}$ (see expression (6-7)) to such an extent that the tube will no longer be safely triggered at a given input voltage amplitude $V_{o}$.

Finally, the coupling capacitors $C$ between the anodes and grids of the tubes must be reduced. A limit is presented here by the fact that the steep voltage rise at the anode of the tube that is suddenly cut off must be passed by this capacitance $\mathrm{C}$ to such a degree that the grid voltage of the non-conducting tube increases rapidly enough to reach its cut-off point earlier than the other tube. In other words, too small a value of $\mathrm{C}$ will prevent the proper triggering of the circuit.

Some practical experience will be dealt with in chapter 10, together with some details about the influence of $C_{c}$ and $C$ both on the trigger sensitivity and the triggering speed. 


\section{DESIGN CONSIDERATIONS}

When designing a bistable multivibrator several aspects will have to be kept in mind. The bistable circuit should if possible have a high triggering speed, a high trigger sensitivity, a low power consumption, a good stability and a low sensitivity to interferences. All these demands, however, cannot be satisfied at the same time, as an improvement of one or more of the properties mentioned mostly results in a deterioration of others. This has been mentioned already at the end of Chapter 1 .

Therefore, general rules for designing a bistable multivibrator are difficult to formulate. Each case will have to be considered separately. For example, if a scaler or any other device containing only a few multivibrator circuits has to be built, then the power consumption will not be restricted to such an extent as it would be when a large number of those circuits have to be incorporated in a high-capacity electronic computer, say. One of the reasons to aim at as low a power consumption as possible in that case would be that the heat dissipation has to be kept within certain bounds.

The choice of component values will generally be greater than the choice of available tube types. Therefore, the first thing to do will be to choose a type of tube that is the best to fulfil the demands in the special case considered. A low internal anode resistance and low capacitances will be advantageous for attaining a high speed; a high amplification factor and particularly a low anode-to-grid capacitance may increase the trigger sensitivity. Furthermore maximum allowed values of anode and grid currents of the tube are published by the manufacturer and it is advisable to choose values within as small a safety margin below these maxima as is possible. A large anode current allows for a small anode load resistance, which is advantageous with respect to the speed to be attained. A large grid current has a large stabilizing effect (see Chapters 3 and 5).

Once the value of the anode current $I_{a o}$ of the conducting tube is chosen, the value of its anode voltage is defined from the $I_{a}-V_{a}$ characteristic at zero grid voltage $\left(V_{a I o}=r_{a} I_{a o}\right)$.

Mostly, the required anode-voltage change, when triggering the multivibrator will be known. It may, for example, be defined by the further use to be made of this voltage change, or occasionally by the kind of indication of the position of the multivibrator. Mostly gas discharge tubes are used for this purpose and then a certain minimum voltage change is wanted to ignite these tubes. If the anode-voltage change is 
fixed the anode voltage of the non-conducting tube $V_{a I I o}$ is known from $V_{a I o}$ and the anode-voltage change.

Next, the voltage at the grid of the non-conducting tube, $V_{g I I o}$, can be fixed to a value safely below the cut-off point to prevent the influence of interfering signals.

According to the foregoing remarks it can be considered a rather general case to take as known quantities $I_{a o}, I_{g o}, V_{a I o}, \Delta V_{a}\left(=V_{a I I_{o}}-V_{a I o}\right)$, $V_{g I I o}$.

From the expressions derived for the static condition in chapter 5 four independent equations can be extracted, which are conveniently chosen as follows:

$$
\begin{aligned}
& V_{g I I o}=\varepsilon_{g} V^{\prime}-\left(1-\varepsilon_{g}\right) V^{\prime \prime}-\varepsilon_{g} R_{a} I_{a o} \\
& V_{a I I o}-V_{a I_{o}}=\left(1-\varepsilon_{a}\right) R_{a} I_{a o}-\varepsilon_{a} R_{g} I_{g o} \\
& \left(1-\varepsilon_{a}\right) R_{a} I_{a o}=\left(1-\varepsilon_{a}\right) V^{\prime}-\varepsilon_{a} V^{\prime \prime}-V_{a I o} \\
& \left(1-\varepsilon_{g}\right) R_{g} I_{g o}=\varepsilon_{g} V^{\prime}-\left(1-\varepsilon_{g}\right) V^{\prime \prime}
\end{aligned}
$$

The unknown quantities in these equations are $\varepsilon_{a}, \varepsilon_{g}, V^{\prime}, V^{\prime \prime}, R_{a}$ and $R_{g}$. However, a relation exists between some of them:

$$
\begin{aligned}
& R_{a}=\varepsilon_{a}\left(R_{g}+R+R_{a}\right) \\
& R_{g}=\varepsilon_{g}\left(R_{g}+R+R_{a}\right)
\end{aligned}
$$

or: $\quad \varepsilon_{g} R_{a}=\varepsilon_{a} R_{g}$

This reduces the number of unknown quantities to five. Thus, still one of them shall have to be chosen before the other can be determined.

One of them may conveniently be the value of the positive HT supply voltage $V^{\prime}$, as this must be at any rate higher than the anode voltage of the non-conducting tube $V_{a I I_{0}}$, say by an amount of some ten volts. As mostly the output voltages of conventional $H T$ supply apparatus have more or less standardized values, one of these values that best fits the foregoing demand may be chosen.

It is possible to find from equations (5-7), (5-16), (5-9) and (5-14) explicit expressions for $\varepsilon_{a}, \varepsilon_{g}, R_{a}, R_{g}$ and $V^{\prime \prime}$ as functions of the known quantities. These expressions will be derived.

Elimination of $R_{a}, R_{g}$ and $I_{g o}$ from the four equations is possible in the following way. From equations (5-9) and (5-14) $R_{a} I_{a o}$ and $R_{g} I_{g o}$ can be expressed in terms of $\varepsilon_{g}$ and $\varepsilon_{n}$ and then substituted in equations 
$(5-7)$ and $(5-16)$. These equations are then reduced to the following simple forms:

$$
\begin{aligned}
& \varepsilon_{g}=\left(1-\varepsilon_{a}\right)\left(V_{g I I_{o}}+V^{\prime \prime}\right) /\left(V_{a I_{o}}+V^{\prime \prime}\right) \\
& \varepsilon_{a}=\left(1-\varepsilon_{g}\right)\left(V^{\prime}-V_{a I I_{o}}\right) / V^{\prime}
\end{aligned}
$$

From these equations it easily follows that:

$$
\begin{aligned}
\varepsilon_{g}= & V_{a I I_{o}}\left(V_{g I I_{o}}+V^{\prime \prime}\right) /\left\{V^{\prime}\left(V_{a I o}-V_{g I I_{o}}\right)+V_{a I I_{o}}\left(V_{g I I_{o}}+V^{\prime \prime}\right)\right\}(10-6) \\
\varepsilon_{a}= & \left(V^{\prime}-V_{a I I_{o}}\right)\left(V_{a I_{o}}-V_{g I I_{o}}\right) /\left\{V^{\prime}\left(V_{a I_{o}}-V_{g I I_{o}}\right)+\right. \\
& \left.\quad+V_{a I I_{o}}\left(V_{g I I_{o}}+V^{\prime \prime}\right)\right\}
\end{aligned}
$$

As both $\varepsilon_{g}$ and $\varepsilon_{a}$ are ratios of resistances, their values must be positive. This condition leads to another condition with respect to the value of $V^{\prime \prime}$. The denominator of both expressions is positive, which can be seen by re-arranging it in the following form: $V^{\prime} V_{a I_{o}}+V^{\prime \prime} V_{a I I_{o}}-V_{g I I o}\left(V^{\prime}-\right.$ $\left.V_{a I I o}\right)$.

The first two terms are positive; the last one also, because $-V_{g I I_{o}}$ is positive as well as $V^{\prime}-V_{a I I o}$. The denominator being always positive, it can directly be seen that $\varepsilon_{a}$ is positive, as its numerator is also positive. For $\varepsilon_{g}$ to be positive it is necessary that $V_{g I I o}+V^{\prime \prime}>0$ or $V^{\prime \prime}>-V_{g I I o^{*}}$ The third ratio of resistances, viz. $\varepsilon$ must also be positive. This gives the condition $1-\varepsilon_{a}-\varepsilon_{g}>0$. Substitution of $(10-6)$ and $(10-7)$ leads to $V_{a I I o}\left(V_{a I o}-V_{g I I_{o}}\right)>0$, which condition is indeed always fulfilled. From the fact that $\varepsilon_{g}, \varepsilon_{a}$ and $\varepsilon$ are all positive it can be concluded that all resistances must have the same sign.

Next $R_{a}$ can be solved from equation (5-7):

$R_{a}=\left\{V^{\prime}\left(V_{a I I_{o}}-V_{a I_{o}}\right)-V_{g I I_{o}}\left(V_{a I I_{o}}-V^{\prime}\right)\right\} / I_{a o} V_{a I I_{o}}$

From equation $(10-3)$ :

$$
\begin{aligned}
R_{g}= & R_{a} \varepsilon_{g} / \varepsilon_{a}=\left(V_{g I I_{o}}+V^{\prime \prime}\right)\left\{V^{\prime}\left(V_{a I I_{o}}-V_{a I_{o}}\right)-V_{g I I_{o}}\left(V_{a I I_{o}}-V^{\prime}\right)\right\} \mid \\
& \mid I_{a o}\left(V^{\prime}-V_{a I I_{o}}\right)\left(V_{a I o}-V_{g I I_{o}}\right)
\end{aligned}
$$

As in practice $V^{\prime}>-V_{g I I_{o}}$ and $V_{a I I_{o}}-V_{a I_{o}}>V^{\prime}-V_{a I I_{o}}$, the expressions for $R_{a}$ and $R_{g}$ are positive. The value of $R$ can be determined from expr. (10-1) or (10-2), and will be positive, because $R_{a}$ and $R_{g}$ are. Finally $I_{g o}$ is to be found from equation (5-14): 


$$
\begin{gathered}
I_{g o}=\left(V^{\prime}-V_{a I I o}\right)\left\{V_{a I I_{o}} V_{g I I_{o}}+V^{\prime \prime}\left(V_{a I I_{o}}-V_{a I o}+V_{g I I_{o}}\right)\right\} I_{a o} / \\
/\left(V_{g I I o}+V^{\prime \prime}\right)\left\{V_{a I I_{o}}\left(V^{\prime}-V_{g I I o}\right)-V^{\prime}\left(V_{a I_{o}}-V_{g I I_{o}}\right)\right\} .
\end{gathered}
$$

From this equation $V^{\prime \prime}$ can be expressed in known quantities:

$$
\begin{aligned}
& V^{\prime \prime}=\left[V_{g I I o} V_{a I I_{o}}\left(V^{\prime}-V_{a I I_{o}}\right) I_{a o}-V_{g I I o}\left\{V^{\prime}\left(V_{a I I_{o}}-V_{a I o}\right)-\right.\right. \\
& \left.\left.V_{g I I o}\left(V_{a I I o}-V^{\prime}\right)\right\} I_{g o}\right] /\left(-\left(V^{\prime}-V_{a I I o}\right)\left(V_{a I I o}-V_{a I o}+V_{g I I o}\right) I_{a o}+\right. \\
& \left.\quad+\left\{V^{\prime}\left(V_{a I I o}-V_{a I o}\right)-V_{g I I o}\left(V_{a I I o}-V^{\prime}\right)\right\} I_{g o}\right]
\end{aligned}
$$

In practice, when designing a multivibrator circuit, one will first have to calculate the value of $V^{\prime \prime}$ from expression $(10-10)$. Then check whether $V^{\prime \prime}$ is larger than $-V_{g I I_{o}}$, which is necessary for a positive value of $\varepsilon_{g}$, as shown before. Once $V^{\prime \prime}$ is determined the other unknown quantities can be calculated.

A numerical example will be given. Starting from the following given quantities: $V^{\prime}=200 \mathrm{~V}, V_{a I o}=50 \mathrm{~V}, V_{a I I o}=150 \mathrm{~V}, V_{g I I o}=-20 \mathrm{~V}$, $I_{a o}=5 \mathrm{~mA}, I_{g_{0}}=0,8 \mathrm{~mA}$ the calculations give the following results:

$V^{\prime \prime}=93 \mathrm{~V}, R_{a}=25 \mathrm{k} \Omega, R=73.5 \mathrm{k} \Omega, R_{g}=80 \mathrm{k} \Omega$.

By the foregoing procedure the static condition is determined. For this condition the capacitances do not come into play. For the dynamic condition, however, the values of the coupling capacitances between anodes and grids and between trigger-pulse source and grids are of importance. Both trigger sensitivity and speed are influenced by them. At first thought it seems to be rather difficult to find a method for straight-forward determination of optimum values of the coupling capacitors mentioned, and termed $C$ and $C_{c}$ respectively in foregoing chapters. However, the following reasoning may show that it is possible to derive a certain relation between $C$ and $C_{c}$ that must be fulfilled for obtaining optimum speed and sensitivity. This relation is the following:

or

$$
\begin{aligned}
R C & =R_{g} C_{i} \\
T & =T_{g}
\end{aligned}
$$

(see expressions $(\mathrm{I}-1)$ and $(\mathrm{I}-2)$ ) where $C i=C_{c}+C_{g}, C_{g}$ being the total capacitance between grid and cathode. Or in words, the time constant of the coupling circuit between anodes and grids must equal the time constant in the grid circuit. If this relation exists, then the quantities $X$ derived in appendix II will be equal to the quantities $Y$ derived in appendix III, because $D^{\prime}=T$ according to expression (I-20). In that 
case the transient voltage $V_{g I} *$ at the grid of tube I (expr. (III-8)) will be a true copy of the transient anode voltage of tube II (expr. (II-21)), only decreased by a factor $R_{g} /\left(R+R_{g}\right)$, the transients at $A_{I I}$ and $G_{I}$ from the first phase being of minor importance, because tube II is not yet conducting.

If $T>T_{g}$ then the shape of $V_{g I}$ will be such that it falls rapidly to a high negative value and then gradually rises to its final value ("overshoot"; see for example the oscillograms of figs. 7.5 and 7.7 , where $T$ was twice the value of $T_{g}$ ). If the next trigger pulse appears at an instant when the grid voltage $V_{g I}$ has not risen sufficiently, then it may occur that the corresponding tube $\mathrm{I}$ is not brought into the conducting state before tube II has reached this state and then the triggering fails.

In the opposite case, $T<T g$, (to be called "undershoot") the grid voltage $V_{g I}$ falls to a rather small negative value and then continues to fall with a much smaller slope to its final value. This may seem advantageous for high speed triggering, but now the positive-going voltage at grid $G_{I I}$ may not reach the cut-off point rapidly enough to achieve proper triggering.

Therefore it is to be expected that the case $T=T_{g}$ is the most favourable condition for attaining a high triggering speed at a reasonable sensitivity. With these considerations in mind it can be recommended to proceed in the following way for determining the values of the coupling capacitances. Choose a value of $C_{c}$, next a value of $C$ in accordance with condition (10-11) and then calculate the trigger sensitivity as indicated in chapter 8 . Should the required minimum trigger pulse amplitude be too high with respect to the available amplitude then $C_{c}$ and $C$ have to be chosen larger, their ratio remaining unchanged, until the sensitivity is in accordance with the available trigger pulse amplitude. Then one is sure to have the maximum speed obtainable with that sensitivity.

The above statements about the influence of the coupling capacitors on speed and sensitivity have been confirmed by measurements on the same circuit that has been mentioned and defined at the beginning of section $8-1$. The values of $C$ and $C_{c}$ in this circuit have been varied. For a large number of combinations of these values the trigger sensitivity and the maximum speed have been determined. The results are represented in table VII. The sensitivity is measured at an input pulse repetition frequency of $10 \mathrm{kc} / \mathrm{s}$, well below the lowest maximum speed that ever occurred. It is expressed by the minimum trigger pulse amplitude $V_{c r}$ at that frequency. The speed is expressed in $\mathrm{kc} / \mathrm{s}$, being the maximum frequency $f_{m}$ at which the multivibrator still operated correctly as a 
binary frequency divider when triggered at both grids simultaneously by pulses of an amplitude of $30 \mathrm{~V}$. The maximum pulse frequency available was $200 \mathrm{kc} / \mathrm{s}$; the maximum pulse amplitude $37 \mathrm{~V}$.

\section{Table VII}

\begin{tabular}{|c|c|c|c|c|c|c|c|c|c|}
\hline $\begin{array}{l}C_{c} \\
(\mathrm{pF})\end{array}$ & $\begin{array}{c}C \quad 30 \\
(\mathrm{pF})\end{array}$ & 40 & ธ0 & & 60 & & 100 & 120 & 150 \\
\hline $\begin{array}{r}20 \\
30 \\
40 \\
50 \\
60 \\
70 \\
80 \\
90 \\
100 \\
120 \\
150\end{array}$ & $\begin{array}{lr}V_{c r} & f_{m} \\
33.5 & - \\
29.5 & >200 \\
29.5 & >200 \\
>37 \quad-\end{array}$ & $\begin{array}{lr}V_{c r} & f_{m} \\
32.5 & - \\
27.5 & >200 \\
24.5 & >200 \\
25.5 & >200 \\
>37 \quad-\end{array}$ & $\begin{array}{cr}V_{c r} & f_{m} \\
30.0 & - \\
24.5 & 140 \\
21.3 & >200 \\
20.5 & >200 \\
20.5 & >200 \\
22.0 & >200 \\
>37 & \end{array}$ & $\begin{array}{l}V_{c r} \\
28.0 \\
23.0 \\
20.0 \\
19.0 \\
18.5 \\
18.5 \\
18.5 \\
20.0 \\
31.0\end{array}$ & $\begin{array}{r}f_{m} \\
52 \\
110 \\
195 \\
>200 \\
>200 \\
>200 \\
>200\end{array}$ & $\begin{array}{l}V_{c r} \\
25.5 \\
20.5 \\
17.7 \\
16.5 \\
15.5 \\
\\
\\
\\
\\
11.5 \\
11.5 \\
12.1\end{array}$ & $\begin{array}{r}f_{m} \\
40 \\
72 \\
112 \\
150 \\
175 \\
\\
\\
>200\end{array}$ & $V_{c r} f_{m}$ & $V_{c r} f_{m}$ \\
\hline
\end{tabular}

From table VII it can be seen that at a fixed value of $C$ the trigger sensitivity shows a maximum at that value of $C_{c}$ which equals $C$. Because the values of $R$ and $R_{g}$ are also the same $(200 \mathrm{k} \Omega)$, this means that the time constants $T$ and $T_{g}$ are equal if $C=C_{c}$.

At a fixed value of $C_{c}$ the sensitivity increases with increasing value of $C$, the speed on the other hand decreases.

At a fixed value of $C$ the speed increases with increasing $C_{c}$. At equal values of $C$ and $C_{c}\left(T=T_{g}\right)$ the trigger sensitivity increases with increasing capacitances, whereas the speed decreases. However, the speed will be higher than at $C_{c}<C$.

Note: The equations, governing the static condition allow for the determination of the influence of component and tube tolerances on the stability of this condition. This is not dealt with here, because it has been the subject of several articles, mentioned in chapter 2. 


\section{VARIATIONS OF THE FUNDAMENTAL CIRCUIT AND WAY OF TRIGGERING}

\subsection{AUTOMATIC GRID BIAS}

Instead of incorporating the separate negative grid bias supply $-V^{\prime \prime}$ in the multivibrator circuit as shown in fig. 3-1, automatic negative grid bias may be applied by inserting a by-passed cathode resistor in the circuit (see fig. 11-1).

If the time constant of the cathode circuit is sufficiently large, the voltage

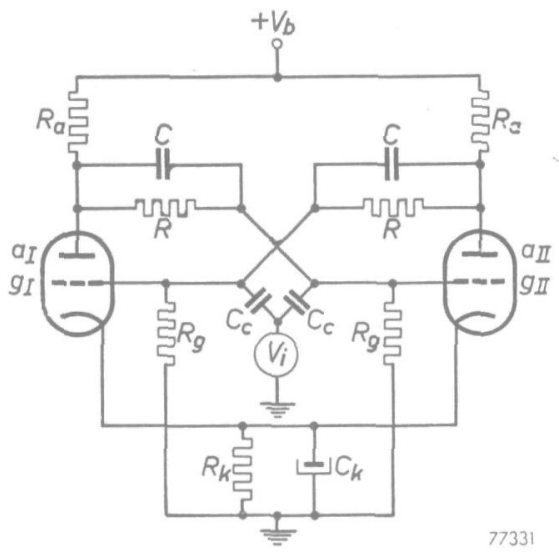

Fig. 11-1 drop thus produced may be considered as a constant voltage source, at least during the triggering action. This voltage drop depends, however, on the value of the anode current in the static condition. The foregoing considerations and formulae derived from them may be used in analysing the circuit of fig. 11-1 as long as it is kept in mind that

$$
V^{\prime \prime}=R_{k} I_{a o}
$$

and

$$
V^{\prime}=V_{b}-R_{k} I_{a o}
$$

In these expressions the influence of the grid current $I_{g o}$, that also flows through $R_{k}$, has been neglected with respect to the anode current $I_{a o}$. In the static condition the voltages at the grids and anodes must be taken with respect to the cathode. Their values with respect to earth will be larger by an amount $R_{k} I_{a 0}$.

For the transient voltages it does not matter whether they refer to cathode or to earth as it is assumed that the value of the by-pass capacitor is such that it represents a short-circuit for these transients.

\subsection{TRIGger PULSES APPLIED TO ONE GRID ONLY}

As already mentioned in the introduction, the triggering may be produced either by applying pulses to the grids of both tubes simultaneously, or by applying pulses to the grids of tube I and tube II alternately.

The first method is used for instance in frequency-division circuits: one multivibrator circuit will halve the input pulse frequency. The second method is used for instance in those circuits that are used to open or close 
gates. When negative pulses are only applied to the grid of the conducting tube, the circuit operation can be analysed in an analogous way to the methods of the foregoing chapters.

If, for instance, in the circuit of fig. 3-1 only a negative-going voltage is applied to the grid of tube $I$, that is assumed to be conducting, then it will be clear that in fig. 6-2 the current source $I_{i}$ must be omitted. Conse quently, during the first phase of the dynamic condition the voltage at grid $G_{I I}$ will be represented by the following expression instead of by expression (I-36):

$V_{g I I}(t)=V_{g I I o}+I_{a o} \varepsilon_{a} R_{g}\left\{1-\frac{1}{2}(1-P) e^{p_{1} t}-\frac{1}{2}(1+\mathrm{P}) e^{p_{2} t}\right\} U(t)$

and the voltage at $\mathrm{A}_{I}$ by

$V_{a I}(t)=V_{a I o}+I_{a o}\left(1-\varepsilon_{a}\right) R_{a}\left\{1-\frac{1}{2}(1-L) e^{p_{1} t}-\frac{1}{2}(1+L) e^{p_{2} t}\right\} U(t)$

instead of by expression (I-40).

The voltages at $G_{I}$ and $A_{I I}$ remain the same as those represented by expression (I-42) and (I-44), resp.

Referring to expressions (6-15) to (6-26) inclusive, the changes can also be indicated in the following way:

$V_{1}, V_{4}, V_{5}, V_{6}, V_{7}, V_{10}, V_{11}, V_{12}$ remain unchanged

$V_{2}=-\frac{1}{2} I_{a o} \varepsilon_{a} R_{g}(1-P)$

$V_{3}=-\frac{1}{2} I_{a o} \varepsilon_{a} R_{g}(1+P)$

$V_{8}=-\frac{1}{2} I_{a o}\left(1-\varepsilon_{a}\right) R_{a}(1-L)$

$V_{9}=-\frac{1}{2} I_{a o}\left(1-\varepsilon_{a}\right) R_{a}(1+L)$

When introducing these values in the formulae given in chapter 6 , the grid and anode voltages during the complete dynamic condition can be evaluated.

One of the results of this single-grid triggering will be that the trigger sensitivity is increased, since the positive-going voltage at grid II originating from the rising voltage at anode $\mathrm{I}$ is no longer counteracted by the negative input-voltage pulse at grid II, as in the case of double-grid triggering. Thus, the cut-off grid voltage of tube II will be attained sooner. 


\section{CONCLUSION}

It has been shown in the previous chapters that it is possible to analyse the operation of a bistable multivibrator. It has been attempted to approach as nearly as possible practical circumstances. However, some assumptions are unavoidable in order to keep the results practicable. It will be good to summarize here the restrictions under which the results obtained are valid.

The shape of the trigger voltages, applied to the grids is taken to be trapezoidal, only the influence of the negative going front flank being considered (see fig. 3-2). The choice of this special shape is thought to be a reasonable approximation to practical pulse shapes and offers the advantage that the input voltage source is readily converted into an input current source, giving a rectangular current pulse, for which the response of the network is relatively easy to calculate. It is, however, quite possible to calculate the response to another kind of voltage function, for instance an exponential time function but it would complicate the calculation without necessarily being a better approximation to practice. The influence of the positive going rear flank of the input voltage is not calculated, though it could as well be done. In chapter 7 it is argued that the influence of this rear flank is not very important and in general does not endanger the right trigger operation.

The amplitude $V_{o}$ of the trigger voltage and the slope $\alpha$ of the negative going front flank are taken to be so large, that the time it takes to cut off the conducting tube is negligibly small compared with the inherent time constants of the circuit, in other words this tube is assumed to be instantaneously cut off. Again this is thought to be a good approximation to general practice, but it is also possible to take into consideration a finite time for cutting off the conducting tube. This would of course considerably complicate the calculation.

The voltage between the grid and cathode of the conducting tube is taken to be zero, which is very nearly attained when this tube draws grid current. It means that at grid-to-cathode voltages of zero or positive values the internal grid resistance is very small. A better approximation to practice would be to take into account a finite internal resistance between grid and cathode, involving again more complicated calculations. Next, a few assumptions are introduced that make it possible to separate the multivibrator into two parts, which do not influence one another. The first assumption we make is that we can neglect the internal resistances of the supply voltage and trigger voltage sources. It is thought 
to be admissible in most practical cases, especially for the supply voltage sources when these are stabilized. For the trigger voltage source it will mostly be a necessary condition to have a low internal resistance as it is loaded with the low internal grid-to-cathode resistance of the conducting tube.

In the second place the influence of the capacitance between the anode and grid of each tube is not taken into account when calculating the waveforms of the voltage changes at the anodes and grids of the tubes. It is theoretically not impossible to include these capacitances in the circuit to be analysed, but impracticably complicated calculations would result. In the first phase of the dynamic condition, when both tubes are non-conducting, an approximative method to take into account these capacitances is used in the calculation of the trigger sensitivity.

All other tube, wiring and stray capacitances can be included in the analysis.

Under the foregoing assumptions and restrictions it is possible to analyse completely the static and transient conditions of a triggered bistable multivibrator. The waveforms of the voltage changes at the anodes and grids of the tubes can be determined when a trigger pulse applied to both grids simultaneously or to only one grid at a time causes the circuit to switch over from one static condition to the other. The dynamic condition can be divided in three successive phases with transients occurring at the commencement of each phase.

The analysis also enables the calculation of the trigger sensitivity and determination of the influence of tube characteristics, circuit components and trigger pulse shape on the sensitivity.

As the time constants determining the shape of the transient time functions are known from the analysis, an idea of the maximum triggering speed can be got. An actual calculation of this speed is not possible from the analysis, as one of the assumptions has been that the circuit is completely at rest at the instant a trigger pulse appears. At high pulse repetition frequencies this condition is not fulfilled.

Moreover, experiments reveal that the speed increases with the amplitude of the trigger pulse, which would make it still more difficult to give an exact definition of the speed.

Calculated waveforms and trigger sensitivity agree very well with measurements on practical circuits. 
Appendix I. Calculation of the anode- and grid voltages in the first phase

(a) The impedance between $G_{I I}$ and earth (see fig. 6-2).

Indicating the impedance of $R_{g}$ and $C_{i I I}$ in parallel by $Z_{g I I}$, the impedance of $R$ and $C$ in parallel by $Z$, the impedance of $R_{a}$ and $C_{a I}$ in parallel by $Z_{a I}$, and denoting the time constants by

$$
\begin{aligned}
R_{g} C_{i I I} & =T_{g I I} \\
R C & =T \\
R_{a} C_{a I} & =T_{a I}
\end{aligned}
$$

the expressions for the impedances become:

$$
\begin{gathered}
Z_{g I I}=R_{g} \frac{1}{1+T_{g I I} p} \\
Z=R \frac{1}{1+T p} \\
Z_{a I}=R_{a} \frac{1}{1+T_{a I} p}
\end{gathered}
$$

The impedance between $G_{I I}$ and earth will be:

$$
\begin{gathered}
Z_{i g I I}=\frac{Z_{g I I}\left(Z+Z_{a I}\right)}{Z_{g I I}+Z+Z_{a I}}= \\
\frac{R_{g}\left\{R\left(1+T_{a I} p\right)+R_{a}(1+T p)\right\}}{R_{g}(1+T p)\left(1+T_{a I} p\right)+R\left(1+T_{g I I} p\right)\left(1+T_{a I} p\right)+R_{a}(1+T p)\left(1+T_{g I I} p\right)}
\end{gathered}
$$

The expression for $Z_{i g I I}$ is of the form

$$
Z_{i g I I}=\left(1-\varepsilon_{g}\right) R_{g} \frac{1+A p}{1+B p+E p^{2}} .
$$

where $\varepsilon_{g}$ is given by expression (5-6).

$$
\begin{gathered}
A=\frac{R T_{a I}+R_{a} T}{R+R_{a}} \\
B=\varepsilon_{g}\left(T+T_{a I}\right)+\varepsilon\left(T_{g I I}+T_{a I}\right)+\varepsilon_{a}\left(T_{g I I}+T\right)
\end{gathered}
$$

where $\varepsilon_{a}$ is given by expression (5-3)

64 
and

$$
\varepsilon=1-\varepsilon_{g}-\varepsilon_{a}=\frac{R}{R_{g}+R+R_{a}}
$$

$$
E=\varepsilon_{g} T T_{a I}+\varepsilon T_{g I I} T_{a I}+\varepsilon_{a} T_{g I I} T .
$$

It will be clear that the expression for the impedance $Z_{i g I}$ between $G_{I}$ and earth (see fig. 6-3) has a form similar to that of expression (I-7), in which only the indices I and II have to be interchanged and where

$$
\begin{aligned}
T_{g I} & =R_{g} C_{i I} \\
T_{a I I} & =R_{a} C_{a I I} .
\end{aligned}
$$

(b) The transfer impedance $Z_{a I g I I}$ will be:

$$
Z_{a I g I I}=\frac{Z_{g I I} Z_{a I}}{Z_{g I I}+Z+Z_{a I}}
$$

or

$$
Z_{a I g I I}=\varepsilon_{a} R_{g} \frac{1+T p}{1+B p+E p^{2}}
$$

(c) The transfer impedance $Z_{g I I a I}$ is equal to $Z_{a I g I I}$ :

$$
Z_{g I I a I}=Z_{a I g I I} \cdot
$$

In the same way it holds, for the circuit of fig. $6-3$, that

$$
Z_{g I a I I}=Z_{a I I g I} \text {. }
$$

(d) The impedance $Z_{\text {iaI }}$ between $A_{I}$ and earth is:

$$
\begin{gathered}
Z_{i a I}=\frac{Z_{a I}\left(Z+Z_{g I I}\right)}{Z_{g I I}+Z+Z_{a I}} \\
Z_{i a I}=\left(1-\varepsilon_{a}\right) R_{a} \frac{1+D p}{1+B p+E p^{2}},
\end{gathered}
$$

where

$$
D=\frac{R T_{g I I}+R_{g} T}{R+R_{g}}
$$

The voltages at the anodes and grids will now be calculated.

(1) The voltage between $G_{I I}$ and earth (fig. 6-2).

This voltage will be:

$$
V_{g I I}(t)=V_{g I I o}+Z_{i g I I} I_{i}+Z_{g I I a I} I_{a}
$$


$V_{g I I o}$ is given by expression (5-7):

$$
\begin{gathered}
Z_{i g I I} I_{i}=Z_{i g I I}\left[-a C_{c}\left\{U(t)-U\left(t-t_{o}\right)\right\}\right] \\
(\text { see expression } 6-7) \\
Z_{g I I a I} I_{a}=Z_{g I I a I} I_{a o} U(t)
\end{gathered}
$$

The expression for $Z_{i g I I}$ and $Z_{g I I a I}$ can be split up into partial fractions.

$$
\left.Z_{i g I I}=\frac{\left(1-\varepsilon_{g}\right) R_{g}}{E\left(p_{1}-p_{2}\right)} \mid-\left(\frac{1}{p_{1}}+A\right) \frac{-p_{1}}{p-p_{1}}+\left(\frac{1}{p_{2}}+A\right) \frac{-p_{2}}{p-p_{2}}\right]
$$

Where

$$
\begin{aligned}
& p_{1}=-\frac{B}{2 E}\left\{1-\sqrt{1-\frac{4 E}{B^{2}}}\right\} \\
& p_{2}=-\frac{B}{2 E}\left\{1+\sqrt{1-\frac{4 E}{B^{2}}}\right\} .
\end{aligned}
$$

$p_{1}$ and $p_{2}$ will both be negative, real quantities, as the network of fig. (6-2) contains only capacitances and resistances.

A unit current step applied to an impedance

$$
Z(p)=\frac{a}{p+a}
$$

will cause a voltage across this impedance

$$
V(t)=\left(1-e^{-a t}\right) U(t)
$$

This will be expressed by the following notation:

$$
Z(p) U(t) \equiv\left(1-e^{-a t}\right) U(t)
$$

Applying this transformation to expression (I-24) gives

$$
Z_{i g I I} U(t) \equiv \frac{\left(1-\varepsilon_{g}\right) R_{g}}{E\left(p_{1}-p_{2}\right)}\left[-\left(\begin{array}{c}
1 \\
p_{1}
\end{array}+A\right)\left(1-e^{p_{1} t}\right)+\left(\frac{1}{p_{2}}+A\right)\left(1-e^{p_{2} t}\right)\right] U(t)
$$

This can be re-shaped and finally written:

$Z_{i g I I} U(t) \equiv\left(1-\varepsilon_{g}\right) R_{g}\left[1-\frac{1}{2}(1-K) e^{p_{1} t}-\frac{1}{2}(1+K) e^{p_{3} t}\right] U(t),(\mathrm{I}-30)$ where

$$
K=\frac{2 A-B}{B \sqrt{1-4 E / B^{2}}}
$$


Now, expression (I-22) can be evaluated, remembering that the response to a unit-step function $U\left(t-t_{o}\right)$ is the same as that to a unit-step function $U(t)$, provided the time scale is shifted by replacing $t$ by $t-t_{\sigma^{*}}$. Thus:

$$
\begin{aligned}
& Z_{i g I I} I_{i}=-\alpha C_{c}\left(1-\varepsilon_{g}\right) R_{g}\left[\left\{1-\frac{1}{2}(1-K) e^{p_{1} t}-\frac{1}{2}(1+K) e^{p_{2} t}\right\} U(t)-\right. \\
& \quad-\left\{1-\frac{1}{2}(1-K) e^{p_{1}\left(t-t_{o}\right)}-\frac{1}{2}(1+K) e^{p_{2}\left(t-t_{o}\right)}\right\} U^{\prime}\left(t-t_{o}\right) \quad(\mathrm{I}-32)
\end{aligned}
$$

In the same way it can be deduced that the transformation of the impedance $Z_{g I I a I}$ is

$$
Z_{g I I a I} U(t) \equiv \varepsilon_{a} R_{g}\left\{1-\frac{1}{2}(1-P) e^{p_{1} t}-\frac{1}{2}(1+P) e^{p_{2} t}\right\} U(t) .
$$

where

$$
P=\frac{2 T-B}{B \sqrt{1-4 E / B^{2}}} .
$$

Then, expression (I-23) will be:

$$
Z_{g I I a I} I_{a}=\varepsilon_{a} R_{g} I_{a o}\left\{1-\frac{1}{2}(1-P) e^{p_{1} t}-\frac{1}{2}(1+P) e^{p_{1} t}\right\} U(t)
$$

The total voltage between $G_{I I}$ and earth during the first phase of the dynamic condition, as given by expression (I-21), will be the following time-function:

$$
\begin{gathered}
V_{g I I}(t)=V_{g I I o}-\alpha C_{c}\left(1-\varepsilon_{g}\right) R_{g}\left[\left\{1-\frac{1}{2}(1-K) e^{p_{1} t}-\frac{1}{2}(1+K) e^{p_{2} t}\right\}\right. \\
\left.U(t)-\left\{1-\frac{1}{2}(1-K) e^{p_{1}\left(t-t_{o}\right)}-\frac{1}{2}(1+K) e^{p_{2}\left(t-t_{o}\right)}\right\} U\left(t-t_{o}\right)\right]+\varepsilon_{a} R_{g} I_{a o} \\
\left\{1-\frac{1}{2}(1-P) e^{p_{1} t}-\frac{1}{2}(1+P) e^{p_{2} t}\right\} U(t)
\end{gathered}
$$

(2) The voltage between $A_{I}$ and earth (fig. 6-2)

This voltage will be:

$$
V_{a I}(t)=V_{a I o}+Z_{i a I} I_{a}+Z_{a I g I I} I_{i} .
$$

The transformation of the impedance $Z_{i a I}$ into a time function is:

$Z_{i a I} U(t) \equiv\left(1-\varepsilon_{a}\right) R_{a}\left\{1-\frac{1}{2}(1-L) e^{p_{1} t}-\frac{1}{2}(1+L) e^{p_{2} t}\right\} U(t)$ where

$$
L=\frac{2 D-B}{B \sqrt{1-4 E / B^{2}}}
$$

Expression (I-37), therefore, will be

$$
\begin{aligned}
& V_{a I}(t)=V_{a I o}+\left(1-\varepsilon_{a}\right) R_{a} I_{a o}\left\{1-\frac{1}{2}(1-L) e^{p_{1} t}-\frac{1}{2}(1+L) e^{p_{2} t}\right\} U(t)- \\
& -\alpha C_{c} \varepsilon_{a} R_{g}\left[1-\frac{1}{2}(1-P) e^{p_{1} t}-\frac{1}{2}(1+P) e^{p_{2} t}\right\} U(t)- \\
& \left.-\left\{1-\frac{1}{2}(1-P) e^{p}{ }^{\left(t-t_{0}\right)}-\frac{1}{2}(1+P) e^{p_{2}\left(t-t_{0}\right)}\right\} U\left(t-t_{0}\right)\right] \text {. }
\end{aligned}
$$


(3) The voltage between $G_{I}$ and earth (fig. 6-3)

$$
V_{g I}(t)=V_{g o I}+Z_{i g I}\left(I_{i}+I_{g}\right),
$$

where

$$
I_{i}+I_{g}=\left(-\alpha C_{c}+I_{g_{o}}\right) U(t)+\alpha C_{c} U\left(t-t_{o}\right)
$$

and

$$
V_{g I o}=0 .
$$

Thus:

$$
\begin{gathered}
V_{g I}(t)=\left(-\alpha C_{c}+I_{g o}\right)\left(1-\varepsilon_{g}\right) R_{g}\left\{1-\frac{1}{2}\left(1-\mathrm{K}^{\prime}\right) e^{p_{1}^{\prime} t}-\right. \\
\left.-\frac{1}{2}\left(1+K^{\prime}\right) e^{p},^{t}\right\} U(t)+\alpha C_{c}\left(1-\varepsilon_{g}\right) R_{g}\left\{1-\frac{1}{2}\left(1-K^{\prime}\right) e^{p_{1}{ }^{\prime}\left(t-t_{o}\right)}-\right. \\
\left.-\frac{1}{2}\left(1+K^{\prime}\right) e^{p_{2}^{\prime}\left(t-t_{o}\right)}\right\} U\left(t-t_{o}\right)
\end{gathered}
$$

(4) The voltage between $A_{I I}$ and earth (fig. 6-3)

$$
\begin{gathered}
V_{a I I}(t)=V_{a I I o}+Z_{a I I g I}\left(I_{i}+I_{g}\right) \\
V_{a I I}(t)=V_{a I I o}+\left(-\alpha C_{c}+I_{g o}\right) \varepsilon_{a} R_{g}\left\{1-\frac{1}{2}\left(1-P^{\prime}\right) e^{p_{1}{ }_{1}^{\prime} t}-\right. \\
\left.-\frac{1}{2}\left(1+P^{\prime}\right) e^{p_{a}{ }^{\prime} t}\right\} U(t)+\alpha C_{c} \varepsilon_{a} R_{g}\left\{1-\frac{1}{2}\left(1-P^{\prime}\right) e^{p_{1}{ }^{\prime}\left(t-t_{o}\right)}-\right. \\
\left.-\frac{1}{2}\left(1+P^{\prime}\right) e^{p_{2}^{\prime}\left(t-t_{o}\right)}\right\} U\left(t-t_{o}\right)
\end{gathered}
$$

$K^{\prime}$ is found from $K$ by substituting $p_{1}{ }^{\prime}, p_{2}{ }^{\prime}$ and $A^{\prime}$ for $p_{1}, p_{2}$ and $A$ resp., where $A$ is given by expression (I-8) and $A^{\prime}$ is derived from A by substituting $T_{a I I}$ for $T_{a I}$. (see expressions (I-3) and (I-13)).

$p_{1}{ }^{\prime}$ and $p_{2}{ }^{\prime}$ are derived from $p_{1}$ and $p_{2}$ by replacing $T_{a I}$ by $T_{a I I}, T_{g I I}$ by $T_{g I}$ (see expressions (I-1) and (I-12)).

$P^{\prime}$ is derived from $P$ by replacing Index I by II and vice versa. 
Appendix II. Calculation of $V_{a I I}$ in the second phase

Expression (6-29) can be evaluated if the expression $\frac{Z_{\text {iaII }}}{Z_{\text {iaII }}+r_{a}}$ and the time function $V_{a I I}(t)_{1}+\mu V_{g I I}(t)$ are known. The first expression results from (I-19) by interchanging the indices I and II:

$$
\frac{Z_{\text {iaII }}}{Z_{\text {iaII }}+r_{a}}=\frac{\left(1-\varepsilon_{a}\right) R_{a}\left(1+D^{\prime} p\right)}{\left(1-\varepsilon_{a}\right) R_{a}\left(1+D^{\prime} p\right)+r_{a}\left(1+B^{\prime} p+E^{\prime} p^{2}\right)}
$$

Calling

$$
\frac{\left(1-\varepsilon_{a}\right) R_{a}}{\left(1-\varepsilon_{a}\right) R_{a}+r_{a}} D^{\prime}+\frac{r_{a}}{\left(1-\varepsilon_{a}\right) R_{a}+r_{a}} B^{\prime}=F^{\prime}
$$

and

$$
\frac{r_{a}}{\left(1-\varepsilon_{a}\right) R_{a}+r_{a}} E^{\prime}=G^{\prime},
$$

expression (II-1) can be written

$$
\frac{Z_{\text {iaII }}}{Z_{\text {iaII }}+r_{a}}=\frac{\left(1-\varepsilon_{a}\right) R_{a}}{\left(1-\varepsilon_{a}\right) R_{a}+r_{a}} \frac{1+D^{\prime} p}{1+F^{\prime} p+G^{\prime} p^{2}} .
$$

The time function $V_{a I I}(t)_{1}+\mu V_{g I I}(t)$ is to be found from expressions $(6-14)$ and $(6-11)$. It is the sum of a constant term $V_{o}$ and a time function $V(t)$

$$
V_{a I I}(t)_{1}+\mu V_{g I I}(t)=V_{o}+V(t) .
$$

From expression (6-28) it follows that

$$
V_{a I I}\left(t_{I I}\right)_{1}+\mu V_{g I I}\left(t_{I I}\right)=0 .
$$

or:

$$
V_{o}+V\left(t_{I I}\right)=0 .
$$

Subtracting (II-7) from (II-5) gives

$$
V_{a I I}(t)_{1}+\mu V_{g I I}(t)=V(t)-V\left(t_{I I}\right) .
$$

$V(t)$ is a sum of exponential functions

$$
V(t)=\Sigma j V_{j} e^{p_{j} t}=V_{5} e^{p_{1}^{\prime} t}+V_{6} e^{p_{2}^{\prime} t}+\mu V_{2} e^{p_{1} t}+\mu V_{3} e^{e_{2} t}
$$

$V_{5}, V_{6}, V_{2}$ and $V_{3}$ are given in chapter 6 .

Thus:

$$
V(t)-V\left(t_{I I}\right)=\sum j V_{j}\left(e^{p_{j} t}-e^{\left.p_{j} t_{I I}\right)},\right.
$$


or: $\quad V_{a I I}(t)_{1}+\mu V_{g I I}(t)=\Sigma j-V_{j} e^{p_{j} t_{I I}}\left\{1-e^{p_{j}\left(t-t_{I I}\right)}\right\} . \quad(\mathrm{II}-10)$

Transformed into a $p$-function, this becomes:

$$
\left\{V_{a I I}(t)_{1}+\mu V_{g I I}(t)\right\} U\left(t-t_{I I}\right) \equiv \Sigma j-V_{j} e^{p_{j} t_{I I}} \frac{-p_{j}}{p-p_{j}} U\left(t-t_{I I}\right)
$$

The evaluation of expression (6-29) is now reduced to the calculation of time functions, corresponding to an operational expression of the following form:

$$
f_{j}\left(t-t_{I I}\right) \equiv \frac{1+D^{\prime} p}{1+F^{\prime} p+G^{\prime} p^{2}} \frac{-p_{j}}{p-p_{j}^{\prime}} U\left(t-t_{I I}\right)
$$

Expression (II-12) can be split up into partial fractions, the result being:

$$
f_{j}\left(t-t_{I I}\right) \equiv-\frac{p_{j}}{G}\left(\frac{X_{1^{j}}}{p-p_{3}}+\frac{X_{2^{j}}}{p-p_{4}}+\frac{X_{3^{j}}}{p-p_{j}}\right) U\left(t-t_{I I}\right) .(\mathrm{II}-13)
$$

where

$$
\begin{aligned}
& p_{3}=-\frac{F^{\prime}}{2 G^{\prime}}\left\{1-\sqrt{1-\frac{4 G^{\prime}}{F^{\prime 2}}}\right\} \\
& p_{4}=-\frac{F^{\prime}}{2 G^{\prime}}\left\{1+\sqrt{1-\frac{4 G^{\prime}}{F^{\prime 2}}}\right\}
\end{aligned}
$$

$p_{3}$ and $p_{4}$ are negative, real quantities.

$$
\begin{aligned}
& X_{1^{j}}=\frac{1+D^{\prime} p_{3}}{\left(p_{3}-p_{4}\right)\left(p_{3}-p_{j}\right)} \\
& X_{2^{j}}=\frac{1+D^{\prime} p_{4}}{\left(p_{4}-p_{3}\right)\left(p_{4}-p_{j}\right)} \\
& X_{3^{j}}=\frac{1+D^{\prime} p_{j}}{\left(p_{j}-p_{3}\right)\left(p_{j}-p_{4}\right)}
\end{aligned}
$$

The time functions, corresponding to the $p$-functions in expression (II-13) are well-known exponential functions, thus:

$$
\begin{aligned}
f_{j}\left(t-t_{I I}\right)=- & \frac{p_{j}}{G^{\prime}}\left[\frac{X_{1^{j}}}{-p_{3}}\left\{1-e^{p_{3}\left(t-t_{I I}\right)}\right\}+\frac{X_{2^{j}}}{-p_{4}}\left\{1-e^{p_{4}\left(t-t_{I I}\right)}\right\}+\right. \\
& \left.+\frac{X_{3^{j}}}{-p_{j}}\left\{1-e^{p_{j}\left(t-t_{I I}\right)}\right\}\right] U\left(t-t_{I I}\right) .
\end{aligned}
$$

Substituting expressions (II-4), (II-11) and (II-12) in (6-29) gives: 


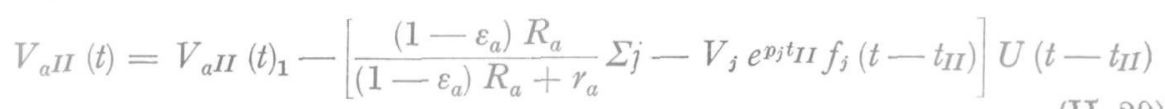

Finally, expression (II-19) must be substituted, giving:

$$
\begin{aligned}
V_{a I I}(t)= & V_{a I I}(t)_{1}-\frac{\left(1-\varepsilon_{a}\right) R_{a}}{\left(1-\varepsilon_{a}\right) R_{a}+r_{a}} \Sigma_{j} \frac{V_{j} p_{j}}{G^{\prime}} e^{p_{j} t_{I I}}\left[\frac{X_{1^{j}}}{-p_{3}}\left\{1-e^{p_{3}\left(t-t_{I I}\right)}\right\}+\right. \\
& \left.+\frac{X_{2^{j}}}{-p_{4}}\left\{1-e^{p_{4}\left(t-t_{I I}\right)}\right\}+\frac{X_{3^{j}}}{-p_{j}}\left\{1-e^{p_{j}\left(t-t_{I I}\right)}\right\}\right] U\left(t-t_{I I}\right) . \quad \text { (II-21) }
\end{aligned}
$$

For the asymmetrical multivibrator there are four terms, constituting the sum in expression (II-21), because there are four reciprocal time constants $p_{j}$, viz. $p_{1}, p_{2}, p_{1}{ }^{\prime}, p_{2}{ }^{\prime}$.

To $p_{1}$ corresponds:

$$
\begin{gathered}
V_{j}=\mu V_{2}=\mu\left\{\frac{1}{2} a C_{c}\left(1-\varepsilon_{g}\right) R_{g}(1-K)\left(1-e^{-p_{1} t_{o}}\right)-\right. \\
\left.-\frac{1}{2} I_{a o} \varepsilon_{a} R_{g}(1-P)\right\}
\end{gathered}
$$

To $p_{2}$ corresponds:

$$
\begin{gathered}
V_{j}=\mu V_{3}=\mu\left\{\frac{1}{2} \alpha C_{o}\left(1-\varepsilon_{g}\right) R_{g}(1+K)\left(1-e^{-p_{2} t o}\right)-\right. \\
\left.-\frac{1}{2} I_{a o} \varepsilon_{a} R_{g}(1+P)\right\} .
\end{gathered}
$$

To $p_{1}^{\prime}$ corresponds:

$$
V_{j}=V_{5}=\frac{1}{2} \alpha C_{c} \varepsilon_{a} R_{g}\left(1-P^{\prime}\right)\left(1-e^{-p_{1}^{\prime} t_{o}}\right)-\frac{1}{2} I_{g o} \varepsilon_{a} R_{g}\left(1-P^{\prime}\right) .
$$

To $p_{2}{ }^{\prime}$ corresponds:

$$
V_{j}=V_{6}=\frac{1}{2} \alpha C_{c} \varepsilon_{a} R_{g}\left(1+P^{\prime}\right)\left(1-e^{-p_{2}{ }^{\prime} t_{o}}\right)-\frac{1}{2} I_{g_{0}} \varepsilon_{a} R_{g}\left(1+P^{\prime}\right) .
$$

For the symmetrical multivibrator there are only two terms in the sum of expression (II-21) corresponding to $p_{1}$ and $p_{2}$, respectively.

$$
\begin{gathered}
V_{j}=\mu V_{2}+V_{5}=\left\{\frac{1}{2} \mu \alpha C_{c}\left(1-\varepsilon_{g}\right) R_{g}(1-K)+\frac{1}{2} \alpha C_{c} \varepsilon_{a} R_{g}(1-P)\right\} \\
\left(1-e^{-p_{1} t_{o}}\right)-\left(\mu I_{a \circ}+I_{g o}\right) \varepsilon_{a} R_{g}(1-P) \\
V_{j}=\mu V_{3}+V_{6}=\left\{\frac{1}{2} \mu \alpha C_{c}\left(1-\varepsilon_{g}\right) R_{g}(1+K)+\frac{1}{2} \alpha C_{c} \varepsilon_{a} R_{g}(1+P)\right\} \\
\left(1-e^{-p_{2} t_{o}}\right)-\frac{1}{2}\left(\mu I_{a o}+I_{g o}\right) \varepsilon_{a} R_{g}(1+P)
\end{gathered}
$$

For this case, the complete expression for $V_{a I I}$ will be given, expressions (II-26) and (II-27) being substituted into expression (II-21): 
Appendix II

$$
V_{a I I}(t)=V_{a I I}(t)_{1}-\frac{\left(1-\varepsilon_{a}\right) R_{a}}{\left(1-\varepsilon_{a}\right) R_{a}+r_{a}} \mid \frac{p_{1}}{G^{\prime}} e^{p_{1} t_{I I}}
$$

$\left\{\left\{\frac{1}{2} \mu \alpha C_{c}\left(1-\varepsilon_{g}\right) R_{g}(1-K)+\frac{1}{2} \alpha C_{c} \varepsilon_{a} R_{g}(1-P)\right\}\left(1-e^{-p_{1} t_{o}}\right)-\right.$

$\left.-\frac{1}{2}\left(\mu I_{a o}+I_{g o}\right) \varepsilon_{a} R_{g}(1-P)\right\}\left\{\frac{1+D p_{3}}{-p_{3}\left(p_{3}-p_{4}\right)\left(p_{3}-p_{1}\right)}\left(1-e^{p_{3}\left(t-t_{I I}\right)}\right)+\right.$

$$
\frac{1+D p_{4}}{-p_{4}\left(p_{4}-p_{3}\right)\left(p_{4}-p_{1}\right)}\left(1-e^{p_{4}\left(t-t_{I I}\right)}\right)+\frac{1+D p_{1}}{-p_{1}\left(p_{1}-p_{3}\right)\left(p_{1}-p_{4}\right)}
$$

$$
\left.\left(1-e^{p_{1}\left(t-t_{I I}\right)}\right)\right\}+\frac{p_{2}}{G^{\prime}} e^{p_{2} t_{I I}}\left\{\left\{\frac{1}{2} \mu \alpha C_{c}\left(1-\varepsilon_{g}\right) R_{g}(1+K)+\frac{1}{2} \alpha C_{c} \varepsilon_{a} R_{g}\right.\right.
$$

$$
\left.(1+P)\}\left(1-e^{-p_{2} t_{o}}\right)-\frac{1}{2}\left(\mu I_{a o}+I_{g o}\right) \varepsilon_{a} R_{g}(1+P)\right\}
$$

$$
\left\{\frac{1+D p_{3}}{-p_{3}\left(p_{3}-p_{4}\right)\left(p_{3}-p_{2}\right)}\left(1-e^{p_{3}\left(t-t_{I I}\right)}\right)+\frac{1+D p_{4}}{-p_{4}\left(p_{4}-p_{3}\right)\left(p_{4}-p_{2}\right)}\right.
$$

$\left.\left.\left(1-e^{p_{4}\left(t-t_{I I}\right)}\right)+\frac{1+D p_{2}}{-p_{2}\left(p_{2}-p_{3}\right)\left(p_{2}-p_{4}\right)}\left(1-e^{p_{2}\left(t-t_{I I}\right)}\right)\right\}\right] U\left(t-t_{I I}\right)(\mathrm{II}-28)$ 


\section{Appendix III. Calculation of $V_{g I}$ in the second phase}

The voltage between $G_{I}$ and cathode during the second phase of the dynamic condition will be the sum of the value derived for the first phase and a component produced by the response of the network of fig. III-1 to the voltage source:

$$
\begin{aligned}
V_{c}(t) & =-\left[V_{a I I}(t)_{1}+\mu V_{g I I}(t)\right] U\left(t-t_{I I}\right) \equiv \\
& \equiv \Sigma_{j} V_{j} e^{p_{j} t_{I I}} \frac{-p_{j}}{p-p_{j}} U\left(t-t_{I I}\right) .
\end{aligned}
$$

according to expression (II-11).

Comparison of fig. III-1 with fig. 6-3 will make clear that

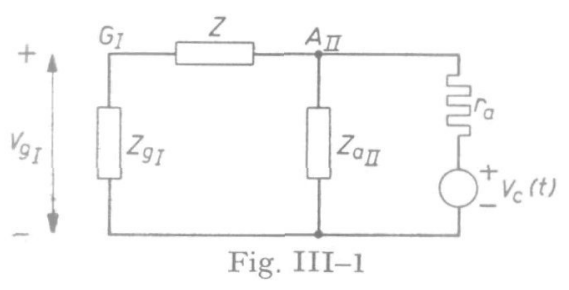

$$
\begin{gathered}
Z_{g I}=\frac{R_{g}}{1+T_{g I} p} \\
Z=\frac{R}{1+T p} \\
Z_{a I I}=\frac{R_{a}}{1+T_{a I I} p} .
\end{gathered}
$$

Now it can be deduced by simple application of Kirchhoff's laws that the response to $V_{\mathrm{c}}(t)$ causes a component:

$$
V_{g I}^{*}(t)=\frac{Z_{g I} Z_{a I I}}{\left(Z+Z_{g I}\right) Z_{a I I}+r_{a}\left(Z+Z_{g I}+Z_{a I I}\right)} V_{e}(t) .
$$

After introducing expressions (III-2), (III-3) and (III-4), this gives finally:

$$
V_{g I}^{*}(t)=\frac{R_{g}\left(1-\varepsilon_{a}\right) R_{a}(1+T p)}{\left(R+R_{g}\right)\left\{\left(1-\varepsilon_{a}\right) R_{a}+\gamma_{a}\right\}\left(1+F^{\prime} p+G^{\prime} p^{2}\right)} V_{c}(t),
$$

where $F^{\prime}$ and $G^{\prime}$ correspond to the values given in appendix II by expressions (II-2) and (II-3) resp. Introducing expression (III-1) gives:

$$
\begin{aligned}
V_{o I}^{*}(t)= & \frac{R_{g}\left(1-\varepsilon_{a}\right) R_{a}}{\left(R+R_{g}\right)\left\{\left(1-\varepsilon_{a}\right) R_{a}+r_{a}\right\} G^{\prime}} \Sigma_{i}-V_{j} e^{p_{j} t_{I I}} p_{j} \\
& \frac{1+T p}{\left(p-p_{j}\right)\left(p-p_{3}\right)\left(p-p_{4}\right)} U\left(t-t_{I I}\right) .
\end{aligned}
$$

where $p_{\mathbf{3}}$ and $p_{\mathbf{4}}$ are given by expressions (II-14) and (II-15).

In an analogous way to the method of appendix II, by splitting the $p$ function into partial fractions, the sum can be written: 


$$
\Sigma_{j}-V_{j} e^{p_{j} t_{I I}} p_{j}\left(\frac{Y_{1^{j}}}{p-p_{3}}+\frac{Y_{2^{j}}}{p-p_{4}}+\frac{Y_{3^{j}}}{p-p_{j}}\right) U\left(t-t_{I I}\right) .
$$

which gives for $V^{*}{ }_{g I}$ as a function of time:

$$
\begin{gathered}
V_{g I}^{*}(t)=-\frac{R_{g}\left(1-\varepsilon_{a}\right) R_{a}}{\left(R+R_{g}\right)\left\{\left(1-\varepsilon_{a}\right) R_{a}+r_{a}\right\} G^{\prime}} \Sigma j V_{j} p_{j} e^{p_{j} t_{I I}\left[\frac{Y_{1^{j}}}{-p_{3}}\right.} \\
\left.\left\{1-e^{p_{3}\left(t-t_{I I}\right)}\right\}+\frac{Y_{2^{j}}}{-p_{4}}\left\{1-e^{p_{4}\left(t-t_{I I}\right)}\right\}+\frac{Y_{3^{j}}}{-p_{j}}\left\{1-e^{p_{j}\left(t-t_{I I}\right)}\right\}\right] U\left(t-t_{I I}\right)
\end{gathered}
$$

The $Y$-functions have the following form:

$$
\begin{aligned}
Y_{1^{j}} & =\frac{1+T p_{3}}{\left(p_{3}-p_{4}\right)\left(p_{3}-p_{j}\right)} \\
Y_{2^{j}} & =\frac{1+T p_{4}}{\left(p_{4}-p_{3}\right)\left(p_{4}-p_{j}\right)} \\
Y_{3^{j}} & =\frac{1+T p_{j}}{\left(p_{j}-p_{3}\right)\left(p_{j}-p_{4}\right)} .
\end{aligned}
$$

The total voltage at $G_{I}$ in the second phase will be:

$$
V_{g I}(t)=V_{g_{I}}(t)_{1}+V_{g I}^{*}(t) .
$$


Appendix IV. Calculation of the transients at $A_{I I}, G_{I}$ and $A_{I}$ in the third phase

Expression (6-33) is of the same kind as the second right-hand term of expression (6-29), and consequently can be evaluated by the same procedure as was applied in Appendix II. By analogy with expression (II-10), we can write:

$$
\mu V_{g I I}(t)=-\Sigma j V_{j} e^{p_{j} t_{s}}\left\{1-e^{p_{j}\left(t-t_{s}\right)}\right\} .
$$

The sum consists of only two components, viz. for $p_{j}=p_{1}$ and $p_{j}=p_{2}$, corresponding to:

$$
V_{j}=\mu V_{2}
$$

(of expression II-22) and

$$
V_{j}=\mu V_{3}
$$

(of expression II-23), respectively.

The calculation of expr. (6-33) will lead to a form similar to that of the second right-hand term of expression (II-21), viz.:

$$
\begin{aligned}
V_{a I I}^{* *}(t) & =\frac{\left(1-\varepsilon_{a}\right) R_{a}}{\left\{\left(1-\varepsilon_{a}\right) R_{a}+r_{a}\right\} G^{\prime}} \Sigma_{j} V_{j} p_{j} e^{p_{j} t_{s}}\left[\frac{X_{1^{j}}}{-p_{3}}\left\{1-e^{p_{3}\left(t-t_{s}\right)}\right\}+\right. \\
+ & \left.\frac{X_{2^{j}}}{-p_{4}}\left\{1-e^{p_{4}\left(t-t_{s}\right)}\right\}+\frac{X_{3^{j}}}{-p_{j}}\left\{1-e^{p_{j}\left(t-t_{s}\right)}\right\}\right] U\left(t-t_{s}\right)
\end{aligned}
$$

Here the sum contains two terms $\left(p_{j}=p_{1}\right.$ and $p_{j}=p_{2}$ resp. $)$.

For expr. (6-34) it will be found by analogy with expr. (III-8):

$$
\begin{aligned}
V_{g I}^{* *}(t)= & \frac{R_{g}\left(1-\varepsilon_{a}\right) R_{a}}{\left(R+R_{g}\right)\left\{\left(1-\varepsilon_{a}\right) R_{a}+r_{a}\right\} G^{\prime}} \Sigma j V_{j} p_{j} e^{p_{j} t_{s}}\left[\frac{Y_{1^{j}}}{-p_{3}}\left\{1-e^{p_{3}\left(t-t_{s}\right)}\right\}+\right. \\
& \left.+\frac{Y_{2^{j}}}{-p_{4}}\left\{1-e^{p_{4}\left(t-t_{s}\right)}\right\}+\frac{Y_{3^{j}}}{-p_{j}}\left\{1-e^{p_{j}\left(t-t_{s}\right)}\right\}\right] U\left(t-t_{s}\right) \quad(\mathrm{IV}-5)
\end{aligned}
$$

For calculating expression (6-35), reference is made to expr. (I-5), (I-6), from which it follows that:

$$
\frac{Z_{a I}}{Z+Z_{a I}}=\beta_{a} \frac{1+T p}{1+T_{n} p} .
$$

where

$$
\begin{gathered}
\beta_{a}=\frac{R_{a}}{R+R_{a}} \\
T_{n}=\beta_{a} T+\left(1-\beta_{a}\right) T_{a I}
\end{gathered}
$$


$V_{g I I}$ is given by expression (6-11):

$$
V_{g I I}(t)=V_{1}+V_{2} e^{p_{1} t}+V_{3} e^{p_{2} t},
$$

which is equivalent to expression (IV-1) divided by $\mu$. (see also expressions (6-15), (6-16), and (6-17).

At $t=t_{s}, V_{g I I}(t)=0$.

thus:

$$
0=V_{1}+V_{2} e^{p_{1} t_{s}}+V_{3} e^{p_{2} t_{s}}
$$

or:

$V_{g I I}(t) U\left(t-t_{s}\right)=\left[V_{2} e^{p_{1} t_{s}}\left\{e^{p_{1}\left(t-t_{s}\right)}-1\right\}+V_{3} e^{p_{2} t_{s}}\left\{e^{p_{2}\left(t-t_{s}\right)}-1\right\}\right] U\left(t-t_{s}\right)$.

Transformed into a $p$-function:

$$
V_{g I I}(t) U\left(t-t_{s}\right) \equiv V_{2} e^{p_{1} t_{s}} \frac{p_{1}}{p-p_{1}}+V_{3} e^{p_{2} t_{s}} \frac{p_{2}}{p-p_{2}} .
$$

Now expression (6-35) can be written:

$$
V_{a I}^{* *}(t)=\beta_{a} \frac{1+T p}{1+T_{n} p}\left(-V_{2} e^{p_{1} t_{s}} \frac{p_{1}}{p-p_{1}}-V_{3} e^{p_{2} t_{s}} \frac{p_{2}}{p-p_{2}}\right) U\left(t-t_{s}\right) .
$$

Determination of the corresponding time function results in:

$$
\begin{gathered}
V_{a I}^{* *}(t)=\beta_{a} p_{n}\left[p _ { 1 } V _ { 2 } e ^ { p _ { 1 } t _ { s } } \left\{\frac{1+T p_{n}}{-p_{n}\left(p_{n}-p_{1}\right)}\left(1-e^{p_{n}\left(t-t_{s}\right)}\right)+\frac{1+T p_{1}}{-p_{1}\left(p_{1}-p_{n}\right)}\right.\right. \\
\left.\left(1-e^{p_{1}\left(t-t_{s}\right)}\right)\right\}+p_{2} V_{3} e^{p_{2} t_{s}}\left\{\frac{1+T p_{n}}{-p_{n}\left(p_{n}-p_{2}\right)}\left(1-e^{p_{n}\left(t-t_{s}\right)}\right)+\frac{1+T p_{2}}{-p_{2}\left(p_{2}-p_{n}\right)}\right. \\
\left.\left(1-e^{p_{2}\left(t-t_{s}\right)}\right)\right\} \mid U\left(t-t_{s}\right) .
\end{gathered}
$$

where,

$$
p_{n}=-\frac{1}{T_{n}}
$$




\section{Appendix V. Discussion of the method of calculating the influence of $C_{a g}$ on the trigger sensitivity}

Referring to fig. $6-1$, which represents the multivibrator circuit at the start of the first phase of the dynamic condition, it can be seen that several current generators operate on the circuit. The basic cause, which starts all transient phenomena occurring in the whole triggering action, is the application of the input trigger voltage according to fig. $3-2$. This trigger voltage is transformed into a current pulse $I_{i}$, (chapter 6). It causes a current step $I_{a o}$ between the anode of tube I and earth and another current step $I_{g_{o}}$ between grid I and earth. Of the three current sources mentioned, $I_{a o}$ is by far the most important, and it is this, in fact, which enables the multivibrator to be definitely triggered. This current source $I_{a o}$ gives rise to a rather steep and large voltage change at $A_{I}$. The voltage change at $A_{I I}$ will be much smaller as no current source is directly operating at $\mathrm{A}_{I I}$. Only the current source $I_{g o}+I_{i}$ at $G_{I}$ will cause, via the coupling network $R C$, a modest change in potential at $A_{I I}$ (compare figs. $7-3$ and $7-4)$.

The influence of the anode-to-grid capacitances is to feed back a fraction of the anode-voltage changes to the corresponding grids and via the $R C$-coupling elements to the other anode. The change in grid voltage because of this feedback is much more important than that at the anodes, when determining the times $t_{I}$ and $t_{I I}$ (expressions 8-5 and 8-6), as the influence of the anode voltage changes is reduced by a factor $\mu$. Moreover, to a first approximation the feedback in tube $\mathrm{I}$ is the only one to consider because the voltage change at $A_{I}$ is the most important. However, as may be seen from section 8 , in the case of the symmetrical multivibrator, it is wise to consider the feedback in both tubes, as this leads to a more elegant solution of the problem to find the minimum trigger-voltage amplitude. 


\section{SUMMARY}

The operation of a bistable multivibrator circuit is analysed. It possesses two stable positions. To change from one to the other position triggering voltages have to be supplied alternatively or simultaneously to the grids of the two tubes, which are the main parts of the circuit. The transient phenomena which occur during switching from one static condition to the other have been analysed. For this purpose the switching period (the dynamic condition) has been divided into three phases. The first phase starts at the instant the triggering voltage pulse is supplied. The conducting tube is supposed to be instantaneously cut off; the other tube was already cut off, so the first phase can be characterized by saying that it is the time during which both tubes are non-conducting. The transients during the first phase are caused by the trigger pulse, and by the sudden ceasing of the anode current and of the grid current of the originally conducting tube. The second phase starts at the instant the other tube becomes conducting. This causes new transients, which have to be superimposed on the first-phase transients. The third phase commences at the instant that the then conducting tube starts drawing grid current. The third-phase transients have again to be added to those already present from the preceding phases. The last phase does not necessarily occur. It depends on the operation of the conducting tube in the static condition whether grid current will appear or not.

The most general case, viz. that of three phases and application of a trigger pulse to the grids of both tubes simultaneously has been theoretically analysed. The simpler cases are easily deduced from the general case.

The voltage changes at the anodes and grids of the tubes in the dynamic condition have been derived and are expressed in explicit time functions. This makesit possible to calculate the trigger sensitivity expressed by the minimum trigger pulse amplitude at which switching from one stable position to the other will occur. The influence of circuit components and tube characteristics on the sensitivity can also be calculated.

Because it is supposed that at the instant of triggering all transients from a preceding triggering have completely died out it will not be possible to calculate the maximum trigger pulse frequency at which the circuit still operates satisfactorily, for this condition will then not be fulfilled. However, the time functions representing the anode and grid voltages are sums of exponential functions. The time constants, defining these ex- 
ponential functions are known and are a rough measure for the speed to be expected.

The analysis enables rules to be given for the design of a bistable multivibrator circuit.

The results of numerical examples, calculated from the theoretical formulae, agree very well with measurements on practical circuits. 
1. De benaming flip-flop wordt door Amerikaanse auteurs niet steeds voor dezelfde schakeling gebruikt. Het verdient daarom aanbeveling de Eccles-Jordan flip-flop schakeling met de benaming bistabiele multivibrator aan te duiden.

S。 Greenwald, R.C. Haueter, S.N。Alexander:

"SEAC"

Proc。I R.E., October 1953 ("Computer Is sue"") p。1309-1310. P.G.M. Dawe:

Letter to the Editor,

Electronic Engineering 27, July 1955, p. 323, naar aanleiding van het artikel:

W。 Renwick + M。Phister:

"A Design Method for Direct-Coupled Flip-Flops"?

Electronic Engineering 27, June 1955, p. 246 .

2. De benaderingsformule, die Terman en Mather geven voor de frequentie van een astabiele multivibrator, is onder omstandigheden erg onnauwkeurig .

F.E. Terman:

Radio Engineering, $3^{\text {rd }}$ edition, MacGraw-Hi 11 (1947), p。 588. N.W. Mather:

"Multivibrator Circuits"

Electronics, October 1946, p。136.

P.A. Neeteson:

"Flywhee1 Synchronization of Saw-Tooth Generators"

part 2 of Television Receiver Design, Book VIIIB of Philips Technical Library, p. 69-103.

3. De "squareness ratio" is een onvoldoend criterium voor de juiste werking van ferromagnetische ringetjès met rech thoekige hysteresislus in matrix geheugenschakelingen.

D.R. Brown and E。Albers-Schoenberg:

"Ferrites Speed Digital Computers"

Electronics, Apri1 1953, p. 148 .

J. Wy len:

"Pu1se Response Characteristics of Rectangular-HysteresisLoop Ferromagnetic Materials"

Communications and Electronics, November 1953, p. 648 . F. van Tonger 10o:

"Magnetische en diëlectrische rekenmachine-elementen" Tijdschrift van het Nederlands Radiogenootschap, deel XVIII, $\mathrm{Nr} 。 5 / 6$, November 1953, p。278. 
H.P.J. Wi:n, E.W. Gorter, C.J. Esveldt, P. Ge1dermans: "Voorwaarden voor een rechthoekige hysteresislus bij ferrieten" . Philips Technisch Tijdschrift 16, nr. 4-5, April-Mei 1954, p. 125.

E. Albers-Schoenberg:

"Ferrites for Microwave Circuits and Digital Computers" Journal of Applied Physics 25, nr . 2, Februari 1954, p:153.

4. Het is gewenst reeds thans te streven naar eenheid in de symbolische voorstelling van transistors in schakelschema's.

D. Nappin:

"Theoretical Transistor Symbo1" (Letter to the Editor), Electronic Engineering 26, nr。317, p. 322 (July 1954)。

R.F. Shea:

"Principles of Transistor Circuits"

John Wiley and Sons, New York; Chapman and Hali, London (1953) - p. XXX

F.C. Williams and G.B.B. Chaplin:

"A Method of Designing Transistor Trigger Circuits"

Proc。I.E.E。(1953) vo1. 100, part III, nr.66, p。228.

H. Fricke:

"Verstärker mit Transistoren"

II. Scha1 tungen und Ausfuhrungsformen.

Archiv für Technisches Messen Z631-5, Juli 1951, T82。

G.C.Sziklai :

"Symmetrica1 Properties of Transistors and their

Applications" 。Proc. I.R.E. June 1953, p. 717 .

G.B.B. Chaplin:

"The Transistor Regenerative Amplifier as a Computer Element" . Proc. I.E.E. (September 1954) vol.101, p.298.

5. Het is gewenst, dat er uniformiteit komt in de symbolische notatie van fundamentele circuits, welke in electronische rekenmachines gebruikt worden.

S. Greenwa1d, R。C.Haueter, S。N。Alexander:

"SEAC" (National Bureau of Standards)

Proc. I.R.E. October 1953 ("Computèr Is sue") p. 1309-1310.

P. Sherertz:

"Electronic Circuits of the NAREC Computer"

(Navy Research Lab.)

Proc.I.R.E。 October 1953 ( ${ }^{9}$ Computer Issue ${ }^{97}$ ) p。1315。 
S.E. Gluck, H.J. Gray, C.T. Leondes, M. Rubinoff:

"The Design of Logical OR-AND-OR Pyramids for Digita1

Computers". (University of Pennsylvania, Philadelphia)

Proc. I.R.E. October 1953 ("Computer Issue") p. 1388.

J.H. Vogel song:

"A Transistcr Pulse Amplifier Using External Regeneration"

(Be11 Telephone Labs)

Proc. I.R.E. October 1953 ("Computer Issue") po. 1444.

A.D. Booth and K.H.V. Booth:

"Automatic Digital Calculaturs"

Butterworths Scientific Publications (London 1953)

J.H. Felker:

"Notes on the Design cf Hign Speed Digi tal Computers using Transistors"

(Be11 Report).

6. Voor de ontwikkeling van electronische rekenmachines is het een gunstige coincidentie, dat transistors en ferromagne. tische materialen met rech thoekige hysteresislus ongeveer tegelijkertijd tot ontwikkeling gekomen zijn。

7. Een homogeen magneetveld, toegepast voor de afbuiging van de electronenbundel in een beeldbuis bij televisie ontvangst, waarborgt in het algemeen niet een distorsievrij raster.

P.A. Neeteson:

"Improvements in or relating to Cathode-Ray Tube Deflection Systems"

Brits Patent nr。672624。

Amerikaans Patent nr。2617059.

8. Het is gewenst bij het onderricht in de exacte vakken vooral bij het middelbaar onderwijs, behalve het bijbrengen van kennis in deze vakken, ook het toepassen van deze kennis in de practijk naar voren te brengen.

9. De toenemende industrialisatie in Nederland schept steeds meer behoefte aan technici met middelbare en hogere opleiding, die op commercieel gebied activiteiten moeten ontplooien. In verband daarmee is het gewenst bij de opleiding aan daartoe in aanmerking komende technische onderwijsinstellingen de aandacht te vestigen op de mogelijkheden, 
die de technisch-commerciële sector van een industrieel bedrijf biedt aan de activiteiten van de technicus.

10. Het is gewenst bij het middelbaar technisch onderwijs in de electronen- en electro-techniek meer aandacht te besteden aan theorie en practijk van de reactie van electrische netwerken op niet-sinusvormige signalen.

11. Het is gewenst een nauwere samenwerking tussen Europese technici te verkrijgen, waarmee een begin gemakt zou kunnen worden door het doen verschijnen van een gezamenilijk periodiek voor de West-Europese landen, bijvoorbeeld in de trant van de Amerikaanse Proceedings of the Institute of Radio Engineers voor wat betreft de electronentechniek.

12. Aangeboren dip_acusis kan een mogelijke oorzaak zijn van onmuzikali teit .

13. De afhankelijkheid van de doorslagveldsterkte van het argonpercentage in neon-argon mengse 1s, gemeten door MacDonald en Matthews bij een veldfrequentie van $2800 \mathrm{Mc} / \mathrm{s}$, wijkt bij lage argonconcentraties sterk af van de te verwachten afhankelijkheid. Deze afwijking kan verklaard worden door verontreinigingen in het gebruikte gas.

A.D. MacDonald en J.H. Mat thews:

"High-Frequency Ionization Coefficients in Neon-Frgon Mixtures", Physical Review 98, nr。4, p。 1070 (May 15, 1955)。

14. Bi $\mathrm{j}$ de ontvangst van in hun frequentie, phase, breedte of plaats gemoduleerde impulsen is een aanzienlijke verbetering van de signaal-ruis verhouding te verkrijgen door een impulsregenerator in het ontvangsysteem op te nemen, welke a angestoten wordt door de ontvangen impulsen.

15. Bij het aanbrengen van een goed geleidende laag op een niet of slecht geleidende ondergrond, met het doel een goede geleidbaarheid voor hoogfrequente stromen te verkrijgen, is het riet nodig deze laag dik ten opzichte van de indringdiepte in het goed geleidende materiaal te kiezen. Bij een dikte van omstreeks 1,5 maal de indringdiepte is de geleidbaarheid zelfs groter dan die bij een oneindig dikke lä. 